University of Rhode Island

DigitalCommons@URI

Open Access Dissertations

1994

\title{
A CRITICAL INVESTIGATION OF THE IMPACT OF LABELING AND ADVERTISING ON THE SAFE AND EFFECTIVE USE OF RX-TO-OTC SWITCH PRODUCTS
}

Nancy Maria Hewitt

University of Rhode Island

Follow this and additional works at: https://digitalcommons.uri.edu/oa_diss

\section{Recommended Citation}

Hewitt, Nancy Maria, "A CRITICAL INVESTIGATION OF THE IMPACT OF LABELING AND ADVERTISING ON THE SAFE AND EFFECTIVE USE OF RX-TO-OTC SWITCH PRODUCTS" (1994). Open Access Dissertations. Paper 178.

https://digitalcommons.uri.edu/oa_diss/178

This Dissertation is brought to you for free and open access by DigitalCommons@URI. It has been accepted for inclusion in Open Access Dissertations by an authorized administrator of DigitalCommons@URI. For more information, please contact digitalcommons-group@uri.edu. 
A CRITICAL INVESTIGATION OF THE IMPACT OF LABELING AND ADVERTISING ON THE SAFE AND EFFECTIVE USE OF RX-TO-OTC SWITCH PRODUCTS BY NANCY MARIA HEWITT

A DISSERTATION SUBMITTED IN PARTIAL FULFILLMENT OF REQUIREMENTS FOR THE DEGREE OF DOCTOR OF PHLOSOPHY IN PHARMACEUTICAL SCIENCES 


\section{DOCTOR OF PHILOSOPHY DISSERTATION}

$\mathrm{OF}$

NANCY MARIA HEWITT

\section{APPROVED:}

Dissertation Committee

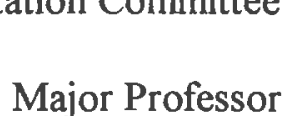

Sara Rosenbawm
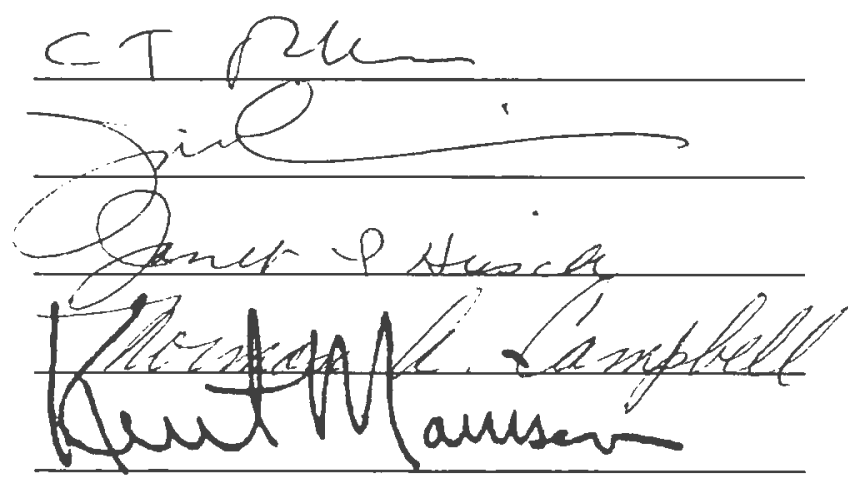

DEAN OF THE GRADUATE SCHOOL 


\begin{abstract}
In the early 1970's, the Food and Drug Administration (FDA) launched an Overthe-Counter (OTC) Drug Review with the objective of creating a uniform market containing medicines that are scientifically proven to be safe and effective for use without supervision of a physician. This project laid the groundwork for the switch policies and generated a tremendous amount of interest for improving or enhancing the concept of patient self-medication and providing a cost-effective alternative routine medical problems.

One concern that has been expressed is that as more powerful prescription products enter the OTC market, the associated benefits of the drug may decrease while the risks increase as a result of less intervention by medical professionals. One solution to alleviate this concern may include better labeling and advertising for OTC products. It is established that these educational tools are relied upon by consumers.

In this study, a survey was used to obtain information relative to consumer perceptions about usefulness of OTC medicines and the ease of reading and understanding product labels. It was found that 97 percent of consumers use OTCs to some extent. Most consumers responded that they read labels (92\%), however, only 32 percent felt that OTC package labels were easy to read. Although more consumers $(92 \%)$ felt that the labels were understandable, only half of the respondents could accurately define some of the terminology used in current package labeling.
\end{abstract}


A second survey was used for physicians and pharmacists to elicit information about their views of consumer capability and readiness to use switch medicines (Rx-toOTC) in self-care. Only 50 percent of physicians and 74 percent of pharmacists approved of the trend of self-medication and even less (26\% and $31 \%$ ) from each group approved of switching prescription drugs to OTC status. Both groups of professionals, $(88 \%$ of each) said they recommend OTC products, including switches, to their patients.

This study showed that both consumers and health care professionals have confidence in OTC products, including those recently switched from prescription status. It also revealed potential problems in the labeling and advertising of OTCs with respect to the general content of information. 


\section{ACKNOWLEDGEMENTS}

The path I chose to follow several years ago was one based upon academic and personal goals and challenges. The ultimate objective was to enhance my knowledge in the field of pharmaceutics and eventually contribute some useful information to the field. The standards which I have held for myself and my research throughout the process were based upon those exemplified by faculty members. The obstacles which surfaced at different stages of the program were difficult and sometimes overwhelming, however, several individuals always seemed to know when and how to reinforce my ambitions and set me back on track. I would like to acknowledge and extend my gratitude to these people, because it is thanks to them I have reached this point.

To my major professor, Dr. Rosenbaum. Although it always seemed as though I would never reach the end because of some sort of problem, you never lost interest in helping me in whatever way you could. Your commitment and ongoing support to me is most appreciated.

To Dr. Lausier. I could not have finished without you. At the most difficult time you kept me going without allowing me to take a moment and consider giving up. From the time I chose to enter the program to a point never ending, you have been a friend, a mentor and a role model both professionally and personally. You have always provided positive support and encouragement; you mean a great deal to me. I hope I can help someone as you have helped me. Thank you. 
To Dr. Rhodes. You are responsible for my following through with my pursuit of a Ph.D. in Pharmaceutics. From the begining, your insight and guidance for my research projects inspired me to set the highest of standards to follow as a scientist and a professional

To all of the members of my committee: Dr. Disney, Dr. Campbell, and Dr. Hirsch. I thank you for the time you have spent in meeting with me and contributing your expertise for my research and attending dissertation-related activities. Dr. Disney, I owe you a special thanks for your guidance in my surveys.

To Reba and Denise. Thank you for always saying the right things and keeping the faith in me that I would finish. You are both very special to me.

To my pharmacy co-workers, Rob, Denise, and Shiela. You are all very special friends. Thank you for all your encouragement and support.

To Brooks Dugs, Inc.,my employer. Thank you for granting me the scheduling flexibilty, financial support, and the use of Brooks pharmacies for my research. I have gained valuable experience as a professional and learned a great deal of managerial practices from fine leaders.

To my fellow graduate students whom I have come to know well: Carl, George, and Polyreddy. Thanks for sharing your knowledge, offering your assistance, and lending your ears for venting frustrations. Good luck in your endeavors.

To my family: Mom, Dad, Bill, Joni, and Spencer. Thanks for your love, continuing support, and reminding me not to give up when I had already put so much effort forward. 
To my family: Taki, Kiki, Nadia, Elias, Anna, and Jerry. You have all given Nicos and me a tremendous amount of love and support. You always knew what to say and do to encourage us to keep going with our plans. Thank you for always being there.

Lastly, but most importantly, to my husband, Nicos. Your love and devotion, through many difficult and frustrating times, were a dependable crutch to lean on. You gave me strength when I needed it most, pushed me forward when I was falling behind, and picked my spirits up when they were down. When my confidence was stripped from me, you replaced it and strengthened it. All my love and gratitude. 


\section{PREFACE}

This dissertation is prepared in accordance with the University of Rhode Island “MANUSCRIPT THESIS PLAN" option. The thesis is a collection of four manuscripts that address the issues of patient self-medication with over-the-counter (OTC) medicines. These issues have developed from the concern that as more prescription drugs achieve OTC status, patients are not being provided clear and sufficient information to use them properly. Manuscript I reviews the federal drug legislations and introduces the process of switching prescription medicines to OTC medicines. It has been submitted for review for publication to the Journal of Legal Medicine. Manuscript II elaborates on the Rx-toOTC switch trend and includes the perspectives of the regulating agencies, the drug manufacturers, and health care professionals regarding the changes in patient selfmedication and the availability of more medicines to improve this practice. This article has also been submitted for review for publication to the Journal of Legal Medicine. Manuscript III discusses the impact of labeling and advertising on the promotion of safe and proper use of OTC medicines with emphasis on the switch products. Regulatory guidelines and developments for both educative tools are reviewed. This article has been accepted for publication in the Clinical Research and Regulatory Affairs journal. Manuscript IV presents a study consisting of three surveys designed to assess current consumer, pharmacist, and physician practices and perceptions of OTC medicines. This article has been submitted to the Drug Intelligence and Clinical Pharmacy journal. 


\section{TABLE OF CONTENTS}

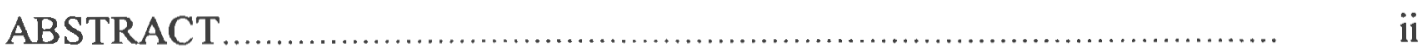

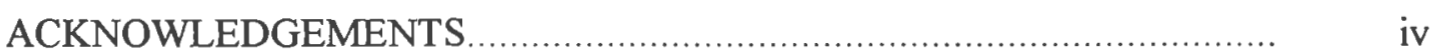

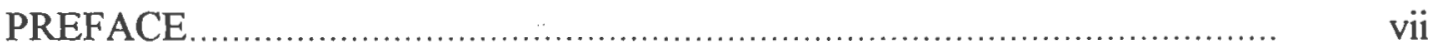

TABLE OF CONTENTS ................................................................. viii

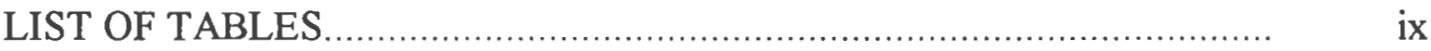

LIST OF FIGURES

MANUSCRIPT I. A Regulatory Overview of the Changing Standards of

Medicines Available to Consumers for Self-Medication.

MANUSCRIPT II. Improving Self-Medication with Rx-to-OTC Switch

Medicines.

MANUSCRIPT III. The Implications of Labeling and Advertising on the

Safe and Proper Use of Rx-to-OTC Switch Medicines............................ 57

MANUSCRIPT IV. Current Perceptions Regarding Over-the-Counter

Medicine Labeling and Advertising ............................................. $\quad 92$

APPENDIX A. Surveys................................................................ 149

APPENDIX B. Conclusions and Considerations for Future Work ................. 158

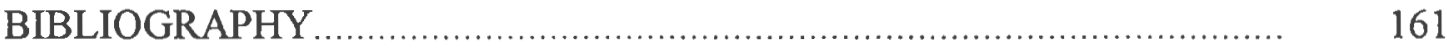




\section{LIST OF TABLES}

Manuscript I

Table I Consumer expenditures for all medicines.

Manuscript II

Table I Early Rx-to-OTC Switch Products........................................... 36

Table II Recent Rx-to-OTC Switch Ingredients.................................... 38

Table III Current Rx-to-OTC Switch Candidates................................. 39

Manuscript III

Table I Advertising volume for select OTC product categories, 1972........ 86

Manuscript IV

Table 1 Sample distribution, size and response rates, consumers............... 101

Table 2 Consumer Demographics.............................................. 102

Table 3 Sample size, response rates, Mds and Rphs........................... 103

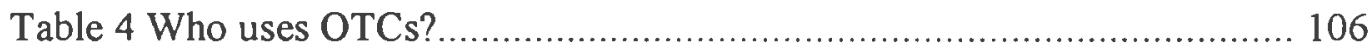

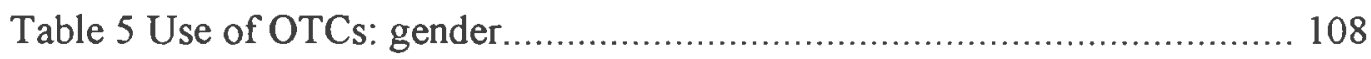

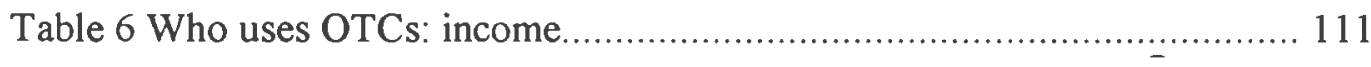

Table 7 Who uses OTCs: education....................................................... 112

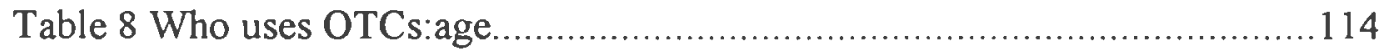

Table 9 Who uses OTCs: language ................................................ 115

Table 10 Where do consumers purchase OTCs?................................. 116

Table 1 1Should Rx drugs be switched?....................................... 124 
Table 12 Consumer Label readability and understandability

Table 13 Health Professional OTC recommending practices.

135

Table $14 \mathrm{MD}$ and $\mathrm{RPh}$ views on label information 140 


\section{LIST OF FIGURES}

Manuscript I

Figure 1 Copy of prescriptions from 1901, New England Area............... 5

Figure 2 Copy of pharmacists prescription $\log , 1907 \ldots \ldots \ldots \ldots \ldots \ldots \ldots \ldots \ldots \ldots$

Manuscript II

Figure 1 National Health Care Expenditures, 1990

47

Manuscript III

Figure 1 Micajah's medicated wafers.......................................... 69

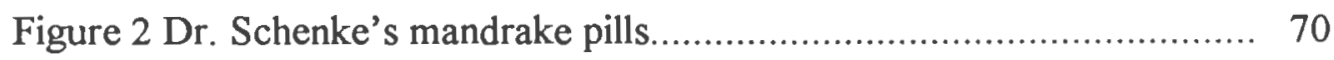

Figure 3 Dr. Morses's Indian Root pills.................................... 71

Figure 4 Dr. J. Pettitt's American eye salve.................................. 72

Figure 5 Package Insert, Dr. Pettitt's pile salve............................. 73

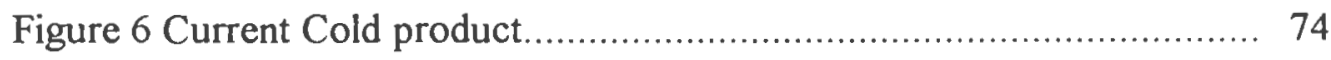

Figure 7 Current Cold product, another format............................. 75

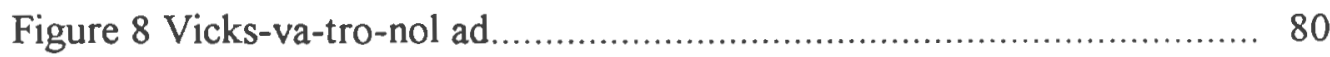

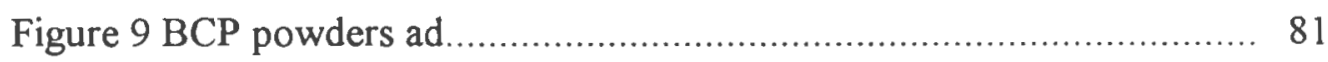

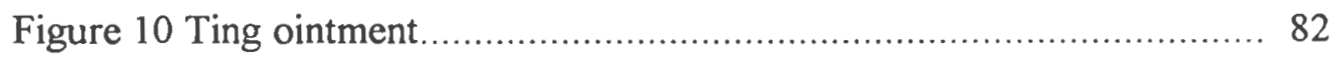

Manuscript IV

Figure 1 What was done 1983 vs 1992 , health care ......................... 120

Figure 2 Source of influence in selecting OTCs........................... 120

Figure 3 Physician and pharmacist perceptions............................ 135

Figure 4 Patient characteristics which affect safe use of OTCs............. 138 


\title{
MANUSCRIPT I
}

\author{
A REGULATORY OVERVIEW OF THE CHANGING STANDARDS OF \\ OVER-THE-COUNTER MEDICINES AVAILABLE TO \\ CONSUMERS FOR SELF-MEDICATIION
}




\title{
A Regulatory Overview of the Changing Standards of Medicines
}

\author{
Available to Consumers for Self-Medication
}

\section{Introduction}

From passages in the Bible to the chapters in Remington's Pharmaceutical Sciences-the mention of drugs, their formulae for preparation, and their descriptions for use, give credence to the practice of self-medication as both an ancient human tradition and a modern science.

Modern pharmacy as we know it evolved primarily during the 19th and 20th centuries. During that period, many new drugs were introduced increasing the number of preparations already in use or replacing those phasing out. Also occurring in the 19th century was the movement toward standardization of drug formulations through publication in compendia known as pharmacopoeias. The first edition of the United States Pharmacopoeia (USP) was written by doctors in 1820.(25) It contained a list of pharmaceutical preparations with their composition and technique for manufacturing. In 1888 , the first issue of National Formulary (NF), written by pharmacists, was published as a supplement to the USP containing drugs not included in the USP.(25) A third compendia, the Homeopathic Pharmacopoeia of the United States, was developed around the 1930 s to include standards for homeopathic agents.

The compendia formulary drugs were contrasted with coexisting numerous patent or proprietary medicines. Patented medicines were those in which ingredients and 
methods of formulating remained secret to all but who assigned them trademark names and sold them as such.(6) When the system of issuing patents to specific combinations of drugs was launched, it gave rise to the practice of establishing proprietary claims which were then universally accepted and protected under patent laws. $(6,24)$ By the early 1900 's, the retail drug market became flooded with proprietary and patent medicines, all of which were accessible to consumers without the intervention of medical personnel. $(6,24)$

The attitudes of the public toward the acceptance of medicines and their purpose for use have changed over time. At one time drugs were used primarily to treat sudden and transient illnesses or ailments. While this practice remains essentially unchanged, additional developments included the employment of drugs for their benefits in the treatment of serious or chronic conditions and the use of drugs in preventative medicine. The chronic administration of drugs in some cases extends the life of individuals who suffer from serious conditions like hypertension or diseases such as diabetes. In other cases, the routine use of vitamins, antianxiety agents, or sleep agents nurtures good physical or emotional health.

As these conventional modes of drug use were employed by the public, confidence in their results grew and drugs became important resources in our society. The increasing role of drugs is exemplified by the amount of legislation designed and published in numerous volumes for the purpose of systemizing and regulating them. To encourage and support this status, pharmaceutical manufacturers grew in size and wealth in order to yield mass production and distribution of drugs. $(6,24)$ 
In the beginning of the $1900 \mathrm{~s}$, there were three methods for consumers to obtain proprietary or patent drugs. $(6,24)$ The traditional method was to visit a doctor, receive a prescription for a specific drug or combination of drugs, and take it to a pharmacist to fill. This seems to replicate the procedure observed toda; however, the difference lies in the function of the prescription. In the early 1900s, all drugs or combinations of them were available to consumers with or without a doctor's order. If a pharmacist filled a prescription once, it then could be used as many different times and for as many different people as the pharmacist desired. In fact, if the drug or combination of drugs seemed to cure, mitigate or promise either result, the pharmacist could manufacture the product on a large scale, advertise it for the desired claims or uses, and sell it with no legal restrictions. $(6,10)$ Only about 25 percent of drug sales from drugstores were ordered by physician prescriptions.(24) 
Figure 1

Copy of prescriptions from 1901, from New England area.

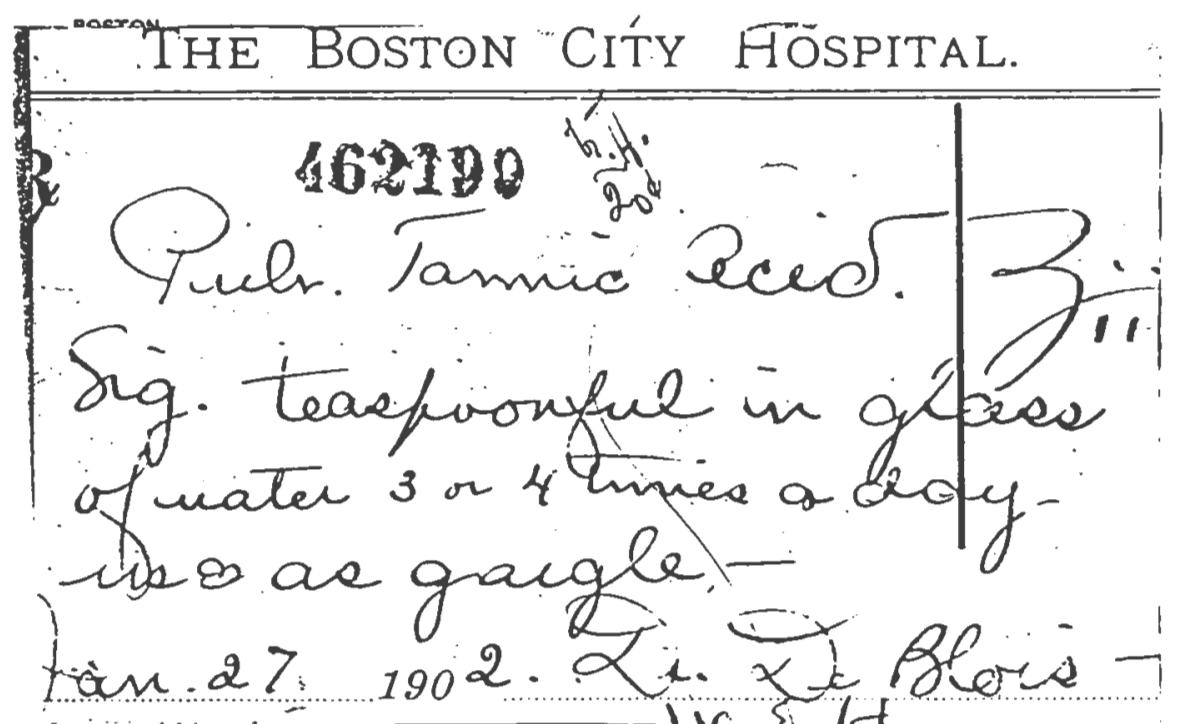

'L'HE BOSTON CITÝ, HOSPITAL. o

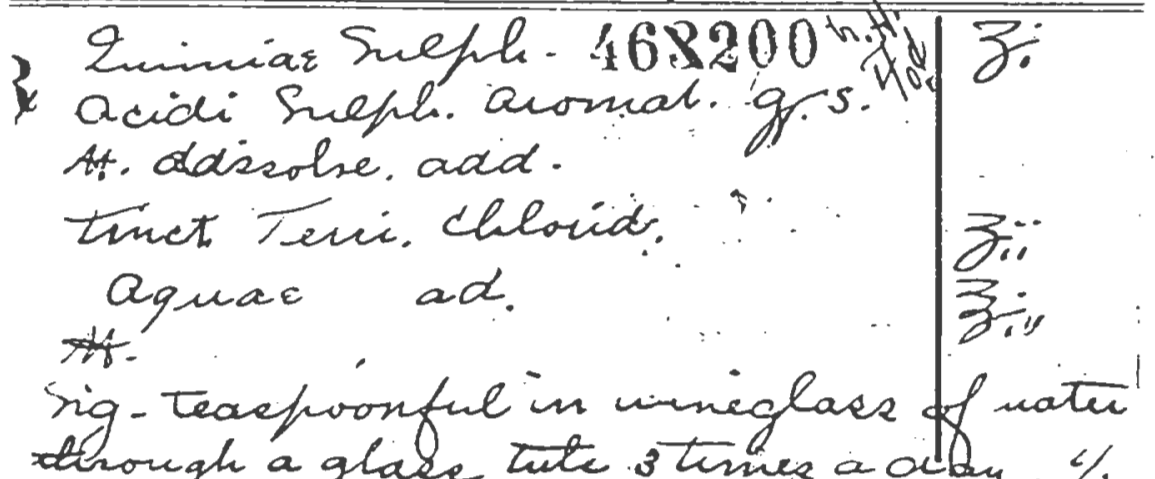
though a glade tue stems a od dy - $1 / 2$ hour before neal.

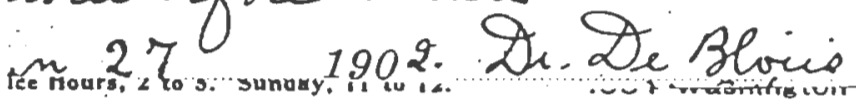

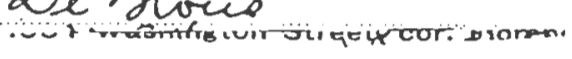

5 
Figure 2

Copy of Pharmacist prescription log, 1907, from Rhode Island.

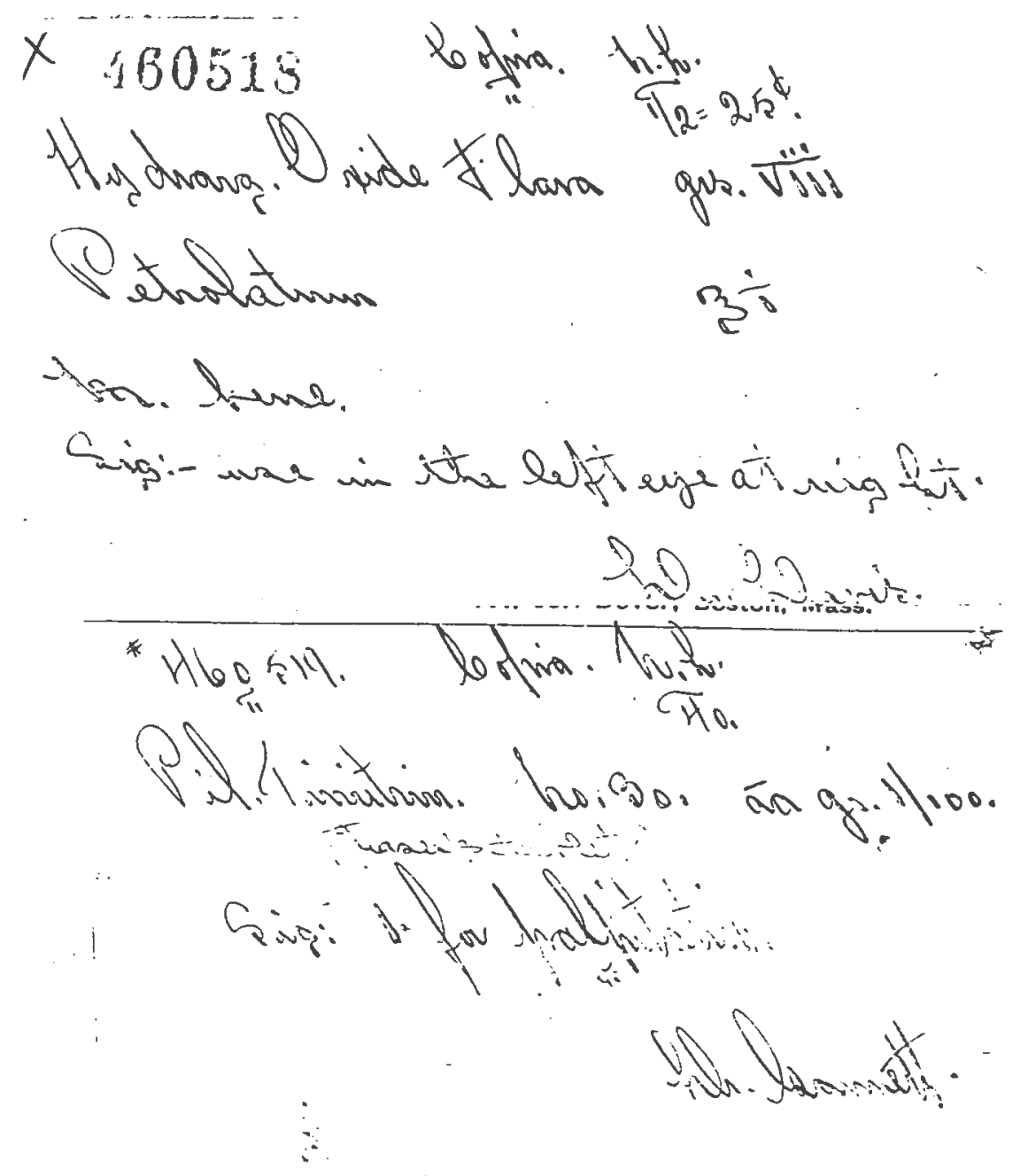


The second method for consumers to purchase drugs was to patronize the local drugstore and buy whatever they wished directly from the pharmacist. Approximately 70 percent of drug sales arose from this practice. $(6,24)$ It was during this time that the government attempted to prevent nonphysicians from practicing medicine through the enforcement of medical licensing laws.(2,6,10,24) These laws ultimately restricted pharmacists from recommending a drug which they did not stock, since recommending would then be considered prescribing and only physicians retained the authority to prescribe. Their flexibility in selling or advertising any of their own commodities was not limited.(2,6) This initiative was important because it revealed the government's recognition for some form of regulation on drug;, however the law was weak in its capacity for controlling accessibility of potentially harmful or useless drugs.

The third way for consumers to obtain drugs was to purchase them directly from doctors. Since doctors realized selling drugs was a way to increase business and enhance their incomes, they too participated in dispensing drugs. This method only accounted for about 5 percent of drug sales around 1929.(24)

For those consumers who relied upon herbs as remedies, individual herbs or herbal preparations could be obtained from herbalists or homeopathic nonphysicians who formulated these products. 
Table 1

Consumer expenditures for all medicines in selected years(dollars in millions).

\begin{tabular}{lccc}
\hline Year & $(\$)$ Rx drugs & (\$)Drugs and drug sundries & $\%$ Rx drugs \\
1929 & $\$ 190$ & $\$ 600$ & $32 \%$ \\
1949 & $\$ 940$ & $\$ 1640$ & $57 \%$ \\
1969 & $\$ 5395$ & $\$ 6480$ & $83 \%$
\end{tabular}

Sources: Rorem, C.R. and Fischelis, R.P. The Costs of Medicines, pub. no. 14 of the Committee on the Cost of Medical Care. Chicago Univ. Press. Chicago (1932)

Worthington, N. "National Health Care Expenditures, 1929-1974." Social Security

Bulletin, 38(Feb. 1975).

* Rx stands for prescription (drugs).

*This table reflects the percentage of prescription expenditures compared to the total amount of dollars spent on all drugs and health and beauty aids. 
Presently, there are two classes of drugs in the United States:nonprescription (OTC) and prescription drugs. Consumers have available to them a broad selection of over-the-counter medicines or they may call or visit their physician and obtain a written prescription for those medicines marketed under prescription-only status.

If we look back through the history of the regulation of drugs, we can observe a cycle. At one time, all medicines were accessible to consumers without medical supervision but slowly, with developing laws, more and more medicines were shifted to prescription-only status. Presently, the prescription market is undergoing a major shift in the direction of the OTC market. Throughout the duration of this cycle, the goal of providing consumers with safe and effective medicines and the information to accompany them has always remained intact.

\section{History of the Food and Drug Administration}

The FDA originated in the Division of Chemistry within the U.S. Department of Agriculture. $(2,8)$ Since the conditions in the drug and food industry were discovered to be unrefined and unsanitary, it became essential for the government to intervene and set guidelines for the production of safe food and drug products.(11) Therefore, in 1879, the Division of Chemistry undertook a major but important task of inspecting food and drug products for their safety, and manufacturing facilities for their cleanliness. $(2,8)$

Congress expanded the divisions responsibilities and recognized it officially as the Bureau of Chemistry in 1883.(8) From that point on, the Bureau of Chemistry devoted its time to auditing and controlling food and drug provisions in the United 
States. To carry out its responsibilities, the Bureau implemented federal legislation aimed at protecting the public. A separate agency within the Bureau called the Food, Drug, \& Insecticide Administration, and later renamed as the Food \& Drug Administration in 1931, was organized for the purpose of enforcing these regulations. Until 1940, the FDA remained a part of the Department of Agriculture. At that time it was relocated to the Public Health Service which fell under the Federal Security Agency. Eventually, this agency became known as the Department of Health and Human Services. $(2,8)$

The FDA, received its authority from Congress, acquired an increase in its realm of responsibilities, and activities through legislation. The mission of the FDA continues to revolve around protecting consumers from unsafe products and providing more truthful product information for them.(2,5) From its history, we can see how the FDA evolved from an inspection agency with limited police powers to a scientific, regulatory agency comprised of expert talent and knowledge, all of which are applied to assuring public safety from food and drug products. Today, challenges from the food and drug industry are presented to the FDA on a daily basis as a result of the developing technology in science and the improved education of consumers.

\section{Legislative overview}

\section{A. Pure Food and Drug Law of 1906}

Food adulteration and contamination had been recognized as a problem for some time before this law was passed in 1906.(11) It was apparent that the integrity and 
ethical standards of manufacturers were blunted by the struggle to survive in an increasingly competitive arena of business. The standards of safety that existed for the public were diminished to an all time low. Uptown Sinclair, author of The Jungle, graphically disclosed the repulsive and unsanitary practices of meat packers and other producers of foodstuff. $(11,24)$ The public response to this book pressured Congress to enact legislation which would set standards for these manufacturers to meet if they were to produce any food or drug for public consumption. The Pure Food and Drugs Act, which was signed into law in June 1906, addressed this issue.(20)

The Pure Food and Drug Act specifically prohibited adulterated or misbranded food or drugs in interstate commerce.(20) The drugs covered under this law included all those (patent and formulary) accessible for consumer use. A drug was deemed to be "adulterated" if it deviated from the standards of purity or strength stated by the compendia without revealing as much on the package container. A drug was considered "misbranded" if it was sold under a false name or it failed to identify the list of ingredients and the quantities of addicting substances that the product contained.(20)

There were obvious inadequacies with this law. First, it did not require manufacturers to disclose ingredients (outside of narcotics) in their preparations. $(7,9)$ However, if the manufactures chose to do this, the FDA would monitor the accuracy of the disclosure. Also, those products containing several ingredients had to be reproduced consistently and under the same name. Last, any information provided on the container could not be false or misleading. $(7,8,24)$ To bypass the requirements of this law, a manufacturer could simply produce a nonnarcotic formula, call it an original name, and 
provide very little information about it. The control of what products were to be made and sold was not affected by this law and therefore remained in the hands of manufacturers who continued to respond to consumer demand.(7)

The pharmaceutical industry's sales increased sixfold from the time of the Pure Food and Drug Act to the beginning of the Depression. (24) Preparations manufactured by pharmacists and doctors accounted for 40 percent of the total medicines consumed by the public throughout this period. The remainder was comprised of patent or proprietary medicines which accounted for more than half of all drug sales in 1929.(24)

\section{B. The Harrison Narcotic Act of 1914}

At this point in time, this act was the first and only legislation which restricted sales of drugs and specified that any drug product containing opium or coca leaf derivatives could be sold only upon the receipt of a physician's written order. $(7,15)$ Overall, this law had little impact over the vast number of drugs available to consumers.

\section{C.The Federal Food, Drug, and Cosmetic Act of 1938 (FD \& C Act)}

In 1937, Massengill, a respected drug company, decided to market a drug that seemed to have miraculous antiinfective properties. This drug, known as sulfanilamide, had been used in powder form on topical wounds to prevent infection. Sulfanilamide was already marketed in tablet and capsule form for some time. The idea to sell this drug in liquid form was quickly implemented when the company found a compatible, pleasant- tasting vehicle, diethylene glycol. Without being tested for toxicity, this 
solution was produced, labeled Elixir Sulfanilamide, and marketed by September 1937.(13)

Subsequently, diethylene glycol was found to be toxic and the product caused approximately 100 deaths. Even though Massengill, which produced the elixir, was responsible for these deaths, the company could be prosecuted only for mislabeling under the 1906 Pure Food and Drug Act. It used the term "elixir" which implies an alcohol solution and this term was not appropriate for the product. $(13,24)$

Consistent with prevailing conditions of the Pure Food and Drug Act of 1906, the occurrence of a health hazard aroused a public outrage and resulted in a quick response from the legislators. It led to an amendment to this 1906 act renamed as the Federal Food, Drug, \& Cosmetic Act of 1938. Additionally, the increasing sales and advertisements of medicines through the first quarter of this century presented a safety concern to the FDA. This new amendment required that drugs and cosmetics be tested for safety with regard to intent of use and that they undergo an approval process. $(15,22)$ For this discussion only drugs will be referenced. Since any drug can be considered harmful if used improperly, the manufacturers had to demonstrate the safety of the drug when used according to the conditions described in the labeling. The term "labeling" refers to the written or graphic material which is placed on the container or any of its wrappers which accompany the drug product. $(26,27)$ According to the 1938 law, label information was to include the contents of the product and adequate directions for use in language understandable by persons of ordinary intelligence. (29) A further requirement of labeling was an inclusive warning which identified the drug product as one containing 
a narcotic or hypnotic ingredient.(29,31,33) This warning came to be known as the “Caution" warning and it stated: "Warning: May be habit forming." $(26,31,35)$

The 1938 law also imposed restrictions on the variety of drugs which could be marketed, and it mandated that information about these drugs be provided to the consumer. The law as written, however, still seemed to allow the consumer to choose from the available drugs on the market. The FDA supported the concept of selfmedication through this legislation and, in fact, the goal was to improve or facilitate patient self-medication, not hinder it. The ultimate expectation of the 1938 act was to make self-medication safe, but this goal appeared to be nullified by subsequent actions of the FDA.

Among the regulations promulgating the enforcement of the FD \& $\mathrm{C}$ Act was one which addressed labeling exemption. Those drugs in which safety could not be assured by adequate directions in the labeling would be exempted from the labeling requirement provided they were labeled with a cautionary statement. $(28,31,35) \quad$ This statement read "Caution: To be used only by or on the order of a physician." $(28,31,35)$ This statement came to be known as the "Caution legend" and it was later revised to read "Caution: Federal Law prohibits dispensing without a prescription." (15) It was to be placed on packages of these medicines, thus identifying them to pharmacists and physicians as those which required a prescription. This legend was placed voluntarily on packages by manufacturers and the FDA approved them for marketing under this restricted status. $(7,24)$ The decision as to which medicines should bear the caution legend was primarily left to the manufacturers. In the development of new drugs, the 
manufacturers would propose prescription or nonprescription status within their new drug application which was submitted to the FDA. $(7,22,24)$ This legislation ignored some important issues. Although the act stated that drugs sold by prescription were exempt from some labeling requirements, it did not specifically differentiate between prescription and nonprescription status for drugs. In other words, there was no mention of which drugs could be sold by prescription or which drugs could not be sold without one.(7) This allowed drug companies to create a class of drugs which could not be sold legally without a prescription. This process curtailed consumer access to drugs since the FDA and manufacturers would decide from what products they could select. This goes against what the FDA proposed or hoped to achieve by the initial enactment of this legislation.

The FDA still had a legitimate concern about some of the potentially harmful substances which were accessible to consumers without supervision of a physician or sufficient labeling to assure their safe use. Since none of the regulations was applicable to the drug products which entered the market prior to 1938, a range of products whose safety was never subject to FDA approval or review remained accessible to consumers. $(22,24)$ Also, as mentioned earlier, prescriptions were not needed to purchase any nonnarcotic drug. This situation revealed the lack of definitive guidelines or operational rules available to the FDA for consistent decision making.

From 1938 through 1951, with the implementation of the FDA approval system, two classes of medicines were evolving without recognition. Newly developed drugs or drug products which were subject to FDA apporval were forming a class which required 
physicians' orders while existing drug products remained directly accessible to consumers. The terms prescription and nonprescription had not been applied to label either class of medicines. (7) An additional inconsistency was recognized by legislators. Two manufacturers could have similar products with the same ingredients. One manufacturer may have been subject to placing the drug under limited access as a result of the approval process, while the other was able to market its product without any restrictions and thus be directly accessible to consumers. The timing of when each product was developed and marketed, compared to when the new regulations were imposed accounted for this discrepancy.(22) Between 1944 and 1951 regulators became aware of the fact that there was little uniformity within the drug marketplace. The 1938 FD \& C Act laid down the framework for the initial organization of the nonprescription and prescription market but left a number of issues to be addressed with further regulatory developments.

\section{Durham Humphrey Amendments of 1951}

In 1951, the FDA proposed some additional general guidelines which would create broad parameters for categorization of drug products, thus providing an opportunity to clear up market inconsistencies. The Durham-Humphrey amendments encompassed these changes and marked the beginnings of a clear distinction between a prescription and nonprescription class of drugs. $(7,9)$ The FDA wanted to make all safe and not misbranded or mislabeled medicines accessible to consumers. Those medicines falling into this category would be classified as nonprescription. Any medicine which 
bore the "Caution Legend" and required use under medical supervision would be considered prescription.(15) Three provisions in the Durham-Humphrey amendment described the criteria which were to be applied toward determining prescription classification. $(4,7,21)$

1. Habit-forming drugs that are specifically identified in section 502(d) of the FD \& C Act. (includes seventeen drugs and their chemical derivatives in this category)(32,35)

2. Any drug which "because of its toxicity or other potentially for harmful effect, or method of its use, or the collateral measures necessary to its use, is not safe for use except under the supervision of a practitioner licensed by law to administer such drug." (32,35)

3. A drug which "is limited by an approved application under section 505 for use under the professional supervision of a practitioner licensed by law to administer such drug." "New drugs," as defined in section 201 of the FD \&C Act are approved by an application under section 505 of the FD \& C Act. $(32,35)$

The enforcement of the distinction between prescription and nonprescription was left to pharmacists in their role as a gatekeeper of medicines. Those pharmacists who sold prescription medicine as Over-the-Counter medicine could be prosecuted for misbranding, but the courts would sue the manufacturers for not placing the appropriate prescription or nonprescription designation on the medicine. (24) 
Another effort toward achieving uniformity of the marketing status of products was focused on those drug products which contained the same ingredients for similar purposes. All drug products with similar ingredients were placed in the same prescription or nonprescription class.(22) These changes began to enhance regulation patterns of drug products but did not have a profound impact in the FDA's process of determining which drugs should be prescription or nonprescription.

\section{E. The Kefauver-Harris Amendments of 1962}

In 1960, the drug company William S. Merrell, submitted a new drug application to the FDA for a drug known as thalidomide. $(3,23)$ The application was returned by the FDA to Merrell on several occasions due to the insufficient safety information.(24) At the same time, in Germany and other European countries, a serious condition called phocomelia appeared at a startling rate.(24) This teratogenic condition caused numerous

children to be born with missing extremities such as hands or feet. It was soon discovered that thalidomide was the culprit for these birth defects and the drug was removed from the market. The new drug application to the FDA for thalidomide was removed without approval for use in the United States. (24) Although thalidomide was never approved here, it was distributed in the United States for clinical testing. This was allowed because the FDA had no authority under the 1938 FD \& C Act to supervise clinical drug testing. The result of this testing was a small but alarming outbreak of phocomelia in this country.(23) 
As is often the case, history had to repeat itself in order to achieve progress in the regulation of drugs. During the thalidomide controversy, .Senator Kefauver proposed a bill to increase FDA surveillance over drug manufacturing and new drugs, to increase competition between drug companies. A more important section of this bill called for an addendum to the safety requirement of drugs. Kefauver proposed that this requirement should include efficacy and evidence of this should be included in new drug applications submitted to the FDA.(4,24) The Kefauver-Harris amendments of 1962, also known as the drug efficacy amendments, were passed by Congress for the purpose of applying more stringent criteria to all drugs, both prescription and Over-the-Counter. Drugs were expected to be proven effective for their proposed claims and safe for their labeled use.(15) These amendments forced the FDA to reevaluate all drugs that had been previously approved based on safety alone.

The FDA reviewed approximately 4,000 drugs. $(5,22)$ Most of these were prescription-only status. Only 512 drugs were OTC products; of these 25 percent were deemed effective. (22) With this finding, the FDA recognized the need for a major revamping of the structure of the OTC market. Since it was well known that an abundance of products comprising the OTC market were never subject to approval, the FDA embarked on a tremendous but important task of reviewing all OTC products. This came to be known as the OTC Drug Review.

These 1962 amendments made important changes in the regulation of existing drugs. They forced manufacturers to conform to good manufacturing procedures, place generic names in addition to the trade name on package label, and be ready to undergo 
frequent inspections by the FDA. $(18,19)$ The amendments also affected the FDA itself by giving the FDA the ability to withdraw previously approved NDA applications based on insufficient evidence of safety and/or efficacy. $(18,19)$ The law applied to any and all drugs, even those marketed prior to 1962 . These regulations appeared to be a cure-all in the regulatory end that would now prevent mishaps from recurring. . But in the case of thalidomide, safety or effectiveness was not disputable then or now. The issue of controlling potentially harmful drugs which meet the safety and efficacy requirements had yet to be addressed. Over time, the solution emerged from the vast amounts of scientific evidence the FDA required for NDA approval. 


\section{The OTC Drug Review}

In 1972, the FDA along with several scientific panels began the most significant and complex endeavor to regulate Over-the-Counter medicines. After many years of addressing the issues of safety and effectiveness and creating a distinction between the prescription (or legend) and nonprescription classes, the FDA launched the-Over-the Counter Drug Review with the objective of achieving uniformity in the OTC market. The review process took approximately twenty years for the FDA to complete. $(5,16,22)$

In the initial phase of the review, the OTC drug advisory panels set out to evaluate all OTC products for their safety and effectiveness, and the labeling conditions which ensured this standard. The first goal of this review was to eliminate products from the market which did not measure up to the standards of safety and efficacy. A second goal was to assess the products for misbranding or mislabeling. $(5,22)$

To accomplish these goals, the panels classified ingredients into three categories:(5,7,21,22,37)

Category I- generally recognized as safe and effective for the-claimed therapeutic indications;

Category II- not generally recognized as safe and effective or the the indications were unacceptable;

Category III- insufficient data available to permit final classification. 
Recognizing the amount of time required for reviewing the thousands of drugs on the market, the FDA elected to organize and condense the review process by developing tangible regulations in the form of monographs for the therapeutic categories of products encompassing the OTC market. $(5,22)$ The decisions on the categorization of ingredients were published in the Federal Register for review by the manufacturers.(5) If a manufacturer found its ingredients in category II or III, it was granted limited time to reformulate the products, or carry out further studies to establish safety and effectiveness for the claimed therapeutic indications. If the company could not meet the designated criteria, it had to remove its ingredient from the market.(4,5)

The Tentative Final Monographs, which eventually became Final Monographs, contain information defining the conditions of use of specific drugs which would be generally recognized as safe and effective. To avoid misbranding or mislabeling, the monograph also provides guidelines for packaging and labeling, the approved dosage forms, the composition of the formulations (essentially the active ingredient or combination of active ingredients), the proposed dosages and directions for use, and any necessary warnings which assures the safe and proper use of the product. It was possible to extend a monograph to include testing procedures if warranted.(22) Once an OTC monograph was created, it was codified in the Code of Federal Regulations.(22) At that point, manufacturers could market a product without prior approval by the FDA as long as that product complied with the guidelines in the appropriate monograph. $(4,5)$ 


\section{Methods of Switching Products from Rx (Prescription) to OTC Status}

The summary below outlines the methods and their applicable circumstances which have been established for switching prescription-only medicines to Over-theCounter status. The discussions which follow describe the conditions for each method.

1. Petition to amend an OTC Monograph

- manufacturers, professional organizations, consumers

- OTC Drug Review Panel recommendations

- FDA proposed (under Switch Regulation)

* prescription medicines to OTC status

* revision or reformulation of an OTC product

2. New Drug Applications or Supplemental New Drug Applications

- manufacturers who are NDA holders of potential switch ingredients

* prescription medicines to be switched to OTC (same dose/indication)

* prescription medicines: a new indication or a change in dose to be switched

* new OTC medicines

* revision or reformulation of OTC product

3. Abbreviated New Drug Application

- manufacturers 
* for prescription or OTC generic drugs

* prescription medicines to be switched to OTC: change from Rx use to OTC use *ANDA method not used in switch process

\section{A. The Switch Regulation (21 CFR 310.200,1956)}

The Switch Regulation, employed by the FDA, allows the commissioner or any interested party, usually a manufacturer, to submit a petition to exempt a drug from its limited access of prescription status as specified under its NDA.(37) This process will lead to the switching of this drug to OTC status if the FDA determines that the limitations for dispensing are unnecessary for the protection of the public health. This regulation has been utilized by the FDA to switch approximately 25 ingredients to OTC status.(5) Most of these product have fallen into the cough and cold and sleep aid categories.

During the OTC review, the panels also reviewed several prescription products for possible OTC use. In addition to proposing that certain over-the counter medicines be switched to prescription status, they proposed 31 prescription-only medicines to be switched to OTC status. These recommendations for switching from the -OTC review panels received favorable support from the FDA, since it approved 18 of the proposed switch ingredients. $(5,22,37)$

The FDA initiated several prescription to OTC switches itself. Under the FDA's Switch Regulation, the FDA may use its authority to switch prescription only products to over-the-counter status based on its own decision or on petitions from manufacturers. 
$(5,37)$ One example of an FDA initiated switch was in the case of the drug metaproterenol, a bronchodilator. In 1982, when the FDA published the bronchodilator tentative final monograph(TFM), it chose to include the drug metaproterenol as an approved ingredient as a bronchodilator for inhalation.(5) Since epinephrine existed on the OTC market in both oral and inhalation forms, the FDA felt metaproterenol could offer similar or possibly better therapeutic benefits with no more risk than epinephrine.(5) This was the first time the FDA switched a drug without consulting with their OTC drug advisory panels. In 1983, the OTC products containing metaproterenol appeared on the market. While excessive complaints were filed with the FDA from physicians regarding their concern about the safety of this drug as an OTC product, the FDA consulted with the Pulmonary-Allergy Drug Advisory Committee about the switch. The committee voted to rescind the decision of switching this drug because of the potential adverse effects which could occur with misuse, and the reversal to prescription status was announced soon after. $(5,37)$ This was the last time FDA used its authority to switch a drug without consulting with its scientific panels.(5)

\section{B. Petition to Amend the Monograph Method}

Manufacturers, regulatory agencies, or any interested party can petition the FDA to amend the Final OTC monograph to include another ingredient for OTC use, based on the indication(s) specified in a therapeutic category. $(5,21,37)$ This method may be used for prescription drugs with potential for OTC marketing, reformulation of an OTC product, or a change in the indication of an OTC product. Manufacturers can not utilize 
the petition method for a "new drug." A "new drug" is one which is not generally recognized as safe and effective (GRAS/GRAE) under the condition prescribed, recommended, or suggested in the labeling. $(1,26,35)$ Products that meet specifications in a final monograph are expected to have a marketing history for "material time and to a material extent." $(1,11,21) \quad$ Material time and material extent refers to at least three years of marketing time and relatively high use of a drug during that time. $(1,21)$ Marketing a drug as a prescription for at least three years permits sufficient data to be collected through ADR reports or revisions in labeling made by the manufacturer due to the occurrence of ADRs.(1) The petition method is not recommended because the FDA applies more stringent standards in its decision and it tends to be reluctant to change expert scientific information which was integrated over an extended period of time.(11) For manufacturers, there are some drawbacks in using with this method. Particularly worrisome to the manufacturer is that the submitted information will be publicly available. Also, there will no marketing exclusivity, and the evaluation time period is expected to be extensive.(11)

\section{New Drug Application Method (NDA)}

Since the OTC drug review began in 1972 , several drugs have been switched by the New Drug Application or supplemental New Drug Application methods. The NDA method requires manufacturers to submit complete safety and efficacy data.(11) A drug which is switched by the NDA method is subject to postmarketing surveillance. $(1,11)$ Compared to the other methods of switch, the NDA route seems to be the most 
expeditious, since the time for review of the application by the FDA and the scientific panels has been on the average of two to three years. A manufacturer's petition to amend a monograph may take several years.(11)

Provided their product has a reputable and lengthy market history (as a prescription), manufacturers usually proceed with the switch process by the NDA method. The basic criteria considered, as stated by the FD \& C Act, is that the ingredient must not be habit forming, must be safe and effective without needing medical supervision, and finally has adequate labeling. $(1,7,9,37)$

Through the NDA method, manufacturers reserve the possibility of obtaining marketing exclusivity depending on whether they include "essential" clinical information from new clinical investigations with their application. (11) This exclusivity may be granted according to the terms of the Drug Price Competition and Patent Restoration Act of 1984.(11) If the FDA does not require this clinical data, the likelihood of being eligible for this exclusivity is lessened. This is worrisome for manufacturers because if no exclusivity is granted, other NDA or ANDA holders could submit labeling supplements to the FDA and quickly enter the OTC market as competitors.(11)

Another benefit available to a manufacturer filing an NDA is the potential confidentiality offered to the manufacturer prior to the final approval stages.(11) This ensures the manufacturer that it will lead the market in the specific product line with its OTC product. 


\section{Abbreviated New Drug Application (ANDA) Method}

An ANDA application as the name denotes is a condensed form of an NDA.

With this application, the drug company is responsible for referencing complete safety and efficacy data but it does not have to be the one who conducted the studies.(11) The ANDA has been most commonly utilized by generic companies interested in entering the market at or close to the time of patent expiration of prescription and nonprescription products. The FDA has implied that this application may be used to switch a drug from prescription to nonprescription, by proposing a change in the indications for use.(11) To date, this method has not been officially integrated into the switch policies; therefore, it is yet to be used by a manufacturer for a switch.

\section{Nonprescription Drug Advisory Committee (NDAC)}

In 1991, the FDA appointed several individuals to a committee known as the Nonprescription Drug Advisory Committee (NDAC).(14) These appointees represent expertise from the health professions (doctors and pharmacists), the industry, the regulatory agencies, and the consumer population. Their primary responsibility is advising the FDA on decisions regarding Rx-to-OTC switch NDAs and petitions.(14) The committee is also responsible for informing the FDA of developments in the Rx-toOTC trend and self-medication.(14) They serve as an important liaison between the FDA and the industry, health care professionals, professional organizations, and consumers. The development of the NDAC committee is another effort the FDA is extending 
towards maintaining the progress of the Rx-to-OTC Switch trend, enhancing selfmedication, and controlling the over-the-counter market.

\section{Summary}

The government has invested a great deal of time and expense in evaluating numerous drugs in order to provide consumers with safe and effective Over-the-Counter products. Consumers have long expressed to the industry and government regulators their concerns about drug safety, effectiveness, cost, availability, and the freedom to choose. The FDA addressed some of these concerns and implemented several laws designed to meet consumer needs.

When it comes to self-health care, consumers have repeatedly demonstrated a positive interest and willingness to assume an active and responsible role. National studies have documented this interest, as well as the habits for self-medication with OTC medicines. Consumers recognize that minor ailments or conditions can be safely and effectively treated with OTC medicines.(4) They appreciate the direct access they have to these medicines since it saves the time and money involved in visiting a physician. With the advent of switching drugs from prescription to Over-the-Counter status, consumers will have more options available to use in self-care. 
1. Botstein, P. “ Criteria for Switching New Molecular Entities from Prescription to Over-The-counter". Drug Information Journal, 24:29-31 (1990).

2. Dunbar, P. B. "Memories of Early Days of Federal Food and Drug Law

Enforcement." Food Drug and Cosmetic Law Journal 14:87-139 (Feb 1959)

3. Fine, R.A. The Great Drug Deception. Stein and Day. NY (1972).

4. Garrity, M. “ Coming to Grips with the Rx-to-OTC Switch.” Drug Topics, 133(11):58-68 (June 5, 1989).

5. Gilbertson, W. The OTC Drug Review-switch without regulation or application Drug Information Journal 19 101-109 (1985).

6. Hechtlinger, A. The Great Patent Medicine Era. Grosset and Dunlap. NY (1970)

7. Hutt, Peter Barton. "A Legal Framework for Future Decisions on Transferring Drugs from Prescription to Nonprescription Status. " Rx:OTC Symposium. The Proprietary Association, Nov.1, 1982.Washington, D.C.

8. Juergens, J.P. "The FDA and community pharmacy: Today and tomorrow". Drug Topics, 88-94(Aug,3 1992).

9. Kaplan, A."OTC and Prescription Drugs: The Legal Distinction Under Federal Law”. Symposium: Rx:OTC; New Resources in Self-Medication. The Proprietary Association, Nov. 1, 1982. Washington, D.C.

10. Kett, J.F. Formation of the Medical Profession, 1760-1860. Yale University Press.New Haven (1968).

11. Lamb, R. American Chambers of Horrors: The Truth about Food and Drugs. Farrar and Rhinehart. NY (1936). 
12. Mahinka, S.P. Direct-to-OTC Marketing. NDMA R \& D Conference.

Washington, D.C. (Nov. 12, 1992).

13. Massengill, S.E. A Sketch of Medicine and Pharmac S.E. Massengill Co. Bristol, Tenn, (1943).

14. NDMA Executive Nesletter. No. 42-92:2 (Nov. 13,1992).

15. Nielson, J.R. Handbook of Federal Drug Law. Lea \& Febiger. Philadelphia, PA(1986).

16. O'Keefe, D. F. Jr. "The Over-the-counter Drug Review- Helping the Client Make Decisions." Food Drug Cosmetic Law Journal. 262-283 (May 1974).

17. Public Law 87-781, 76 Stat. (102)(d).

18. Public Law 87-781, Stat. 76 (102) \& (104)(f).

19. Public Law 87-781 (102) (e).

20. Pure Food and Drug Act,34768 (1906)

21. Rachanow, G. The Switch of Drugs from Prescription to Over-The-counter Status, Food Drug and Cosmetic Law Journal $\underline{39}$ 201-210 (1984).

22. Rippere, J.L. FDA regulation of OTC oral health care drug products, Journal Public Health Dent. 42 329-332 (Feb. 19, 1992).

23. Taussig, A. A Study of the Outbreak of Phocomelia, Journal. of American Medical Association 180 1106-10 (1962).

24. Temin, P. Taking Your Medicine, Drug Regulation in the United States, Harvard University Press. Cambridge, MA (1980). 
25. Thrush, M. C. The U.S. Pharmacopoeia and the National Formulary, Journal.of American Medical Association 54 437-441 (Feb. 5, 1959).

26. 21 U.S.C. $353($ b)(1)(B)(1976).

27. 21 U.S.C. $353(\mathrm{~b})(1)(\mathrm{A})(1976)$.

28. 21 U.S.C. $353(b)(1)(B)(1976)$.

29. 21 U.S.C. $353(b)(1)(C)(1976)$

30. 21 U.S.C. $321(\mathrm{p})(1976)$

31. 21 U.S.C. $355(1976)$.

32. 21 U.S. C. $355(1)(d)(1976)$.

33. 21 U.S.C. $353(1)(a)(1)(1976)$.

34. 21 U.S.C. $355(1)(d)(1976)$.

35. 21 U.S.C. $321(1)(1976)$.

36. 21 U.S.C. $321(p)(1976)$.

37. Wion, A. Rx-to-OTC -The Process and Procedures, Drug Information Journal, 19 119-126 (1985). 
MANUSCRIPT I

IMPROVING SELF-MEDICATION WITH

Rx-TO-OTC SWITCH

MEDICINES 


\section{Improving Self-Medication With Rx-to-OTC \\ Switch Medicines}

\section{Introduction}

Looking back through history, we can observe a pattern in regulation that developed as a response to consumer demand for safe and effective drug products. The consumer has played an integral role in guiding the government towards higher standards of safety for medicines, healthy competition in the industry, and maintaining the freedom to employ self-health care.

A previous paper (manuscript I) outlined the legislative drug history and portrayed the sequence of events that caused regulators to exercise control over the drug market. An original goal of the regulations was to provide consumers with safe drugs. Over a lengthy period of time, the regulations were expanded to address the efficacy of drugs and the sufficiency of product labeling to promote safe and proper use. Although the Food and Drug Administration (FDA) always focused on preserving the consumer's freedom in choosing their own medicines for self-treatable conditions, the regulations gradually adopted, affected this choice by limiting the medicines available without the intervention of a physician. Over time, the Over-the-Counter (OTC) market was restructured to contain a broad selection of safe and effective medicines, restoring the choice of the consumer. 


\section{Background of the Rx-to-OTC Switch Trend}

The switching of prescription products to Over-the-Counter products is not a new phenomenon. It was stated as early as the 1938 FD \&C Act that drugs were to be made available to the public without a prescription if they presented no potential safety concerns. Thus, the process of switching drugs from prescription status to OTC status reinforces the goal of making more drugs available to the consumer. The OTC Drug Review panels and the FDA developed the Rx-to-OTC switch process which today, is the predominant procedure used for switching products. Presently, there are many drugs on the OTC market that contain active ingredients previously available by prescription only. With the switch policies now in place (NDA, Switch Regulation, petitions to FDA, manuscript I), manufacturers are cautiously proceeding in proposing their prescription drug products for the switch to OTC status.

When the OTC Drug Review commenced in the early 1970s, the process for restricting the sale of drugs slowly began to be restructured towards removing the restricted status on any safe and effective medicines. The FDA and several scientific panels reviewed numerous OTC medicines and organized them into therapeutic categories. Monographs, which referenced approved active and inactive ingredients, indications, dosage forms, and proposed labeling, were created for each therapeutic category. These monographs stated the guidelines for manufacturers to follow in their development of new drug products and/or reformulation of previously, or currently marketed products. 
One of the important achievements of the OTC Drug Review was the initiation of switching some prescription products with established safety histories, to OTC status. The OTC Review panels were given the authority, by the FDA, to switch ingredients from either status (prescription or nonprescription). Under the Review procedures, most of the switches recommended by the panels were OTC drugs to be switched to prescription status because of safety and labeling questions. The panels also recommended 27 prescription drug ingredients to be switched to OTC status. The FDA approved 18 of them under the Switch Regulation.(6) Since the OTC Review began, approximately 50 ingredients have been switched from prescription to nonprescription status by the FDA.(11) Listed below are a few of the early switch products resulting from the Review.

Table 1

Early RX-to-OTC Switch Products

$\begin{array}{llll}\begin{array}{l}\text { Ingredient } \\ \begin{array}{l}\text { brompheniramine } \\ \text { maleate }\end{array}\end{array} & \text { Product category } & \text { Date of approval } & \text { Tradename(s) } \\ \begin{array}{l}\text { antihistamine } \\ \text { succinate }\end{array} & \text { Sept. 9,1976 } & \begin{array}{l}\text { Dimetane } \\ \text { (A.H.Robins) }\end{array} \\ \begin{array}{l}\text { oxymetazoline } \\ \text { hydrochloride }\end{array} & \text { sleep-aid } & \text { Oct. 18,1978 } & \begin{array}{l}\text { Unisom } \\ \text { (Pfizer) }\end{array} \\ & \text { nasal decongestant } & \text { Sept. 9, 1976 } & \begin{array}{l}\text { Afrin(others) } \\ \text { (Schering) }\end{array}\end{array}$

Source-Nonprescription Drug Manufacturers Association, Washington,D.C.(Nov. 1991)

This progressive step began to restore the power of choice to the consumer and to allow him to play an active and responsible role in self-medication. Not only does the 
consumer now have an increasing ability to choose but also a continuously broadening selection of safe and effective drugs to choose from.

Self-care is of increasing interest to the public, and self-medication is an essential component in self-care. By placing more safe and effective OTC medicines on the market, the FDA provides consumers with the possibility of improving self-care. However, as more medicines become available without a prescription, it must be recognized that they may be accompanied by more risks to the consumer. The challenge now will be how the institutions-government, manufacturers, public organizations, advertisers and health care professionals, will meet their responsibilities to provide the necessary information to consumers for good decision making. This information must be conveyed in a clear, concise, yet sufficiently detailed manner directly to consumers.

\section{Rx-to-OTC Switch Products}

Within the last few years, the approval of Rx-to-OTC switches has resulted in significant expansion of the OTC market. This is only the beginning, since some of the future candidates considered will lead to more dramatic changes to the increasing and widening selection of over-the counter medicines. The two following tables present both recent $\mathrm{Rx}$-to-OTC switch approvals and future candidates being considered respectively.(12) 
Table 2

\begin{tabular}{|c|c|c|c|c|}
\hline \multicolumn{5}{|c|}{ Recent Rx-to-OTC Switch Ingredients } \\
\hline Ingredient & Product category & Date of approval & Method & Tradename \\
\hline $\begin{array}{l}\text { clotrimazole } \\
1 \%\end{array}$ & $\begin{array}{l}\text { antifungal } \\
\text { topical }\end{array}$ & Oct. 23,1989 & - NDA & $\begin{array}{l}\text { Lotrimin AF } \\
\text { Schering }\end{array}$ \\
\hline $\begin{array}{l}\text { clotrimazole } \\
1 \%\end{array}$ & $\begin{array}{l}\text { anticandidal } \\
\text { vaginal use }\end{array}$ & Nov. 30,1990 & $\mathrm{NDA}$ & $\begin{array}{l}\text { Gyne-Lotrimin } \\
\text { Schering }\end{array}$ \\
\hline $\begin{array}{l}\text { hydrocortisone } \\
0.5-1 \%\end{array}$ & antipruritic & Aug. 30, 1991 & FDA & $\begin{array}{l}\text { Cortaid-Max } \\
\text { Upjohn }\end{array}$ \\
\hline $\begin{array}{l}\text { miconazole } \\
\text { nitrate } 2 \%\end{array}$ & anticandidal & Mar. 13, 1991 & FDA & $\begin{array}{l}\text { Monistat } 7 \\
\text { Ortho }\end{array}$ \\
\hline $\begin{array}{l}\text { ibuprofen } \\
200 \mathrm{mg}\end{array}$ & analgesic & May 18, 1984 & $\mathrm{NDA}$ & $\begin{array}{l}\text { Advil } \\
\text { Whitehall }\end{array}$ \\
\hline $\begin{array}{l}\text { permethrin } \\
1 \%\end{array}$ & pediculicide & May 5, 1990 & $\mathrm{NDA}$ & $\begin{array}{l}\text { Nix } \\
\text { B. W. }\end{array}$ \\
\hline $\begin{array}{l}\text { ketoconazole } \\
1 \%\end{array}$ & $\begin{array}{l}\text { shampoo } \\
\text { dandruff }\end{array}$ & Feb. 16, 1994 & $\mathrm{NDA}$ & J. \& J. \\
\hline naproxen & $\begin{array}{l}\text { analgesic } \\
\text { anti-arthritic }\end{array}$ & Jan. 1994 & FDA & $\begin{array}{l}\text { Aleve } \\
\text { Syntex }\end{array}$ \\
\hline $\begin{array}{l}\text { loperamide } \\
\text { HCL }\end{array}$ & antidiarrheal & Mar. 3, 1988 & $\mathrm{NDA}$ & $\begin{array}{l}\text { Immodium- } \\
\mathrm{AD} \mathrm{J.} \mathrm{\&} \mathrm{J.}\end{array}$ \\
\hline $\begin{array}{l}\text { salicylic } \\
\text { acid }\end{array}$ & wart remover & Oct. 1991 & FDA & $\begin{array}{l}\text { Duofilm } \\
\text { Schering }\end{array}$ \\
\hline
\end{tabular}


Table 3

\begin{tabular}{lll}
\hline & Current Rx-to-OTC Switch candidates \\
\hline Ingredient & Product category & Status/Method \\
\hline acyclovir & cold sore & pending NDA \\
cimetidine & antacid & pending NDA \\
sucralfate & anti-ulcer & pending NDA \\
famotidine & anti-ulcer & pending NDA \\
methocarbamol & muscle relaxant & pending NDA \& petition \\
terfenadine & antihistamine & pending NDA \\
erythromycin & antibacerial & pending FDA \\
diflunisal & analgesic & pending FDA \\
nystatin & antifungal & not cited \\
\hline
\end{tabular}

Source: Nonprescription Drug Manufacturers Association, Washington, D.C. (Nov. 1991)

\section{Future Considerations for Rx-to-OTC Switch}

The list below are some prescription drug ingredients/categories and their indications that will be considered for switch in the near future.(12)

beta blockers - nervous tension/stage fright

beta- 2 agonists- wheezing bronchitis

cromolyn sodium-allergic/ exercise asthma

dicyclomine- irritable bowel syndrome 
promethazine-antiemetic

piroxicam- analgesic

methenamine-genito-urinary(e.g.U.T.Is).

\section{Criteria for Potential Switch Candidates}

\section{A. The FDA perspective}

Before a drug may be considered a candidate for Rx-to-OTC switch, it must meet the criteria established by the FDA for three general categories: safety, efficacy, and labeling. $(2,6,14)$

There are two chief concerns under the safety category and these include toxicity and collateral measures necessary for use. Within the toxicity section, there are four particular issues which must be addressed by the manufacturer. The first of these issues involves the assessment of the overall margin of safety of a drug and its potential to cause harmful effects, both of which must be supported by clinical pharmacological data. The manufacturer must assess the incidence and degree of adverse drug reactions that can occur or has been associated with the use of the drug. If the drug will be subject to use by special populations such as pregnant or nursing women, the elderly, or children, the safety for these populations must be given special attention. (14)

The second issue pertains to the benefit/risk assessment of the product when used according to the directions for use and warnings for unsafe use. (14) It is expected that every drug will have both benefits and risks, and in order to receive the benefits it is necessary to tolerate a certain degree of risk. The manufacturer must show that the 
benefits from a drug are greater than the risks involved, and must develop adequate labeling that can inform consumers about the ways to reduce the potential risks while benefiting from the use of the drug.(14)

The third issue addresses the potential safety problem that may arise from drug misuse/abuse. The manufacture must establish the margin of safety with respect to the possible misuse or abuse of the drug. $(2,14)$ It must demonstrate that the drug is still sufficiently safe even when misused either for a condition not included in the indications, or by a person with a serious disease condition such as diabetes or hypertension. The last issue questions whether medical follow up or laboratory testing is necessary with the use of the drug.(14) Such a requirement would make the drug unsuitable for the OTC market.

Four questions arise when addressing the issue of collateral measures that may be necessary to use with a switch drug. $(2,14)$

1.) Can the condition for which the drug is indicated for be self-diagnosed?

2.) Are the symptoms associated with the condition self-recognizable?

3.) Is the condition self-treatable?

4.) Is medical intervention (lab tests, exams) necessary as the patient continues to use the drug?

These questions must be considered and resolved by the manufacturer in their switch proposal. This area is of utmost importance to the FDA when considering the switch of a drug, and is the most challenging for the drug manufacturer to support scientificly. 
Efficacy refers to the requirement that the drug proposed for switch achieves the claimed effect, and it will do so to the same degree as the prescription form of it when used under the same conditions. $(21,22)$ The manufacturer must support the claimed indication with clinical data. If there is an anticipated change in dose or modification in the formulation for the drug to be switched, the manufacturer must document that these changes do not alter the safety and efficacy profiles for the drug. They should be prepared to support this with data.(14)

The labeling proposed by the manufacturer must include adequate directions for use, warnings against unsafe use, side effects, adverse drug reactions, duration of use limitations, and advisement on seeking medical attention. This information must be clearly readable and understandable for people with low comprehension.(21)

These criteria established by the FDA are intended to provide the manufacturer with sufficient guidelines in order to determine whether their prescription drug product will be marketable as an OTC product.

\section{B. The Industry perspective}

The industry initially approaches the switch of a drug with a perspective different from the FDA. Before the drug company begins to assess is product for the criteria set by the FDA, it first evaluates the candidate from a marketing point of view. Consumer demand and need for the product must be considered before a business commitment will be made.(7) Developing new OTC drug products is challenging to the manufacturer primarily because the product's success is dependent on consumer need and demand. 
Sufficient marketing analysis for consumer interest and intent of purchase must be completed before proceeding with the actual development. (7) With an Rx-to-OTC switch product, the failure rate in the OTC market is minimized because the product already has an established history with consumers, physicians, and pharmacists.(7) Therefore, the support base from health care professionals and consumer interest can only be increased. The Rx-to-OTC switch process allows drug companies to target a wider audience with newly available products and to build a stronger rapport with the health care profession.

From a business perspective, a drug company will consider the product's ability to generate sales and profits. (14) Ideally, in marketing a switch product, a manufacturer hopes to rejuvenate the life cycle of the prescription form of the product. Usually, after a long marketing period as a prescription product, the interest and sales for it decline. This may be attributed to the development of new drugs or aggressive promotion by other manufacturers. After switching the product to OTC status, the drug company essentially creates a new product and the life cycle of the product begins again.(14) The last incentive for the manufacturer to switch a product is to extend a product's patent protection under The Waxman-Hatch Act, provided the FDA requires new clinical trial data. (14) Since generic competition is strong in today's nonprescription and prescription drug markets, drug companies which hold NDAs to prescription drugs that are approaching patent expiration must take advantage of this opportunity to preserve exclusivity for three additional years.(14) The revision of the NDA or supplement to the NDA will encompass a change in specifications for use (as an OTC product) and include 
new clinical data. This will guarantee the manufacturer protection from abbreviated New Drug Application competition.

At this point, the manufactuer will proceed with tarduous task of collecting the required scientific evidence for the switch proposal, whether it is in the form of an NDA, a supplemental NDA, or a petition .

\section{Economic benefits evolving from the Rx-to-OTC Switch Trend}

The tables of switched drugs and those considered for switch, demonstrate the major changes occurring in the OTC market. As a result, consumers experience improved yet affordable opportunities for self-care. Rx-to-OTC switch drugs have already made a dramatic impact on consumer and national health care costs. Since cost is a major factor in the nation's current health care predicament, the cost savings associated with self-medication has been a significant factor in promoting this issue.

The tradition of visiting a physician for minor ailments or even more serious conditions has become less common for many consumers. John Naisbitt states in his book Megatrends: Ten New Directions Transforming Our Lives, “ 75 percent of the people can successfully deal with medical problems without ever walking inte a clinic or doctor's office." Studies have shown that the number of doctor visits have been falling steadily over the past twenty years. In 1989, 1.65 million fewer MD office visits for the treatment of cold symptoms were made as compared to those in 1974.(16,17) These figures may be accounted for by the following: the consumer's overall economic situation, whether or not they have insurance to pay for the doctor visit and/or 
prescription, or their desire to self-treat with OTC medicines. Consumers who do not want to take time from work because of the loss of pay or the risk of losing a job, will often opt for self-treatment with OTCs. A final contributory factor involves consumers requesting doctors to prescribe medication over the telephone for recurring conditions that are recognizable to the patient.

The average doctor visit has been determined to cost $\$ 40.00 .(1,16,17)$ Additional to this expense is the travel to the office, and the cost of a prescription, if not covered by insurance. The average prescription price is now approximately twenty dollars.(16) The time spent to complete the doctor visit is costly as well. The consumer has to take time out of work for travel and to spend time waiting to be seen by the doctor. Often, this time is viewed by the patients as excessive because physicians are trying to maximize their income by seeing more patients. On the other hand, the cost of a typical OTC product is $\$ 4.00$, and it requires only a quick trip to the nearest store, whether it be a convenience store, supermarket, or drugstore. (16) Kline Research revealed from their research that OTCs saved the nation $\$ 10.5$ billion in 1987 . This figure includes prescription costs, doctor visits, lost time from work, travel, and insurance costs.(3)

It is also interesting to see results from studies on switched products-with regard to the economic savings. Economist Peter Temin has determined, from an analysis of the cost benefits of Rx-to-OTC switch for cough and cold medicines, that consumers saved $\$ 770$ million in 1989 alone.(16) In another example, $0.5 \%$ hydrocortisone cream, it was shown that the savings for the American consumer was more than $\$ 1$ billion for the first three years it was available over-the-counter.(16) The most recent Rx-to-OTC switches 
include Gyne-Lotrimin (clotrimazole) from Schering-Plough and Monistat 7

(miconazole) from Johnson \& Johnson. These are two examples of drugs that have been placed in a new class of OTC drugs for gynecological yeast infections. Sales for this category is expected to reach close to $\$ 150$ million by the end of 1994 . (2,5) Sales for new switches combined are expected to fall into the range of $\$ 550$ million and $\$ 600$ million by the year 1996.(2)

As can be seen from the chart provided (Figure 1), the least amount of money spent in any health related category is the over-the-counter medicines and sundries. According to the Health Care Financing Administration, although six out of ten medicines bought by consumers are nonprescriptions, spending for OTC medicines only accounts for

2 percent of the nation's total health care spending. (10) 
Figure 1

\section{National Health Expenditures}

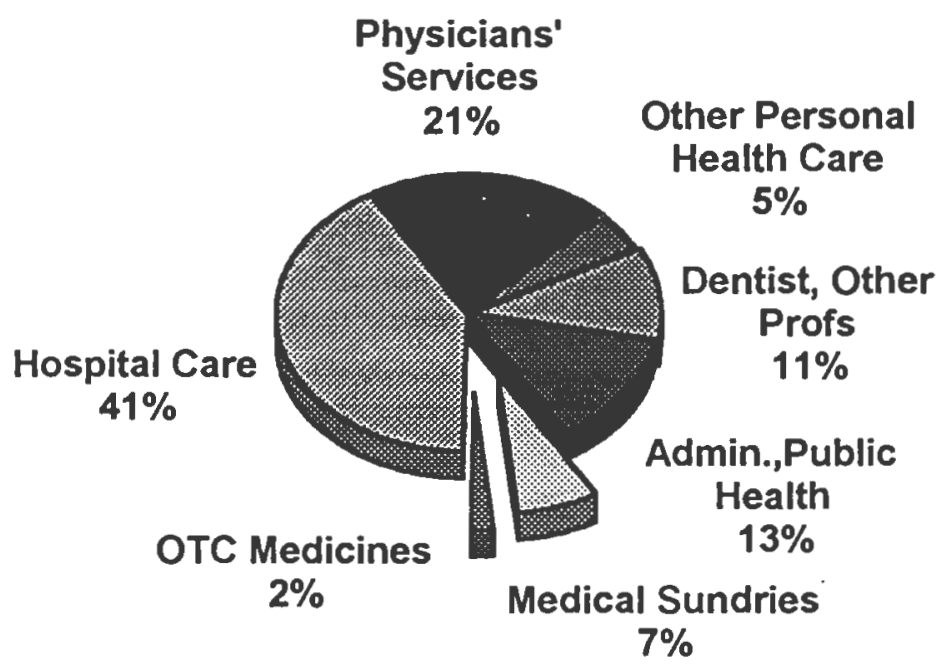

Source: U.S. Health and Human Services Department, Health Care Financing Admin., Office of the Actuary

With the continuing rise of health care costs in the U.S., the government must derive a solution that encourages advancement in medical science but promises a reduction in costs on both individual and national levels. The switching of prescription medicines to OTC status creates the opportunity to improve self-health care economically for the consumers while eliminating costs in other health care categories. 


\section{Physician perspective of Rx-to-OTC Switch Trend}

The physician population appears to be divided in its views of switching prescription medicines to OTC status. On the positive side of this issue, there are many physicians who believe that consumers do want to become their own primary caretakers and that they can be responsible about it. $(9,23)$ Therefore, switching prescription medicines to OTC status will provide a wider selection of effective medicines to work with. These physicians realize that patients who use OTCs for minor ailments rather than checking with them spontaneously, generate extra time the physicians can use for patients who are suffering more serious conditions. The physician, aided by the limitations of self-medication, can also save time and expense for the patient with unnecessary diagnostic testing or inappropriate prescription medications if the use of appropriate OTCs has not provided significant improvement. $(9,23)$

Depending on their practice or field of specialty, physicians commonly prescribe OTC medicines for patients in several different circumstances. National Center for health statistics revealed from its survey that one of every eight drugs prescribed or recommended by physicians in 1985 was an OTC drug. $(1,3)$ These may include: recommending OTCs for patients who call for advice until a follow up office visit can occur, recommending OTCs to relieve symptoms from minor ailments without necessary follow up, using OTCs to treat several gastrointestinal problems,(9) and employing OTCs for the prevention of serious, recurring or worsening conditions (aspirin for 
prevention of myocardial infarctions, bulk fiber for constipation/regulation, insulin for Diabetes). In these circumstances, OTCs are essential to provide immediate or long term benefits.

The other perspective held by some physicians is that patients are not informed enough to be held responsible for their own self-care, and this appears to be a consistent opinion among many physicians. Physicians feel that switching prescription medicines to OTC status is detrimental to their patients' health, and a potential hindrance to their practice. (23) It is difficult to deduce whether the patients have demonstrated this to them through habits, or that physicians believe a sophisticated level of knowledge is required to self-medicate effectively which is beyond the level of most lay people. A further explanation is provided in Dr.Donald Vickery's "office door orientation." This refers to the population of physicians who are concerned only with the patients that walk through their doors, not with the community as a whole. It is not their interest to know whether the community is benefiting by the substantial advantages in cost or treatments offered by OTCs. To further delineate this point, Dr. Vickery feels physicians are concerned with the symptoms or problems presented by the patients in the office and those which bring them back to the office, not what the patients do outside the office with self-treatment for other minor ailments.(23)

Physicians are vital components in the health care delivery system and can provide substantial information on patient habits with regard to medications and general self-care. Physicians must realize that they are in a pivotal position to promote self-care, and they have a responsibility to educate patients on recognizing conditions, self- 
medicating with OTCs, and diagnostic testing. However, some physicians are unwilling to relinquish the power that the profession has acquired over the years. Physicians have assumed authoritative trusting roles with patients and other health care professionals, and now some of them feel threatened by the behavior of the whole health care delivery system which is responding to patient demands for direct participation in their health care issues. The authority in the decision making process is undergoing redistribution to include other health care professionals, regulators, third party payors, and it empowers patients themselves.

\section{Pharmacist perspective of the Rx-to-OTC Switch trend}

Pharmacists are a traditional and important source of OTC medicines for consumers. Although, pharmacists perceive OTC drugs as safe and effective therapeutic agents, they recognize that he limitations of these and all other drugs are dependent on proper and appropriate use. Pharmacists have a great deal of experience in observing patient habits with both OTC and prescription medications. They continue to fulfill their educative responsibilities through counseling and recommending appropriate products for patients. Pharmacists also play a critical role in monitoring the need for patients to be referred to their physicians. As the professional who has the most frequent regular contact with patients, the pharmacist's interaction with the patient can be responsible for the success of a therapeutic plan. Pharmacists enjoy this important role and are proud that they are regarded as the most highly respected and trusted professional.(4) 
With the advent of the Rx-to-OTC switch trend, pharmacists are finding their knowledge and accessibilty a necessity for patients to rely on. Patients frequently consult with pharmacists on the appropriate use of switch products more so than with the traditional OTC products. (15) A survey conducted by a Medical Economics Research Group, in 1989, found that three out of four pharmacists are encountering more consumer discussions about OTC drugs. $(5,15)$ For this reason, the pharmacy profession continues to express some skepticism on the trend of switching prescription medicine to OTC status. Like physicians, pharmacists are hesitant to extend to the patient more responsibilty for their self-care by making available more medicines for more self-treatable conditions.

In 1974, soon after the OTC Review began, (early switches by the Review), many pharmacists and pharmacy organizations proposed to the FDA, the development of a third class, or transitional class, of drugs, to place newly switched drugs. This class of medicines could only be sold by pharmacists. It would eliminate the need for a prescription for the medicines, but would allow the pharmacist to maintain the control over who had access to them. The pharmacist would use his professional judgement, which would include knowledge of the patient's history and a description of -the patient's symptoms, in determining whether the medicine was appropriate. Having a third class of drugs could also facilitate the necessary monitoring of switched drugs for a predetermined period of time ('transitional class').

The response to this proposal by regulators and consumers is negative. Consumer groups feel that this is an attempt by pharmacists to maintain control in sales 
and profits. $(6,13,15)$ The Department of Justice objected to a third class of drugs stating that it would restrain competition, inconvenience the consumer, depart from U.S. economic policy, and cause unnecessary price increases for the consumer. The Federal Trade Commission has also expressed a unfavorable opinion because a it would violate merchants' rights to partake in the sales of these products which do not require a prescription. (12) The FDA shows no interest in the development of a third class because the proposal has yet to be supported with scientific evidence to prove that pharmacist intervention is necessary for the safe and effective use of these drugs. $(6,16)$ More importantly, the FDA feels that the effort and progress made by the regulators and manufacturers to supply the consumers with safe and effective medicines nullifies the need of additional intervention. This issue has caused much debate and will continue to as it receives further objection. Pharmacists will not get the right to establish a third category of drugs until they show clinical evidence to support the need for restriction.

Although the skepticism exists within the pharmacy profession, pharmacists are out in the front lines recommending and selling the switched products. Many of the switch products have generated enormous of sales for their stores. More importantly, opportunities for an increase in consumer contact, have been created and this reinforces the educative role they serve in the self-medication process.

\section{Summary}

The process of switching prescription medicines to OTC status has generated much controversy within the health care industry. Until recently, the general attitude among health care providers was that consumers are not capable of administering self- 
care. However, with the changing objectives of the health care system, the concept of the patient with problems and the physician with the solution ${ }^{1}$ no longer fits into these objectives. Thus, many physicians and pharmacists, regulators, and drug manufacturers have all joined forces to combine their efforts and ideas to contribute towards the success of switch products. The addition of many new drugs to the arena of OTCs, and the consideration of adding many more in the future, has caused an important issue to surface. This issue involves the need for tools and/or methods of relaying necessary information to consumers to advise them on the appropriate use of these new products avilable to them. These tools may be labeling, advertising, and educational programs.

Studies have shown that the consumer relies upon labeling and advertising as two sources of drug information. These two sources have received much attention from regulators because of their important communicative and educative functions, and are especially essential for current and future Rx-to-OTC switch products. Since the labeling for these products was initially designed for pharmacists and physicians, the manufacturer, with the aid of the FDA, has an important task of drafting new labeling for their use as OTC medicines. As these medicines enter the OTC market they bring with them a proven alternative which may prompt consumers to experiment while disregarding important information for their proper use.

The Nonprescription Manufacturers Association (NDMA; formerly The Proprietary Association) is an organization which deserves considerable recognition for its exceptional efforts, in conjuction with the FDA, in developing guidelines for manufacturing labeling. Additionally, it has been devoted to creating and providing 
consumers with educational leaflets, and instructional pamphlets that advise them on reading OTC package labels. 


\section{References}

1. America. National Disease and Therapeutic Index:Diagnosis Estimates (1990).

2. Botstein. P. Criteria for switching new molecular entities from prescrition to over-the-counter, Drug Information Journal 24 29-31 (1990).

3. Business \& Health Report, Special Report, (Feb 1992)

4. Conlan, M. F. The RPh and his image, 1991 Gallup poll, Drug Topics Supplement 21s (1991).

5. Gannon, K. Switched drugs lend vitality to surging OTC market; prescription to OTC switches, Drug Topics 135 32-34 (May 20,1991).

6. Gilbertson, W. The OTC Drug Review- Switch Without Regulation or Application, Drug Information Journal 19 101-109 (1985).

7. Haverkost, L. How Industry Assesses and Picks Suitable Candidates for Switch, Drug Information Journal 19 133-138 (1985).

8. Juergens, J. P. The FDA and Community Pharmacy:Today and Tomorrow, Drug Topics 88-94 (Aug. 1992)

9. Morrissey, J.F. Switch to OTC: A Medical Viewpoint, NDMA Symposium. New Sources in Self-Medication, Washington, D.C. (Nov. 1,1982).

10. NDMA. Facts and Figures, Washington, D.C.(1992).

11. NDMA Issues and Perspectives, Washington, D.C. (1992).

12. NDMA Symposium. Washington, D.C. (September 15, 1992). 
13. Nonprescription Drug Manufacturers Association, 112th Annual Meeting. NDMA focus in1992-93: Cost Benefits \& Consumer Power, Naples, FL (March $5,1993)$.

14. Rheinstein, P. Criteria used by the FDA to determine what classes of drugs are appropriate switch candidates, Drug Information Journal 19 139-142 (1985).

15. Segal, M. Rx to OTC; the switch is on, FDA Consumer 25(2) 8-14 (March 1991).

16. Temin, P. Cost and Benefits in Switching Drugs from Rx-to-OTC, NDMA Symposium. New Resources in Self-medication, Washington, D.C. (Nov.1, 1982).

17. Temin, P. Realized Benefits from Switching Drugs, Journal of Law \& Economic , $\underline{35}(2)$ 351-368 (1992).

18. 21 U.S.C. 330.10 (a)(4)(iii)(1983).

19. 21 U.S.C. $330.10(a)(4)(i),(v i)(1983)$

20. 21 U.S.C. $330.10(a)(4)(i)(1983)$

21. 21 U.S.C. $330.10(a)(4) v)(1983)$.

22. 21 U.S.C. 330.10 (a)(4)(ii)(1983).

23 Vickery, D. M. A Medical Perspective, Drug Information Journal 19 $155-158$ (1985). 


\section{MANUSCRIPT III}

MMPLICATIONS OF LABELING AND ADVERTISING ON THE

SAFE AND PROPER USE OF RX-TO-OTC SWITCH

MEDICINES 


\section{The Implications of Labeling and Advertising on the Safe and Proper Use of Rx-to-OTC Switch Medicines}

\section{Introduction}

Labeling and advertising of Over-the-Counter medicines (OTC) are two reliable sources of instructional information for consumers. They serve as invaluable methods for the OTC industry to communicate important information regarding the safe and proper use of their products, and to promote their products in a competitive market. Labeling especially, is in part responsible for the growing use of OTC medicines in selfcare. Both methods are useful in assisting consumers in the decision making-process for the selection and appropriate use of a product. Several studies have shown that consumers depend on both labeling and advertising to familiarize and educate themselves about OTC medicines. The Princeton Survey Research group on their Council on Family Health report concluded that 91 percent of individuals who use over-the-counter medicines, read the labels; within this group, 98 percent of them read OTC labels when they buy the product the first time, and 92 percent of them read the label when they use a product for the first time. (1)

With the advent of the Rx-to-OTC switch trend, consumers are now provided with an extensive market of stronger and more effective medicines. Until recently, the OTC medicines available on the market have been useful to mitigate or alleviate symptoms. The Rx-to-OTC switch process has added potent medicines which cure and potentially even prevent minor conditions. The labeling and advertising of these 
products is essential to ensure the appropriate and safe use. With the assistance of the FDA, professional associations, and consumer groups, manufacturers have the task of drafting new labeling for these products. They are responsible for correlating the information in the corresponding advertisement to the package labeling in order to comply with guidelines set by the regulatory agencies.

The difference between labeling and advertising lies in the function of each. Labeling provides consumers with information they need to use an OTC medicine safely and effectively. Advertising alerts consumers to the self-treatable nature of specific symptoms and moreover, it introduces the products to use to treat the problem. It is expected of advertising to promote and support the designated use of a product based upon the label claims. $(3,5)$ Both sources should communicate identical information regarding approved uses and any essential warnings in order to comply with regulations and ensure proper use of OTC products. Manufacturers must be cautious in how symptoms which relate to a self-treatable condition are presented in an advertisement because the nature of the advertising can make the labeling of the same product inadequate.(7) This can happen through the message received by consumers to be misconstrued, resulting in the incorrect use of a product. Therefore, the label information will not provide sufficient directions and/or warnings for the misinterpreted purpose.

This paper will address the labeling and advertising issues for Over-the Counter medicines by presenting a review of the guidelines devised by regulatory agencies and implemented through legislation. Some new developments in the labeling of certain 
OTC products will also be presented. Additionally, a discussion of how these educative tools are necessary for promoting the safe and proper use of recently switched drugs and future switch candidates.

\section{Labeling}

\section{A. Regulatory Review}

The Federal Food, Drug, and Cosmetic Act of 1938 mandated manufacturers to demonstrate the safety of a drug when used according to the conditions described in the labeling. The term "labeling" refers to the written or graphic material which is placed on the container or any of its wrappers which accompany the drug product. The label information was to include the contents of the product and adequate directions for use in language understandable by persons of ordinary intelligence.(14) The 1938 Act also required manufacturers to place an inclusive warning on a drug product if it contained a narcotic or hypnotic agent. $(11,13)$ If a manufacturer determined that its drug product could not be adequately labeled for use by consumers, it was exempted from the labeling requirement, but placed under restricted access and available through pharmacists and physicians only. The physician would prescribe the drug and the pharmacist would be responsible for labeling the drug with directions understandable to the consumer. These actions served as the basis for the future developments in the labeling area.

\section{B. Labeling guidelines}

The goal of labeling is to provide sufficient and comprehensible information consumers need to use OTC drug products safely, correctly, and without professional 
supervision. The challenge encountered by manufacturers is to provide this information in a readable and clearly understandable fashion. The label is supposed to include the following basic information: $(7,8)$

1) The name and identity of the product

2) What the product can be used for

3) Contents of the package; dosage form and how many

4) Active ingredients

5) Inactive ingredients

6) Directions for use, time limits for use

7) Side effects, precautions

8) Contraindications, warnings

9) When to seek medical attention

10) Manufacturer name and address

11) Expiration date and batch code

12) Label "flags"

1) The name of the product- The largest print on the package label will enable the reader to immediately identify the trade name, generic or chemical names, and classification of ingredients, e.g. Product Allergy- antihistamine: chlorpheniramine.

2) Claims or indications- The manufacturer must reference only the FDA approved claims or indications for the drug ingredients. It must be in a clear and concise 
presentation. Some manufacturers associate the ingredient with the assigned indication, e.g. dextromethorphan (cough).

3) Contents of package- It should be displayed clearly what the package contains including the net quantity, the dosage form, and the use of a tamper resistant seal. 4) Active ingredients- These ingredients are essential to inform health care professionals and consumers so they can determine proper use of a product, potential drug interactions, or allergies to the product.

5) Inactive ingredients- These ingredients (from United States Pharmacopoeia or National Formulary) must be included to aid consumers in identifying ingredients with which they may have an allergy to, e.g. dyes, starch, flavors, or sugar coatings. 6)Directions for use- The manufacturer must clearly instruct the patient in the dose, specifically, how much (1 tablet or teaspoon) and the frequency of administration, how often (every 4 hours, no more than 4 doses per day). This information may be written or illustrated with symbols. Dosing accessories may be included to help consumers accurately measure liquid quantities.

7) Side effects and precautions- Any potential side effect, such as drowsiness, nausea, or diarrhea, which may debilitate or endanger the user to any degree, must be listed. Precautionary statements may include: time limit for product use, "keep out of reach of children", advisory information in case of accidental overdose, or recommendations for the proper use of the product.

8) Contraindications- This section of labeling references specific drugs or conditions in which the drug product should not be used. 
9) When to seek medical attention- Statements which advise the consumer to consult with a physician after a certain period of time or product use, or if condition worsens, are usually included in the warning or direction sections of the label.

10) Manufacturer name and address- This information is useful for consumers or retailers to inquire or relate to the manufacturers any feedback, problems, questions, comments, or procedures for returning the product. It is common practice for the manufacturers to provide a toll free phone number for quick access.

11) Expiration and batch code- The expiration date should be in print which remains distinguishable over time for the determination of when the product should no longer be used. The batch code is necessary for recall purposes.

13) Label "flags" -Manufacturers should flag the labels of all products when "significant changes" are made in the product or the label information. The flags should be placed in a obvious place on the front of the package or container with conspicuous letter size. These changes may include: change or addition in claim (indication), modification of dosage level, change in ingredients, new warnings, or any other new information added to the label. These are some examples which are used.

"See New Label"

"See label for new ingredients"

"New label information"

All of this information, according to the law, must be "prominently placed" with "such conspicuousness", and in terms to render it to be easily read and understood when purchased and used under customary conditions. $(7,8)$ 
The Fair Packaging and Labeling Act was enacted in 1966 to provide clear and accurate information on the package label with regard to the quantity of the product contained in the package. This allows consumers to make simple value comparisons between products. (7) As a result of this Act, guidelines for uniform package sizes and quantities for four classification of OTC products, were developed by the Nonprescription Drug Manufacturers Association, at the request of the Department of Commerce. These OTC product categories included: liquid mouthwashes, solid dosage form headache remedies, solid dosage form cold remedies, and liquid cold preparations.(7)

The 1992 amendment to the Fair Packaging and Labeling Act mandated the content quantity labeling for any consumer commodity to be in English units and the metric system. This took effect as of February 14,1994. Before manufacturers are subject to this requirement, the FDA must implement regulations.(7)

\section{Recent developments in OTC labeling}

During the initial switch process, the labeling guidelines were rigid.

Manufacturers would propose labeling within their applications for switch, but the labeling which was approved and eventually placed on their OTC product was that developed by the FDA and NDMA. This practice has been gradually changing since the FDA has adopted more flexible policies which allow the manufacturer to apply their own labeling, once it is approved by the FDA. There are guidelines established for the manufacturer to follow but this is on a voluntary basis. Most of the manufacturers 
willingly comply to these guidelines, thus creating a fairly uniform labeling system in the OTC market.

In 1986 , the FDA imposed a flexibility policy on the label indication section of OTCs marketed under an OTC Drug Monograph. This rule allows two additional alternatives for identifying the use of the product other than "Indications." Other acceptable terminology includes "FDA Approved Uses", or "Product benefits." Recently, the FDA has proposed to extend the application of the flexibility rule to include OTCs marketed under an approved New Drug Application and Abbreviated New Drug Application.(3)

More evidence is surfacing pointing to the need to provide additional information on OTC labels which will warrant safe use, one area being potential drug interactions which may occur. In August 1993, the FDA announced that some new warning statements will be required for antacids, laxatives, anti-diarrheals, anti-emetics, and sleep aids.(9) These statements will inform the consumer of some newly acknowledged adverse effects, and will list certain drugs which should not be taken in conjunction with the OTC product.

For antacids which contain aluminum, the current warning advises the consumer not to use the antacid while taking tetracycline, an antibiotic prescription drug. Scientific evidence has shown that calcium-magnesium containing antacids can also interact with prescription drugs as well. Therefore, the new warning statement should read "Antacids may interact with certain prescription drugs. If you are currently taking a prescription 
drug, do not take this product without checking with your physician or other health professional."(9)

In the case of laxative and anti-diarrheal products which contain water-soluble gums as active ingredients, a new warning will appear as follows. "Taking this product without adequate fluid may cause it to swell and block your throat or esophagus and may cause choking. Do not take this product if you experience chest pain, vomiting, or difficulty in swallowing or breathing after taking this product, seek immediate medical attention."(9) It has been reported to the FDA that between 1970 and 1992, approximately 199 cases of esophageal obstruction and eight cases of asphyxia have been associated with concurrent use of laxative and weight control (banned from market in 1992) products containing water soluble gums.(9)

Current labeling for sleep aids and anti-emetics, which contain antihistamines as active ingredients, warn consumers with asthma not to use the product without supervision of physician. The new proposed warning " Do not take this product, unless directed by a doctor, if you have breathing problems such as emphysema or chronic bronchitis, or if you have glaucoma or difficulty in urination due to the enlargement of the prostate gland" will replace the current warning.(9) The FDA advisory committee submits that the warning referring to adverse interactions with asthma therapy is not scientifically supported, and therefore it has been eliminated from the warning.(9) This change has affected the labeling of many OTC products which contain antihistamines.

All information on a label, no matter how important it may be, is relatively useless if it cannot be easily read. Consumer groups and state governments have been 
urging the drug industry to improve the clarity and readability of label information. A special task force from the Nonprescription Drug Manufacturers Association (NDMA) devised voluntary specifications for drug manufacturers to follow in order to enhance the readability of their package labels. $(7,8)$

Readability refers to the ease, speed, and accuracy with which information can be read.(7) It is based upon factors such as individual comprehension, and technical or medical factors which the drug industry may or may not be able to control.(7)

Comprehension is defined as the capacity for understanding fully. It is facilitated by the selection of simple words and phrases which can be understood by people of average intelligence. Comprehension by the patient depends on how information is presented. Problems in labeling lie in part with the FDA since it is responsible for developing the language used and/or approving the language proposed by the manufacturer.

The technical or medical factors mentioned involve consumer variables which the industry or FDA cannot control such as the lighting or the atmosphere used when consumers read labels, age or disease- related visual impairment, or the use, or lack of use, of appropriate visual accessories (glasses, contact lenses). The technical factors which can be controlled pertain to the design of the package. These factors embody the layout of the package with respect to the use of small paragraphs or sections, the typeface which may be altered with using highlights or boldness for distinguishing sections or important phrases, the color of the label and that of the print on the label, and finally, attention getters such as bullets, symbols, or boxing. (7)Some examples of these 
variations (except color) are displayed. These are actual labels which exist on products in the OTC market today. Also for comparison, are photocopies of some proprietary packages which no longer exist in the market.

It can be seen from the guidelines discussed, the new developments in labeling, and the examples of labels shown that significant advancement has been made in the base of OTC drug information currently available for OTC package labeling. Additionally, the label format has been revised to improve readability of this essential information. 
Figure 1

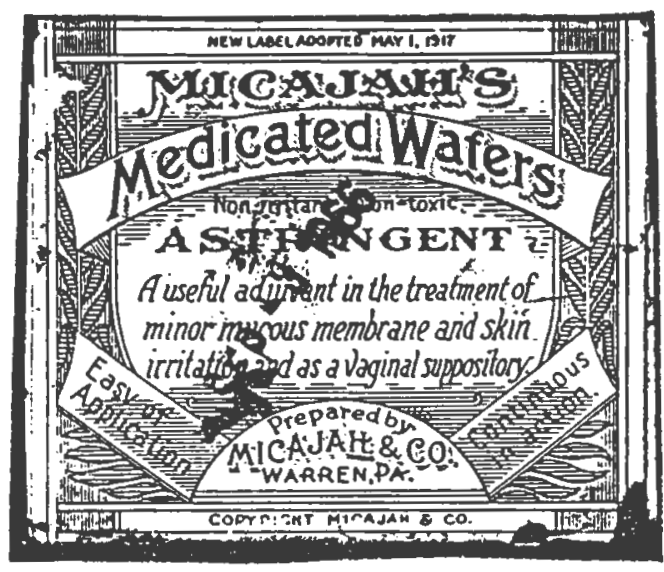

MICAJAH'S Medicated Wafers 
Figure 2

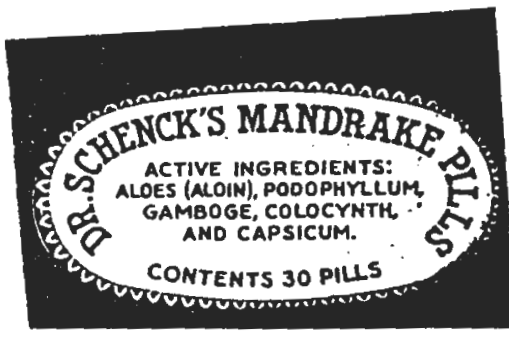

Dr. SCHENCK'S Mandrake Pills 
Figure 3

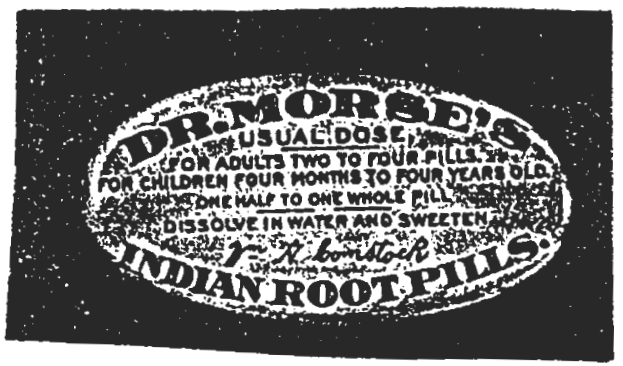

DR. MORSE'S Indian Root Pills 
Figure 4

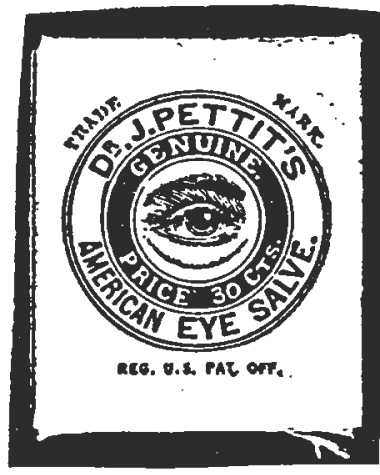

DR. J. PETTIT'S American Eye Salve 
Figure 5

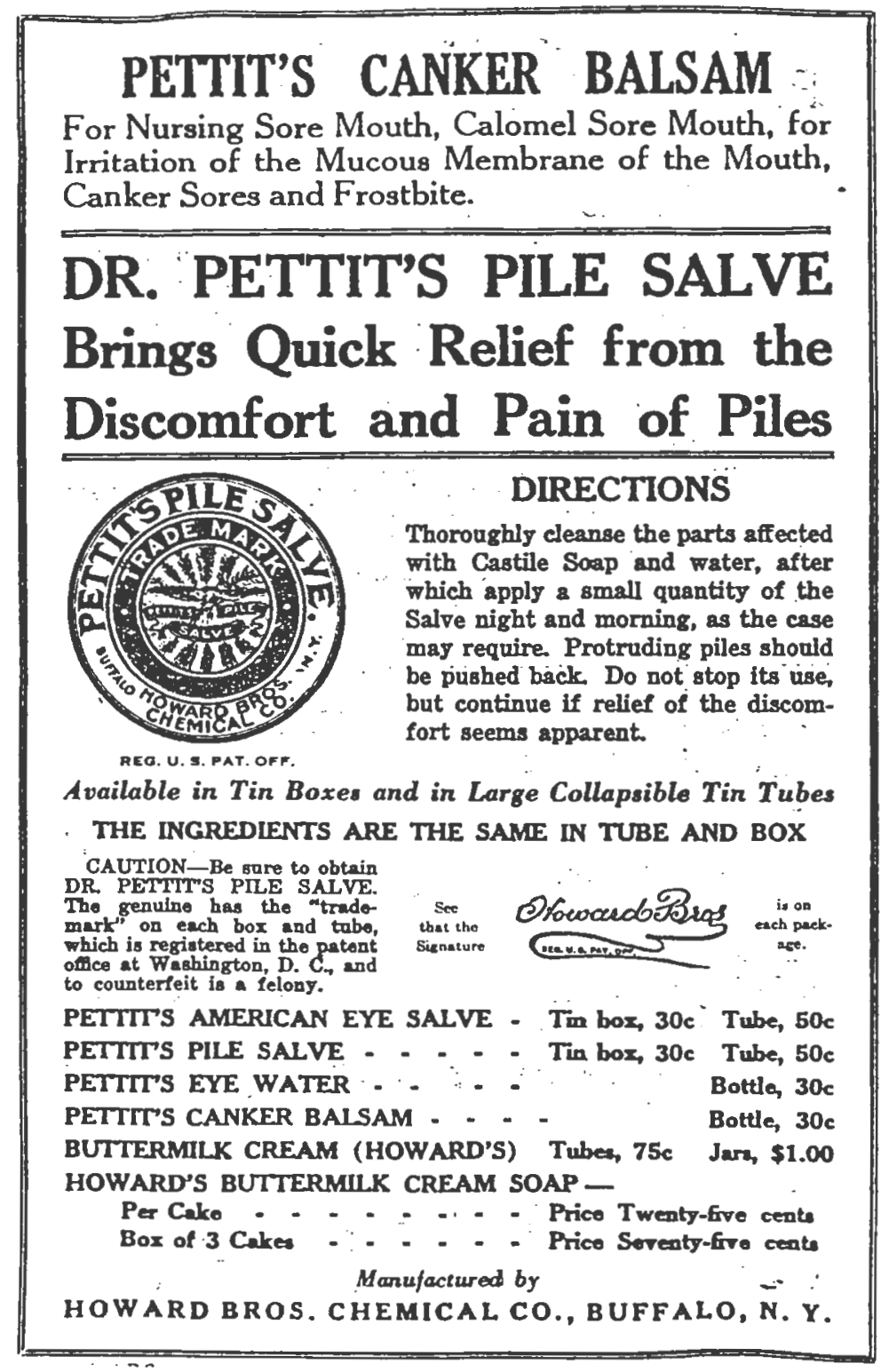

Package insert from DR. PETTIT'S PILE SALVE 
Figure 6

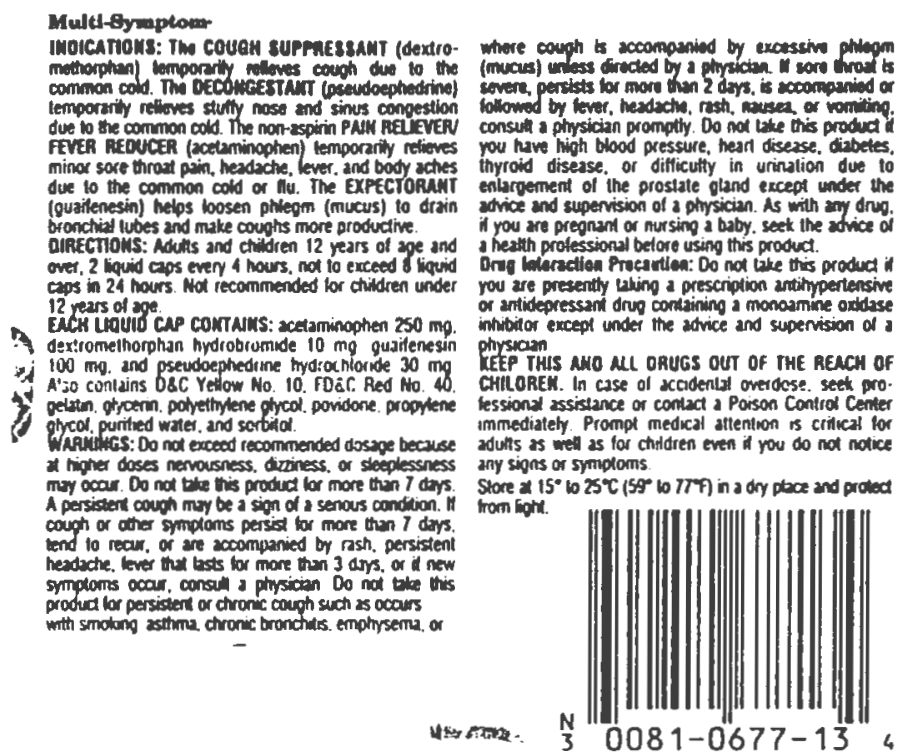

Current cold product, name not disclosed, shows one format of "section" labeling. 
Figure 7

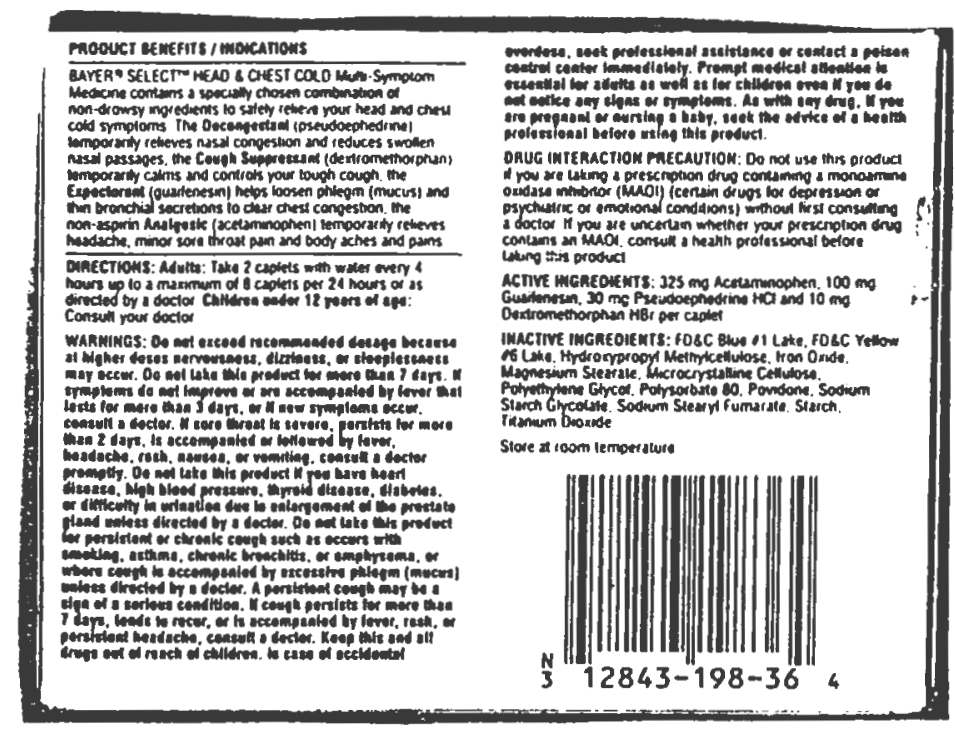

Current cold product, name not disclosed, shows another format utilized. 
For switch medicines, more information may be needed to assist the consumer not only in recognizing symptoms treatable by the OTC drug product, but also identifying symptoms which are not associated with the particular treatment at hand. With these medicines in particular, referring the consumer to seek professional advice is imperative. This warning should appear in more than one section of the label.

It is common for manufacturers to include a statement on package labels of switch medicines informing consumers that the active ingredient was previously available only as prescription. Manufacturers have been creative in stating this in several ways:

Original Prescription Strength

Now Available Without Prescription

Now... In Non-Prescription Strength

Maximum Strength available without prescription

Strongest Formula Available without prescription

Formerly Prescription Strength

Prescription Strength without a prescription

Full Prescription Strength

No Prescription Needed

Referencing prescription status on the label alters consumers' perception of the product as one being very powerful, and therefore more effective. Some consumers may hesitate to use the product and seek professional advice, which is always advisable. For others, the fact that the product is now available to them without a prescription is 
attractive, and therefore the product has the potential of being overused or misused.

For these reasons, labeling is even more important on switch products to provide information that reassures consumers about the products' safety and effectiveness, and emphasizes the importance of reading the label thoroughly. This is an issue which must be considered by the FDA as more switch products enter the OTC market.

\section{Advertising}

\section{A. The Federal Trade Commission}

In March of 1914, five individuals were appointed to a commission with the objective of investigating corporations for violations of antitrust laws and the use of unfair methods of competition in commerce within the United States or between the U.S. and foreign countries. $(2,6)$ The federal act which empowered the commission to perform these duties was the Clayton Act. $(2,6)$ The second legislation that addressed the commission's authority and responsibilities was the Federal Trade Commission Bill, proposed by Congressman Clayton, which was passed on Sept. 26, 1914 and renamed the Federal Trade Commission Act. This Act defined the commission's powers and new identity as Federal Trade Commission (FTC). $(2,6)$ Additional members were transferred to the FTC from the Bureau of Corporations. $(2,6)$ The scope and extent of the FTC's responsibilities has changed over time. Coinciding with the implementation of new regulations of drugs in 1938, the FTC began its involvement with OTC drug advertising. Today, the FTC is charged with extensive and diverse activities, maintaining 
the objective to safeguard the public and businesses from unfair or deceptive practices in competition.

\section{B. Review of Advertising Regulations}

As defined in the Federal Trade Commission Act, "advertisement" shall mean any written or verbal statement, illustration or depiction, other than a label or in the labeling, which is designed to promote the sale of a product, whether the same appears in a television, radio broadcast, newspaper, magazine, leaflet, circular, book insert, catalog, sales promotional material, billboard, or in any display intended for use at the point of purchase of the product. $(11,12,13)$

The first legislation imposed in the United States towards the regulation of advertising was the "Printers' Ink" statute. This statute was drafted in 1911 by the Printers' Ink Publishing Co., Inc., and adopted by most states for the purpose of regulating dishonest and/or misleading advertising. The statute imposed criminal penalties for violations, and prohibited untrue, deceptive, or misleading advertising of products or services.(2)

Some examples of earlier and current advertisements are included for comparison purposes. It can be seen from the examples why regulators were concerned about the messages being sent to the consumers regarding product claims.

- antacids- alleviate complaints resulting from nervous or emotional sickness, consumption of alcoholic beverages, morning sickness

- sleep aids-promote natural or normal sleep 
e.g."Compoz"-Family Circle offered in bold type- "we will give you 50 cents to try compoz today. The ad read

"Compoz is a simple medication formulated for those occasional nights when simple nervous tension keeps you tossing and turning, unable to fall asleep. Compoz helps you relax that simple nervous tension, eases that minor temporary tenseness. Compoz helps you fall asleep more naturally, more easily. And unlike sleeping tablets that leave you with a drugged feeling the morning after, Compoz lets you wake up feeling fresh as you can be. But for those occasional nights when simple nervous tension keeps you awake, take Compoz with confidence." 
Figure 8

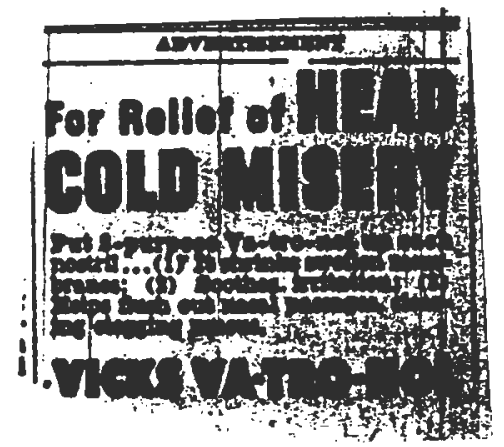

**Vicks-Va-Tro-Nol, Ad reads: Put 3-purpose Va-tro-nol up each nostril ..(1) It shrinks swollen membranes;..(2) Soothes irritation;...(3) Helps flush out nasal passages, clearing, clogging mucus.(no longer marketed)

-appeared in New York Times Jan. 3, 1941 
Figure 9

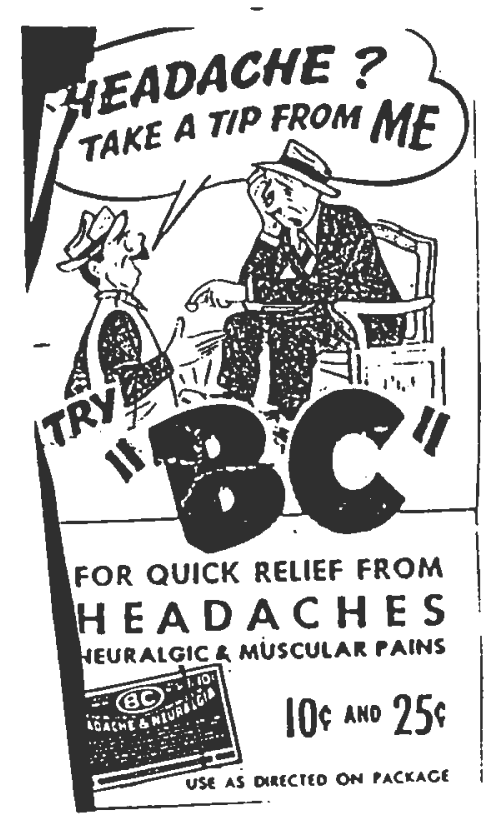

BCP Powders (still marketed)

appeared in LIFE magazine, 1947 
Figure 10

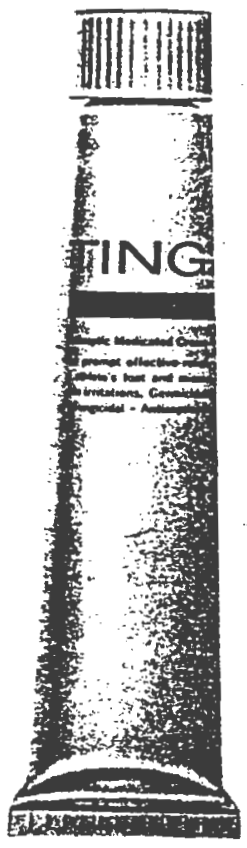

1. Ting stops the itch of athlete's foot.

2. Ting kills the fungus of athlete's foot.

3. Ting kills the bacteria of athlete's foot.

4. Ting checks the recurrence of athlete's foot.

\author{
(And Ting does all this in a unique way.) \\ $\therefore$..s. : : \\ Ting goes on as an antiseptic \\ medicated cream that gets to the cause \\ of athlece's foot. Then, in a few \\ minutes, Ting turns into an antiseptic \\ powder that cools and dries the feet. \\ reduces friction between toes and \\ helps new skin to grow. A cream \\ that turns into a powder; now you see \\ why Ting is unique. Also available: \\ why Ting is unique. Also available: \\ to help prevent re-infection. \\ Waat proof of Theg's effectiveness? \\ Ting-Dept.VE-3, Pharmacratt Laboratories, \\ Cranbury. New Jerser
}

*Ting ointment(not marketed) 
The advertising of Over-the-Counter(OTC) medicines was not specifically addressed until the labeling standards of these products were mentioned in the drug regulations. In 1912, the Sherley Amendment to the $190^{\circ} 6$ Pure Food and Drug Act, was an attempt by regulators to stop deceptive labeling and promoting.(4) The challenge facing the courts was in proving that a promotional claim was false, or that a claim was set forth deliberately with the intent to deceive, which accounted for the existence of erratic advertising. $(2,4)$

The Wheeler-Lea Amendment to the FTC Act in 1938, made it possible for regulators to exert control over the advertising of OTCs. A contributing factor to this was the enactment of the Food, Drug, and Cosmetic Act of 1938 which imposed safety requirements on new drugs. Advertisements could no longer promote medicines in a manner which may lead to unsafe use of drugs.(4)

When the advertising era peaked in the mid 1970's, a new regulation was imposed to monitor the material content in advertisements. It was at this time, the Federal Trade Commission Act was amended to prohibit advertisers, in describing the therapeutic benefits of their OTC products, from using language not approved by the FDA, for labeling as published in its final monograph(4). This requirement would take effect at the time of the publication of the monograph, to avoid a lag time between the effective date for regulation of an OTC product and the regulation of advertising for the same ingredient. 


\section{The Federal Trade Commission and OTC Advertising}

As discussed earlier, the FTC was created to control and prevent persons or corporations from conducting business using unfair or deceptive methods of competition.

To reiterate, the Commission carries out its functions under the Federal Trade

Commission Act. When the Act was amended in the mid 1970s to include deceptive and fraudulent advertising, the FTC's new scope then included and continues to include OTC advertising.(4) The realm of activity continues to be the printed or spoken advertising message, and its functions extend to all national advertisers and their advertising agents. $(11,12,13)$ The Commission's authority is not limited to preventing deceptive acts or practices or false advertisements. It can operate under the theory that a practice is unfair if it offends public policy which Congress has enacted for the protection of public health. $(11,12,13)$

The FDA holds no authority over the advertising of OTC medicines, however, it can prohibit the sales of falsely advertised products. The FDA serves usefully as an advisory body for both the FTC and Federal Communications Commission(FCC). The FCC is a commission which allocates the times and time limits for television advertisements. (4)

The major objectives of the FTC's advertising regulations are to encourage truthful advertising, prevent advertisers from employing deceptive or unfair advertising claims and methods, and to ensure advertisers disclose limitations and health risks. $(2,4)$ 


\section{Nonprescription Drug Manufacturers Association (NDMA)}

In 1973, the NDMA (formerly The Proprietary Association) in conjunction with the National Association of Broadcasters, developed a code of guidelines for manufacturers to follow in creating television advertisements for OTC medicines.(7) These guidelines impose high standards of truthfulness and honesty, and convey the critical nature of the products being advertised. A summary of some of the specifications for advertising of OTCs is outlined below.(7)

- Advertising of an OTC medicine should urge the consumer to read and follow label directions.

- Advertising of an OTC medicine should not contain claims of product effectiveness which are not supported by clinical or other scientific evidence.

- An advertisement of an OTC medicine should not be presented in a manner which suggests prevention or a cure of a serious condition which must be treated by a licensed practitioner.

- An advertisement of an OTC medicine should not show dramatizations of ingestion of medicine unless it is informing the consumer of proper administration of the medicine.

- An advertisement of an OTC medicine should not reference doctors, hospitals, or nurses unless such representations can be supported by independently conducted research.

- An advertisement of an OTC medicine should emphasize uses, results, and advantages of the product advertised. Negative or unfair reflections upon competing 
OTC products should not be presented unless they can be scientifically supported and presented in a manner such that consumers can perceive differences in the uses.

- An advertisement of an OTC medicine which references scientific or consumer studies should present actual research performed and results interpreted honestly and accurately.

\section{E. Advertising Expenditures}

Advertising OTC drug products reaches the public through newspapers, television, radio, magazines, billboards, counter and floor product displays, and several other forms of media. The amount of dollars spent on advertising by manufacturers on drugs and cosmetics continues to exceed that of other categories.(10)

Table 1

\begin{tabular}{ll}
\hline \multicolumn{2}{l}{ Advertising Volume for Selected OTC Product Categories, 1972} \\
\hline Category & 1972 (millions) \\
\hline Dental supplies & $\$ 112 . .0$ \\
Headache, sleep & 99.5 \\
Cold, cough,sinus & 77.4 \\
Digestive, antacids & 45.0 \\
Medicated skin & 39.1 \\
Vitamins & 29.9 \\
Feminine & 26.8 \\
Laxatives & 16.8 \\
Weight control & 4.0 \\
Total & 450.5 \\
\hline Source- Product Management. "The Advertising Age." Drug Topics, (Aug. 23, 1973)
\end{tabular}




\section{F. Advertising of Switch Medicines}

With a large prescription user base, there is a general familiarity of many prescription tradenames which are frequently used in treating common conditions such as allergies, stomach ulcers or excess acid, and arthritis. This is exemplified by the volume of sales (Table 2) for the newly switched products in the market today. It so happens, many switch products and future switches arise from these therapeutic areas. These drug products are considered for OTC use because consumers tend to understand and easily recognize symptoms from these conditions. Since these conditions occur rather frequently throughout the population, the associated prescription products have been heavily relied upon as part of the symptomatic treatments. Once approval for a switch is granted by the FDA, manufacturers have a definite advantage in promoting their switch drug, since their product's tradename and reputation is already established. Manufacturers take advantage of this through product advertising and package labeling. As an example, when Upjohn received approval for a nonprescription strength of their prescription product Motrin (ibuprofen), they wanted to maintain the consumers' recognition for the prescription tradename, therefore, the OTC version was named Motrin IB. If Upjohn received approval for ibuprofen to be switched under a petition method rather than a new drug application, they would have been able to maintain the identical tradename. Since the tradenames are nearly identical, Upjohn has been able to promote their OTC product successfully. Other manufacturers in competition with the same active ingredient do not have the same advantage in promoting their OTC product 
but benefit with focusing their advertising on the availability of an OTC strength of a prescription product.

For the switch product Benedryl, manufactured by Parke Davis (division of Warner Lambert), the tradename was allowed to remain the same because it was switched under the petition method and not treated as a new drug. This has contributed to the success and popularity of the OTC product. Advertising for this product is no longer focused on the switch aspect but on the usefulness in treating allergies and cough and cold symptoms.

Also through advertising, manufacturers emphasize the fact that a potent but safe and effective prescription drug with an established reputation with doctors, pharmacists and the FDA is now available to consumers. Additionally, one can note the use of the word cure in addition to symptomatic relief which is the only approved use of many traditional OTC products. This trend to promote a cure places a special responsibility on the FTC and FDA to ensure that the advertising and labeling is not misleading. Consumers must be made aware of the appropriate use and limitations of a switch product to avoid complications in the condition being treated. The manufacturer also needs to stress the potency of the drug product and the need for careful monitoring of results so that medical intervention can be sought if necessary. 
Table 2

\section{Popularity of Switch Medicines}

Of the ten best selling OTCs, nine were switches and one was switch-related

.

\begin{tabular}{llcl}
\multicolumn{1}{c}{ Product } & \multicolumn{1}{c}{ Marketer } & $\begin{array}{c}\text { 1991 Sales } \\
\text { (\$MM) }\end{array}$ & Type \\
\hline Advil & American Home Products & 285 & Switch \\
Monistat 7 & Johnson \& Johnson & 90 & Switch \\
Sudafed & Burroughs Wellcome & 81 & Switch \\
Dimetapp & American Home Products & 78 & Switch \\
Motrin IB & Upjohn & 74 & New Proprietary \\
Nuprin & Bristol-Myers Squibbb & 74 & Switch \\
Benadryl & Warner-Lambert & 73 & Switch \\
Gyne-Lotrimin & Schering-Plough & 63 & Switch \\
Actifed & Burroughs-Welcome & 61 & Switch \\
Afrin & Shering-Plough & 54 & Switch \\
\hline
\end{tabular}

Source- Sudler \& Henessey, NY 1992. 


\section{Summary}

Appropriate labeling and advertising are crucial instruments that can be useful in educating consumers on the safe and effective use of switch products. The agencies and systems are in place to bring forth smooth transitions of prescription products to OTC status. However, these agencies must be vigilant in monitoring the potential for manufacturers to promote their products in false or misleading ways in order to gain a market edge. Afterall, success in the consumer market goes to whomever has the most persuasive labeling and advertising. 


\section{References}

1. Council on Family Health. Study by Princeton Survey Research Group, Using Medicines Safely, Prevention Magazine (March 1993).

2. Digges, I.W. The Modern Low of Advertising and Marketing New York, Funk

\& Wagnalls Company. (1964).

3. Food and Drug Administration. Federal Register, (August 26,1993).

4. Guerard, C. The Impact of Advertising and Its Regulations, A Federal Trade Commission Perspective, Drug Information Journal 19 163-172 (1985).

5. Hearings before the subcommittee on monopoly and anticompetitive activities of the select committee on small business, U.S. Senate, part 5. (Oct. 29,30, 1975) and (June 14, 21, 1977).

6. Henderson, G. The Federal Trade Commission Yale University Press. New Haven. (1924).

7. NDMA. Voluntary Codes and Guidelines of the OTC Medicines Industry, Washington, D.C. (1991).

8. NDMA. Label Readability Guidelines, Washington, D.C. (1992).

9. PR Newswire, p0826DC005. (August 26, 1993).

10. Silverman, M. and Lee, P. Pills, Profits, and Politics, University of California Press. LA, CA. (1976).

11. 16 U.S.C. $450(2)(a) 1(1975)$.

12. 16 U.S.C. $450(1)(1975)$.

13. 16 U.S.C. $450(1)(b)(1975)$

14. 21 U.S.C. $353(1)(a)(1)(1976)$. 
MANUSCRIPT IV

CURRENT PERCEPTIONS ABOUT OVER THE COUNTER MEDICINE LABELING AND ADVERTISING 


\section{Current Perceptions About Over-the-Counter \\ Medicine Labeling and Advertising}

\section{Introduction}

Several prescription medicines are currently being switched, or considered for switch to the over-the-counter (OTC) market for direct availability to consumers. As a result of this Rx-to-OTC switch trend, and in light of health care reform to reduce the cost of health services, the roles of heath care professionals are changing. Physicians have long assumed the role as the primary care giver with the consumer as the care recipient. Today, there is an additional level of health care providers. Nurses, nurse practitioners and physician assistants provide direct patient care for many health problems. In some states these professionals are authorized to prescribe drugs applicable to their scope of training. Additionally, in Florida and California, pharmacists are authorized to prescribe a limited number of drugs to consumers without any intervention of physicians. Pharmacists are the most approachable health care professional to consumers and their accessibility complements the trend toward self-medication. They have served and continue to serve as the mediator between physicians and consumers, supplying both with OTC and prescription drug information, monitoring drug interactions and patient compliance. These particular responsibilities will persist for pharmacists but with the ongoing trend of switching prescription drugs to OTC, more time and effort will be directed toward counseling patients for the appropriate use of OTC medicines. 
Health care professionals generally recognize that the worsening economic situation has contributed to a reduction in doctor office visits by consumers seeking medical intervention. $(4,5,8)$ Consumers are additionally seeking assistance from lower level providers, especially in managed care environments. They also have the option of visiting any retail store and selecting an OTC product. In fact, more OTC medicines are being used by consumers, in part as an effective and affordable alternative to an expensive office visit.(6,8) At the same time consumers are currently accepting more responsibility for their own health care. This includes recognizing symptoms of conditions previously diagnosed by physicians, such as yeast infections, allergies, skin conditions, and arthritic episodes. Consumers now routinely make the decision to self-medicate these problems, and determine when or if a physician, or other health care professional, needs to be consulted.

Pharmacists, physicians, nurses, and other health care professionals will no doubt continue to be vital components in the health care delivery system, although, as self-care increases, their role as a primary provider is changing to one of an educator. The information they can provide to consumers is essential to promote the safe, appropriate, and responsible use of the newly available OTC medicines. For this reason they must be knowledgeable about these products. In addition to the input from health professionals, the consumer can also rely on two other methods for obtaining information about OTC products labeling and OTC advertising. It is essential, therefore, that consumers receive accurate, clear, and complete information from these venues if the products are to be used properly. 
The fact that American consumers have become increasingly health conscious has resulted in their assuming greater responsibility for their health care. This "take-charge" attitude has had a significant impact on the use of OTC medicines in self treatment. With the $\mathrm{Rx}$-to-OTC switch trend in place, consumers are experiencing constant changes in their options for various drug treatments. It is well established that consumers are no longer running to physicians with minor ailments or even recurring conditions which were previously diagnosed by physicians. $(5,6)$ In addition to seeing health care professionals, they can visit any retail store and choose from an a wide selection of effective OTC products, read package labeling for instructions, and begin treatment almost immediately.

The first phase of this study was designed to assess consumers' attitudes and perceptions about prescription medicines being switched for OTC use, their patterns of use for OTC medicines, and the factors that influence their decision in selecting a product. One important issue throughout this part of the study was to gain insight on consumer perceptions of OTC package labeling in terms of readability and understandability since the information on the product is crucial to appropriate use. Understandability was evaluated through consumers' interpretation of terminology found on current package labels. The responses were then compared across consumer variables such as age, gender, education, income, and language skills to see if differences existed across the variables.

Phase II of this study examined pharmacists' and physicians' perceptions of current labeling and advertising with respect to the content, readability, and comprehensibility of the information provided. Another part of the study was to assess pharmacists' and 
physicians' awareness of the trend of switching safe established prescription medicines to OTC status for the improvement of patient self-medication. It was also of interest to identify patient characteristics that these health professionals believed contributed to safe and proper use. 


\section{Methods}

\section{A. Phase I}

Since Phase I was an exploratory study designed to evaluate certain consumer variables for their effect on the readability and understandability, the distribution of the surveys was based upon two considerations. The first goal was to target specific populations that were expected to provide useful data on the use of OTC products. The second goal was to obtain responses from consumers in various demographic categories.

The sample size and distribution were designed to meet the cost limitations allowed for the study.

To meet the first goal, a large chain drugstore was selected for sample collection since it is well established that consumers prefer purchasing OTC medicines in drugstores compared to supermarkets or other retail establishments. This preference has been verified through sales analyses and consumer polls. In 1992, Towne-Oller \& Associates analyzed on the sales of OTCs in drugstores and foodstores and found that drugstore sales accounted for $\$ 6.2$ billion while foodstores showed $\$ 5.3$ billion.(12 ) Consumer polls have revealed that consumers prefer drugstores in part because of the accessibility of pharmacists for OTC information. (3)

Since the goal was to target a sample of consumers who are likely to use OTC medicines and/or seek assistance from pharmacists, it was decided to make the surveys accessible through the pharmacy service end of the drugstore only. The distribution involved placing the surveys with a clipboard on pharmacy counters. A sealed box, labeled URI RESEARCH. was also placed on the counter for the consumers to place their 
completed surveys. A cover letter attached to a three-page survey introduced the research focus, the purpose of the project, and assured confidentiality to encourage completion. The survey requested the following demographic data from consumers: age, level of annual income, last school completed, gender, and native language. While cost and time limitations precluded drawing a statistically random sample, this blend of urban and rural stores across the states was used to approximate a balance blend of respondents.

The second consideration for targeting the sample population was a demographic distribution to represent the urban, suburban, and rural geographic areas in the state of Rhode Island. The 1990 census data aided in the selection of eight cities and towns from the total 39 comprising the state. These eight locations were primarily selected for their distribution of educational level, yearly income, and language skills.

\section{B. Phase II}

Both pharmacists and physicians were solicited in this study because their direct patient interaction should result in an awareness of consumer perceptions of health and of their self- medication practices. In general, the size of the sample was determined by the cost of conducting the study, and by the desire to limit the scope to in-state practitioners. A random sample from the physician and pharmacist populations was selected from the Rhode Island Department of Health's listing of registrants. The list of registered physicians contained 3,050 names and addresses. Every fifth physician name was selected for the mail distribution if it included a Rhode Island address and did not identify specialties including pathology or radiology. If either were the case, the next name in line 
was selected. The list of registered pharmacists contained 1,243 names. To obtain a sufficient sample size comparable to the physician sample, every other name was selected for the mail distribution provided it was a Rhode Island address.

The three page survey for health professionals did not request demographic information and practice characteristics for physicians or pharmacists. Rather, the questions were designed to allow the respondents to identify if their scope of practice was such that it was inappropriate to answer a question. Regardless of their scope of practice, it was expected to be useful to have their views as health care professionals, and as consumers, about the changing health care trends and package labeling. The distribution involved a one-time mailing without any form of announcement, reminder, or second mailing. Confidentiality was assured to encourage completion of the survey.

The data was analyzed using SAS software program and statistical significance was determined by the Chi Square test statistic with a probability (p) value less than 0.05 . 


\section{Results and Discussion}

Several national studies have been conducted to find out about the practices of American consumers with respect to self-treatable health problems. In these studies, much emphasis was placed on how and to what extent consumers use OTC medicines and whether the package labels are read and/or understood. These studies will be frequently referenced in the comparison of national data to the Rhode Island regional data. The Rhode Island survey obtained similar information to these studies, however, it placed more focus on consumer's ability to understand the terminology on package labels. Additionally, the survey inquired about consumer views on the trend of switching drugs from prescription status to OTC status. The Rhode Island study also surveyed pharmacists and physicians, not only for their knowledge of label and advertising, but also their perceptions of consumer capabilities of understanding OTC labels and advertising.

The locations for the consumer survey are listed in Table 1 which also shows the distribution, sample size and response rates. The consumer respondent demographics are presented in Table 2. A total of 164 surveys were used in the data analysis.

Valid responses were received from $154(25.4 \%)$ of the 606 physicians surveyed, and these were used in the analysis. Four responses were eliminated because of retirement status. For pharmacists, $202(32.7 \%)$ of the 617 surveyed provided valid responses used in the analysis. Three of the responses were eliminated because of retirement status. The sample sizes and response rates for phase II are illustrated in Table 3. 
Table 1

\section{SAMPLE DISTRIBUTION, SIZE AND RESPONSE RATES, CONSUMERS}

\begin{tabular}{lccc}
\hline Category of Data & Urban & Suburban & Rural \\
\hline Original Sample & 200 & 300 & 100 \\
Final Sample* & 40 & 84 & 40 \\
Response Rates(\%) & $20 \%$ & $28 \%$ & $40 \%$ \\
\hline
\end{tabular}

* Includes completed surveys returned.

Urban includes the cities of Providence and Pawtucket.

Suburban includes North Kingstown, Wakefield, and Westerly.

Rural includes Tiverton and Slatersville.

The net response rate for all consumers $=27 . \%$ 
Table 2

CONSUMER RESPONDENT DEMOGRAPHICS

\begin{tabular}{lcc}
\hline Income & 29 & $18 \%$ \\
\hline Under $\$ 10,000$ & 29 & $18 \%$ \\
$\$ 10,000-\$ 19,000$ & 33 & $20 \%$ \\
$\$ 20,000-\$ 29,000$ & 42 & $26 \%$ \\
$\$ 30,000-\$ 44,000$ & 17 & $11 \%$ \\
$\$ 45,000-\$ 59,000$ & 12 & $7 \%$ \\
$\$ 60,000+$ & & \\
\hline Education & & $2 \%$ \\
\hline Less than High School & 4 & $39 \%$ \\
High School Graduate & 63 & $8 \%$ \\
Trade School & 13 & $31 \%$ \\
4 Year College & 50 & $15 \%$ \\
More than 4 Year College & 25 & $5 \%$ \\
None of the Above & 8 & $67 \%$ \\
\hline Gender & & $33 \%$ \\
\hline Female & & \\
Male & 110 & $12 \%$ \\
\hline Age & 54 & $30 \%$ \\
\hline $19-24$ & & $30 \%$ \\
25 - 34 & & $8 \%$ \\
35 - 44 & 20 & $20 \%$ \\
45 - 59 & 49 & \\
$60+$ & 49 & $11 \%$ \\
\hline Native Language & 13 & \\
\hline English & 33 & \\
Spanish & & \\
\hline & & \\
\hline
\end{tabular}


Table 3

SAMPLE SIZE AND RESPONSE RATES FOR PHYSICIAN AND PHARMACIST POPULATIONS

\begin{tabular}{lll}
\hline Category of Data & Physicians & Pharmacists \\
\hline Original Sample & 610 & 620 \\
Final sample* & 606 & 617 \\
Valid Responses & 154 & 202 \\
Response Rate(\%) & $25.4 \%$ & $32.7 \%$ \\
\hline
\end{tabular}

* Excludes survey respondents who identified themselves as retired and felt unable to respond accurately. 


\section{Phase I - Consumer Survey}

The consumer survey was divided into three sections. The first section was designed to find out who uses OTC products and the frequency of use. This section asked consumers for demographic information including their age range, last level of school completed, gender, native language, and range of annual income. The second section identified the factors which are used in the selection of an OTC product. These factors included where they were purchased, whether a professional was consulted, and if television advertising influenced their decision. The third section asked consumers for their opinion on the readability and understandability of OTC package labels. The final section asked about consumer perceptions on switching drugs from prescription to OTC status. The following discussion focuses on the points identified above.

\section{Who uses OTC medicines?}

The Rhode Island study found that 97 percent of consumers rely to some degree on OTC medicines. This number was expected since the sample contained drug-store patrons. Of this group, 31 percent say they always use OTCs. This trend seems to be consistent with the results reported by Princeton Survey,(10) where 88 percent of adult consumers said they use OTCs, with 19 percent saying they use them often.

The 1992 study conducted by the Princeton Survey Research Associates, for the Council on Family Health, published in Prevention Magazine, "Using Medicines Safely", surveyed American consumers for their use and attitudes regarding OTC and prescription medicines.(10) Specifically, the incidence of OTC use, and the practice of reading and 
understanding labels, were of particular interest. The study was conducted by interviewing 1,250 consumers, randomly selected, by telephone during November and December of 1992.

The Rhode Island study may be biased in these results because of the limited study population. Table 4 displays the breakdown relating the frequency of use. These results reflect the changing health care environment in which consumers are interested in assuming responsibility for their general well being. OTC medicines are viewed as a useful therapeutic alternative to costly, time-consuming physician intervention. Today, a significant number of people rely on OTCs or home remedies to treat minor ailments. 
Table 4

\section{WHO USES OTCS?}

How often?

\% Total Respondents (N)

Always

Sometimes

Rarely

Never
$31 \% \quad(51)$

$57 \% \quad(93)$

$9 \% \quad(15)$

$3 \% \quad(5)$ 
The national trend of women using more OTC medicines than men is not observed in the findings in this survey. Ninety-one percent of women said they use OTC medicines. Of these women, 33 percent responded using OTCs always, 58 percent said sometimes and only one respondent said never. In the case of men, 82 percent responded favorably to the use of OTCs. Of this group, 28 percent said always, while 54 percent said they use OTCs sometimes. Only 7 percent of men compared to 1 percent of women said they never use OTCs. There is no significant difference observed between women and men in using OTCs. Since more women responded to the Rhode Island survey, this may account for the slight increase in the observed percentages and result in bias. Table 5 shows the results broken down by gender. The Princeton survey reported women(62\%) were more likely than men to use OTCs compared to men(47\%). (10) Table 5 also shows results for this study.

In this country, women have traditionally taken care of such domestic duties as household shopping which included buying groceries and health and beauty aids. Although more women are finding themselves in the paid work force, in most cases, they maintain the same shopping practices. (8) Among their traditional responsibilities is caring for children. When children are sick, women are usually the ones to take them to the doctors, and then to the pharmacy for prescription or OTC medicines that the doctor prescribed. Although these roles have been gradually changing, the gender factor may account for the availability of more data from women about OTC medicine use. The Rhode Island study obtained completed surveys from 110 females compared to 54 males. 
Table 5

WHO USES OTCS? GENDER COMPARISON

\begin{tabular}{lcccc}
\hline How often? & $\%$ Male (N) & $\%$ Female (N) \\
\hline Always & $28 \%$ & $(15)$ & $33 \%$ & $(29)$ \\
Sometimes & $54 \%$ & $(29)$ & $58 \%$ & $(64)$ \\
Rarely & $11 \%$ & $(6)$ & $8 \%$ & $(9)$ \\
Never & $7 \%$ & $(4)$ & $<1 \%$ & $(1)$ \\
& & & & \\
\hline
\end{tabular}


Other demographic characteristics assessed for their potential influence in the use of OTC medicines were income and education. See tables 6 and 7 for the results. It appears as though both of these factors affect the consumer reliance on OTCs. For the respondents with income in the range of $\$ 10,000$ and $\$ 19,000,76$ percent said they used OTC medicines compared to the five other income levels where 88 to $93 \%$ of these respondents use them. The highest reported use (93\%) was by respondents with an income in the range of $\$ 30,000$ to $\$ 44,000$. Since most of the respondents (42) fell into this income category, the results may be biased. Consistent with national data, there are no statistically significant differences in the use of OTCs with respect to income.

Heller Research Group in their study "Self-Medication in the'90s: Practices and Perceptions" reported 38 percent of adults earning $\$ 20,000$ or more reported frequent us of OTCs compared to 33 percent of adults earning $\$ 20,000$ or less. Overall, there were no major differences observed in the use of OTCs with respect to income. The Heller study's national sample included 1,500 American consumers who were interviewed by monitored telephone interviews and self-completion questionnaires. These consumers were asked about their practices with OTCs and self-medication and their overall attitudes regarding OTC drugs and moreover, their feelings about the Rx-to OTC switch trend.

With regard to education and the use of OTCs, there was a significant difference for those respondents with an education less than high school. Fifty percent of them reported using OTCs. For those respondents with high school education and above, the reported use of OTCs ranged from 84 to $94 \%$. The maximum use (94\%) was reported by respondents who completed 4 years of college. These results are unexpected since 
consumers in the lower income and less education groups would be expected to have the most reliance on OTCs as an alternative to medical intervention for health care services. The Heller study showed similar results. For adults with high school education or less, 35 of them were inclined to use OTCs where 38 percent of adults with some college or more would use OTCs.(6) 
Table 6

WHO USES OTCS? COMPARISON OF INCOME

\begin{tabular}{cccc}
\hline Level of Income & $\%$ Total (N) & $\%$ Ýes (N) & $\%$ No (N) \\
\hline$<\$ 10,000$ & $18 \%(29)$ & $89 \%(26)$ & $3 \%(1)$ \\
$\$ 10-\$ 19,000$ & $18 \%(29)$ & $76 \%(22)$ & $10 \%(3)$ \\
$\$ 20-\$ 29,000$ & $20 \%(33)$ & $87 \%(29)$ & $3 \%(1)$ \\
$\$ 30-\$ 44,000$ & $26 \%(42)$ & $92 \%(39)$ & $-\cdots--$ \\
$\$ 45-\$ 59,000$ & $11 \%(17)$ & $88 \%(15)$ & ----- \\
$>\$ 60,000$ & $7 \%(12)$ & $92 \%(11)$ & ----- \\
\hline
\end{tabular}

- Yes includes the responses always and sometimes. It does not include rarely. 
Table 7

\section{WHO USES OTCS? COMPARISON OF EDUCATION}

\begin{tabular}{lccc}
\hline Education level & \% Total (N) & $\%$ Yes (N) & $\%$ No (N) \\
\hline Less than High School & $2 \%(4)$ & $50 \%(50)$ & $25 \%(1)$ \\
High School equiv. & $39 \%(63)$ & $86 \%(54)$ & $5 \%(3)$ \\
Trade School & $8 \%(13)$ & $92 \%(12)$ & $-\cdots---$ \\
4 Year College & $31 \%(50)$ & $94 \%(47)$ & $-13 \%(1)$ \\
$>4$ Year College & $15 \%(25)$ & $84 \%(21)$ & \\
None of the above & $5 \%(8)$ & $87 \%(7)$ & \\
\hline
\end{tabular}

-Yes include always and sometimes. It does not include rarely. 
The age factor was also evaluated by the Rhode Island survey. Table 8 displays the results for each age range. For the ages between $19-44,30$ percent of the respondents said they always used OTCs, while an average of 58 percent of the respondents said they sometimes use OTCs. The $15 \%$ of the $45-59$ age group said they always use OTCs and $69 \%$ of them sometimes use OTCs. Thirty-nine percent of the 60 and over respondents said they always use OTCs and 39\% sometimes use OTCs. This last finding is unexpected since the Heller study showed for the $65+$ group, only $28 \%$ relied on OTCs compared to the $38 \%$ average for the other age groups. One would expect that elderly would avoid using as many OTCs as younger people since they are usually taking other prescription medicines or have conditions in which OTCs are contraindicated with. On the other hand, with the lessened availability of medical insurance for doctor office visits and prescription medicines, the elderly may be more inclined to rely on OTC medicines as a cost effective alternative. 


\section{Table 8}

\section{WHO USES OTCS? COMPARISON OF AGE}

\begin{tabular}{llll}
\hline Age range & \%Total (N) & $\%$ Yes (N) & $\%$ No (N) \\
\hline $19-24$ & $12 \%(20)$ & $85 \%(17)$ & ---- \\
$25-34$ & $30 \%(49)$ & $90 \%(44)$ & $4 \%(2)$ \\
$35-44$ & $30 \%(49)$ & $94 \%(46)$ & ----- \\
$45-59$ & $8 \%(13)$ & $84 \%(11)$ & $6 \%(1)$ \\
$60+$ & $20 \%(33)$ & $78 \%(26) *$ & \\
\hline
\end{tabular}

-Yes includes always and sometimes. It dose not include rarely.

* $15 \%$ said rarely accounting for no significant difference between age groups for responding favorably to the use of OTCs. 
The last factor studied for its effect on the use of OTCs was language skills. Table 9 includes the results. Although the test group only included twenty respondents who identified a language other than English as their native tongue, and attempt was made to determine if language had an effect on selection. One hundred percent $(\mathrm{N}=2)$ of Portuguese individuals reported using OTCs sometimes. Spanish respondents reported $73 \%(\mathrm{~N}=18)$ use OTCs always or sometimes and $15 \%$ never use them. Comparing English and non-English speaking respondents in their use of OTCs, 88 percent and 80 percent respectively use OTCs always or sometimes. It is impossible to draw conclusive evidence that language affects the selection of OTC products from such a small sample.

These data and the national statistics cited support the routine use of OTCs by consumers. The Heller study showed that OTC use has actually increased from 1983 to 1992 . Figure 1 shows the breakdown of what consumers do for health problems. This reinforces the concept that consumers are willing to find their own solution to recurring problems and OTCs provide an available option. 


\section{Table 9}

\section{WHO USES OTCS? COMPARISON OF LANGUAGE}

\begin{tabular}{lccc}
\hline How often? & $\%$ English (N) & \% non-English (N) \\
& $33 \%$ & $(47)$ & $20 \% \quad(4)$ \\
Always & $56 \%$ & $(81)$ & $60 \%(12)$ \\
Sometimes & $8 \%$ & $(12)$ & $15 \% \quad(3)$ \\
Rarely & $3 \%$ & $(4)$ & $5 \% \quad(1)$ \\
Never & & & \\
& $88 \%$ & $(144)$ & $12 \%(20)$ \\
\hline
\end{tabular}

Total Yes for English $=97 \%$ and non-English $95 \%$ resulting in no significant difference Sample size to small to make accurate inferences about language skills. 


\section{What factors influence consumer selection of an OTC product?}

Questions were posed to identify not only the retail environment preferred for purchasing OTC medicines, but also to see what other factors may influence these preferences. Specifically, the survey asked the consumer which of the following was a significant influence in their decision to choose an OTC drug: primary care provider, package labels, family, friends, media, or any other mentioned source.

The Rhode Island study showed that consumers prefer to purchase OTC medicines from drugstores. The results from this study may be biased since the survey was only accessible to consumers in the drugstore environment. The results are shown in table 10 for all demographic groups. Eighty-two percent of consumers said they most often purchase OTC products from drugstores. 
Table 10

\section{WHERE DO CONSUMERS PREFER TO PURCHASE OTCS?}

\begin{tabular}{|c|c|c|c|}
\hline Category of data & \%Drugstore (N) & \%Supermarket $(\mathrm{N})$ & Total(N) \\
\hline \multicolumn{4}{|l|}{ Gender } \\
\hline Female & $84 \%(92)$ & $11 \%(12)$ & 110 \\
\hline Male & $78 \%(42)$ & $15 \% \quad(8)$ & 54 \\
\hline \multicolumn{4}{|l|}{ Age } \\
\hline $19-24$ & $95 \%(19)^{*}$ & $5 \%(1)$. & 20 \\
\hline $25-34$ & $82 \%(40)$ & $8 \%(4)$ & 49 \\
\hline $35-49$ & $80 \%(39)$ & $14 \%(7)$ & 49 \\
\hline $50-59$ & $85 \%(11)$ & $8 \%(1)$ & 13 \\
\hline $60+$ & $76 \%(25)^{*}$ & $21 \%(7)$ & 33 \\
\hline \multicolumn{4}{|l|}{ Income } \\
\hline$<\$ 10,000$ & $86 \%(25)$ & $10 \%(3)$ & 29 \\
\hline$\$ 10-\$ 19,000$ & $69 \%(20)^{*}$ & $17 \%(5)$ & 29 \\
\hline$\$ 20-\$ 29,000$ & $88 \%(29)$ & $6 \%(2)$ & 33 \\
\hline$\$ 30-\$ 44,000$ & $79 \%(33)$ & $17 \%(7)$ & 42 \\
\hline$\$ 45-\$ 59,000$ & $100 \%(17)^{*}$ & ------ & 17 \\
\hline$>\$ 60,000$ & $69 \%(9)^{*}$ & $23 \%(3)^{*}$ & 13 \\
\hline \multicolumn{4}{|l|}{ Education } \\
\hline$<$ High School & $50 \%(2)^{*}$ & $50 \%(2)^{*}$ & 4 \\
\hline$=$ High School & $78 \%(49)$ & $13 \%(8)$ & 63 \\
\hline Trade School & $77 \%(10)$ & $23 \%(3)^{*}$ & 13 \\
\hline 4 Year College & $88 \%(44)$ & $8 \%(4)$ & 50 \\
\hline$>4$ Yr. College & $84 \%(21)$ & $12 \%(3)$ & 25 \\
\hline None of the above & $88 \% \quad(7)$ & ------ & 8 \\
\hline \multicolumn{4}{|l|}{ Native Language } \\
\hline English & $84 \%(119)$ & $12 \%(17)$ & 144 \\
\hline non-English & $78 \% \quad(14)$ & $17 \% \quad(3)$ & 20 \\
\hline
\end{tabular}

* denotes statistical difference for that range compared to other ranges in that category. 
A few statistical differences were found within categories of data, however, it is difficult to explain these findings with such a limited sample. A national Business Marketing survey conducted in 1988 revealed in their study sample that consumers generally favored buying OTCs in drugstores compared to supermarkets. (11)

Overall, consumers depend on health care providers to assist them in their decision on product selection and moreover, to provide directions for the product. In the Rhode Island survey, $34 \%$ of consumer respondents rely on the pharmacist to help them select a product while $30 \%$ rely on physicians. Figure 2 shows the results for each source. Kline \& Company reported in their national study a similarity to these findings; $40 \%$ of respondents rely on physicians while $67 \%$ said they asked a pharmacist to recommend something. While there was no statistical difference observed between pharmacists and physicians as the preferred consultant in the Rhode Island survey, national statistics suggest that pharmacists are consulted more often because they are more directly accessible to consumers. 
Figure 1

What Was Done About Problems"

What Was Done ' 83 vs. '92

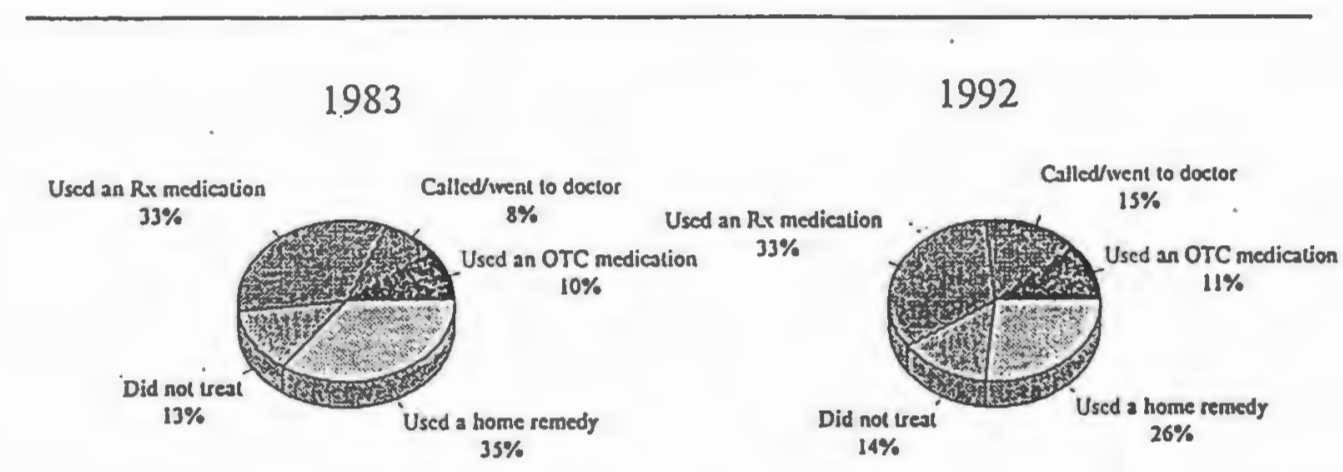

*Source: Heller Research Group

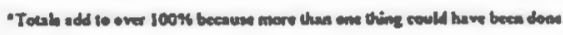

Figure 2

\% Of Consumers Who Rely On Different Sources Of Influence In Selecting OTC Products

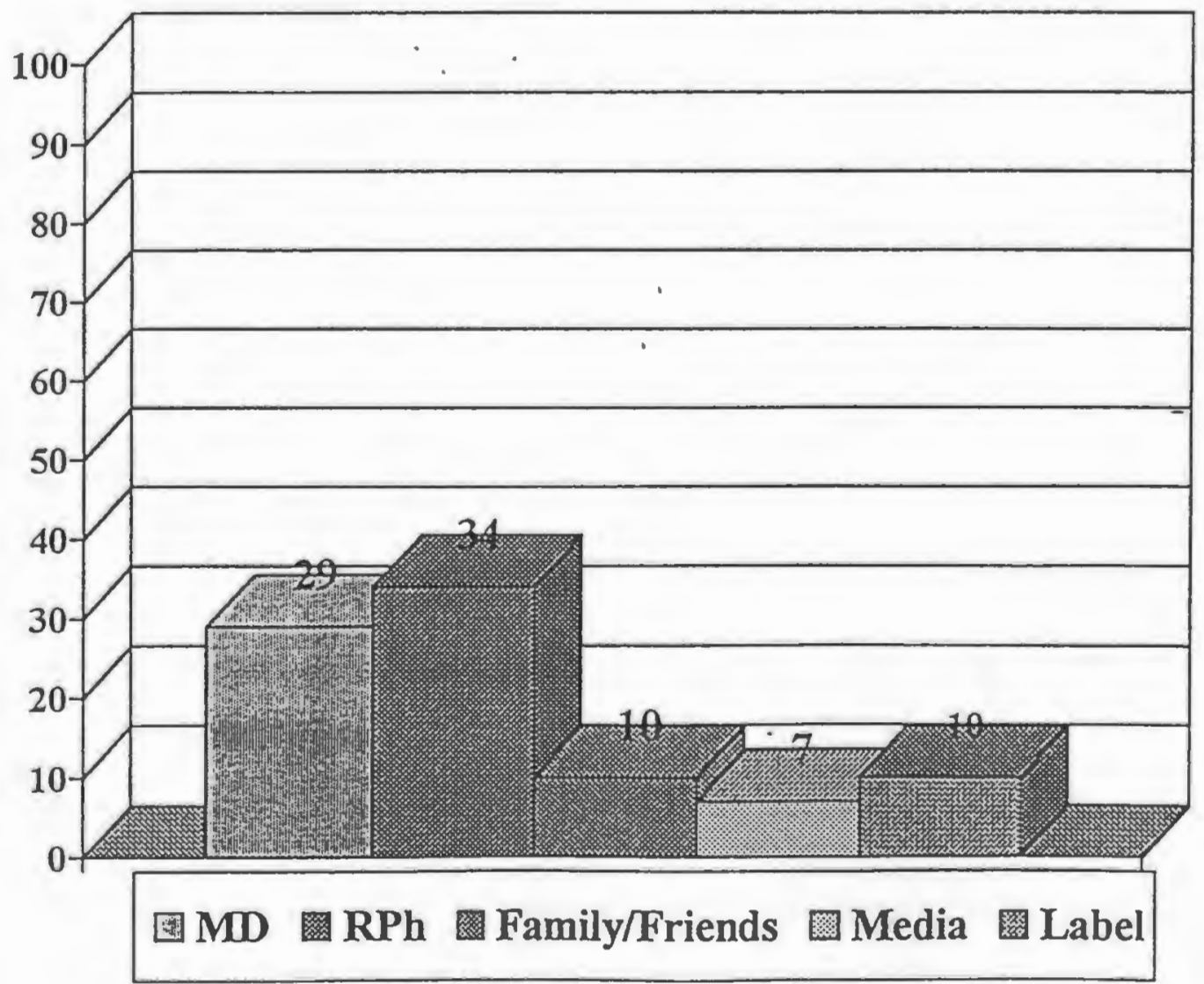


An interesting finding in the national data is the fact that more women choose drugstores over supermarkets. The Rhode Island study did not reflect a significant difference between men and women. Table 10 shows this data. The literature shows that 'one-stop' shopping is becoming more popular than the usual fashion of shopping at specialty stores for different products. The reason for this change is time constraints with work schedules, overall convenience, and the use and value for coupons (double coupons) in supermarkets compared to drugstores. The Rhode Island survey found that $82 \%$ of respondents buy their OTC products in drugstores. Since more women responded to the survey it may suggest that more women shop in drugstores and may buy OTC products more so than men. A higher statistic for women would be expected and it appears Rhode Islanders are still traditional in many of their buying habits.

Age may be an influential factor since the elderly notably use more prescription drugs, and they traditionally prefer the service and personal relationships established in drugstores, specifically independent drugstores. (11) They can conveniently purchase OTC medicines in drugstores as well. A study by National Association of Retail Druggists and Johnson \& Johnson reports 69 percent of consumers over the age of sixty prefer drugstores. (11) The Rhode Island found that 76 percent of elderly preferred drugstore outlets for their OTC drugs. Table 10 also shows the results for this variable. Overall, the Rhode Island survey did not reveal and significant differences between age groups in their preference of drugstores to supermarkets. 


\section{How influential is television advertising?}

With regard to advertising, the Rhode Island study determined that $35 \%$ of consumers are strongly influenced by television advertising. However, when television is compared to other venues, advertising in general was only reported to a major factor in the choice of OTCs by $7 \%$ of respondents. National statistics show that 13 percent of consumers believe that advertising is a significant factor in OTC choice. (7)

\section{What are consumers' perceptions on prescription drugs compared to OTCs?}

In this section of the study consumers were first asked if prescription medicines are more effective than OTC products in order to determine their overall attitude about OTC drugs. Ninety-one percent of participants indicated that prescription drugs work better. Of these $65 \%$ concluded that prescription drugs sometimes work better while only $22 \%$ felt that these products are always superior. Eight percent of consumers felt that prescription drugs are never better than OTC products. National statistics show a different result, in that only $10 \%$ of respondents felt that prescription medicines are likely to work better than OTC's. The discrepancy may be due to how the question was asked in the Rhode Island survey. In the national survey, consumers had the opportunity to compare the usefulness of OTC products to prescription drugs for a variety of conditions, and the data support the general satisfaction reported in the wide use of OTC products. In the Rhode Island study consumers were given limited choices. 


\section{Should safe prescription drugs be switched to OTC status?}

Consumers were also asked if safe prescription drugs should be available for OTC use. For this question $87 \%$ responded favorably to this question. Table 11 displays the results for all demographic groups. In general, consumers appear to be in favor of continuing the process of switching prescription drugs to OTC status. Some statistical differences arise within categories of data, however, it is difficult to apply reasoning which would explain such results. To further support this opinion, consumers were asked how often they would choose a relatively new switch product over an OTC product which has been on the market for a long time. Seventy-five percent would generally prefer a switch product ( $58 \%$ sometimes, $17 \%$ always). This response confirms the confidence that consumers have in the effectiveness of prescription drugs. Heller showed that $50 \%$ of respondents were more likely to choose switch products. The availability of more OTC products from the switch process gives consumers more choice at a lower cost. 
Table 11

\begin{tabular}{|c|c|c|c|}
\hline \multirow[b]{2}{*}{ Category of Data } & \multicolumn{3}{|c|}{$\begin{array}{l}\text { SHOULD RX DRUGS BE SWITCHED? } \\
\text { ( Income, Education, Language, Age, Gender) }\end{array}$} \\
\hline & $\%$ Good Idea (N) & $\begin{array}{l}\text { \% Somewhat of } \\
\text { a Good Idea(N) }\end{array}$ & $\%$ Bad Idea (N) \\
\hline \multicolumn{4}{|l|}{ Income } \\
\hline$<\$ 10,000$ & $18 \%(5)$ & $64 \%(18)$ & $14 \%(4)$ \\
\hline$\$ 10-\$ 19,000$ & $38 \%(11)$ & $48 \%(14)$ & $14 \%(4)$ \\
\hline$\$ 20-\$ 29,000$ & $33 \%(11)$ & $58 \%(19)$ & $9 \%(3)$ \\
\hline$\$ 30-\$ 44,000$ & $48 \%(20)$ & $43 \%(18)$ & $10 \%(4)$ \\
\hline$\$ 45-\$ 59,000^{*}$ & $18 \%(3)$ & $59 \%(10)$ & $24 \%(4)$ \\
\hline$>\$ 60,000$ & $39 \%(5)$ & $46 \%(6)$ & $8 \%(1)$ \\
\hline \multicolumn{4}{|l|}{ Education } \\
\hline$<$ High School & $50 \% \quad(2)$ & $50 \% \quad(2)$ & \\
\hline$=$ High School & $27 \%(17)$ & $56 \%(35)$ & $15 \%(9)$ \\
\hline Trade school & $54 \%(7)$ & $38 \%(5)$ & $8 \%(1)$ \\
\hline 4 Yr. College & $42 \%(21)$ & $50 \%(25)$ & $8 \%(4)$ \\
\hline$>4$ Yr. College & $24 \%(6)$ & $60 \%(15)$ & $12 \%(3)$ \\
\hline None of the above* & $13 \%(1)$ & $50 \%(4)$ & $38 \%(3)$ \\
\hline \multicolumn{4}{|l|}{ Native Language } \\
\hline English & $32 \%(46)$ & $55 \%(78)$ & $13 \%(19)$ \\
\hline non-English & $46 \%(9)$ & $44 \%(8)$ & $6 \%(1)$ \\
\hline \multicolumn{4}{|l|}{ Age } \\
\hline $19-24$ & $25 \% \quad(5)$ & $60 \%(12)$ & $15 \%(3)$ \\
\hline $25-34$ & $39 \%(19)$ & $55 \%(27)$ & $4 \%(2)$ \\
\hline $35-44$ & $29 \%(14)$ & $58 \%(28)$ & $13 \%(6)$ \\
\hline $45-59 *$ & $23 \%(3)$ & $38 \%(5)$ & $38 \%(5)$ \\
\hline $60+$ & $42 \%(14)$ & $42 \%(14)$ & $1-2 \%(4)$ \\
\hline \multicolumn{4}{|l|}{ Gender } \\
\hline Males & $44 \%(24)$ & $43 \%(23)$ & $11 \% \quad(6)$ \\
\hline Females & $28 \%(31)$ & $58 \%(63)$ & $13 \%(14)$ \\
\hline \multicolumn{4}{|l|}{ Total } \\
\hline Respondents & $34 \%(55)$ & $53 \%(86)$ & $12 \%(20)$ \\
\hline
\end{tabular}

* denotes statistical difference for specified range compared to other ranges in category of data. 


\section{How well do consumers understand package labels?}

In the Rhode Island study, a special attempt was made to assess consumers' ability to understand examples of terminology which appear on package labels. Four terms which are used quite frequently in labeling were defined with correct and incorrect simple definitions. The consumer was to select the most appropriate definition. Table 12 displays the terms and the results for correct responses. These terms included: indication, contraindication, active ingredient, and hypertension. Since these terms were not presented in the context of the package label, the results may be slightly biased. Despite this, $68 \%$ of the respondents accurately defined 'indication' while $8 \%$ defined it inaccurately and $24 \%$ said they did not know. This pattern was consistent for all four terms. The results clearly imply that those respondents reporting labels as understandable $(92 \%)$ overestimate their ability to understand medical terminology. A good portion of respondents were not able to define these standard words correctly or even attempt to do so. This is a clear signal that there is a need for more improvement in the standard terminology approved by the FDA. It does reflect, however, that pharmacists and physicians are accurate in their assessment of consumer abilities to understand package labeling and have some basis, at this point in time, to be hesitant about granting more responsibility to the consumer in self-medication. This is discussed later in phase II results. It is reassuring that the FDA is extremely conservative in their approval and switching of prescription medicines, and they continue to direct a great deal of attention and effort into the labeling of these newly available products. 
Table 12

Consumer Understandability of Terminology on Labels

\begin{tabular}{lccc}
\hline & & & \\
Term & Correct & Incorrect & Don't know \\
Indication & $68 \%$ & $8 \%$ & $24 \%$ \\
Contraindication & $48 \%$ & $18 \%$ & $34 \%$ \\
Active Ingredients & $67 \%$ & $34 \%$ & $7 \%$ \\
Hypertension & $70 \%$ & $18 \%$ & $12 \%$ \\
\hline
\end{tabular}


The research study has raised a number of issues which could have a significant impact on the successful use of OTC products in the future. Consumers think they understand what is on the label but they frequently don't. Also they often have difficulty reading the labels and advanced education experience does not necessarily reduce this problem. Clearly these problems need to be addressed quickly to ensure that the more powerful switch drugs will be successful as OTC products.

If manufacturers and regulatory agencies do not find ways to raise the level of understanding of information often found on labels, the risk for inappropriate and/or unsafe use is likely to increase. Since some switch products are intended to "cure" certain conditions, patients must clearly understand how, when, and how long to use the products to effect the desired result.(13) With regard to readability of labels, attention must also be given to designing labels which contain appropriate information in a clearly readable type and style to allow the safe use of the products.(9) Perhaps packaging in larger container (e.g. blistapak, larger volume), will improve the readability of the label since larger type and easier to read formats could be used. At some point a balance needs to be found between the amount of required information and the ease of reading and understanding of material on the label. If regulatory agencies are reluctant to reduce the amount of required labeling for safe use of these products, a method should be devised to insure that consumers are able to receive additional explanations and cautions from another venues (e.g. videos or computers at the counter for first time users, and accompanying pamphlet, 
required counseling by a health professional etc..) Perhaps manufacturers could educate the population using mass media.

\section{Do consumers find OTC package labels readable? .}

Consumers were also given the opportunity to assess the readability and understandability of OTC package labels. Tables 13 presents these results. From the overall sample, $98 \%$ of consumers said that they read OTC package labels. Only $2 \%$ said they did not read labels. The survey went a step further with regard to label readability based upon label appearance and understandability of the information provided. Thirty two percent of the sample reported that the label was not difficult to read and $92 \%$ said the label was understandable. This compares favorably to the Princeton national study which found $90 \%$ of respondents who read OTC labels said they understood the labels. The Heller study reported $90 \%$ of the respondents acknowledged the importance of reading labels and did so before taking an OTC medication. The Rhode Island study was unique in that both label readability and understandability was addressed

This study clearly showed that most people read OTC labels. (Table 12) When asked about the ease of reading the label based on the appearance, i.e., word selection type style and size, placement, bullets, etc., $32 \%$ consumer responded that labels were difficult to read, while $65 \%$ said OTC labels were difficult to read. Thirty percent of women reported labels were readable, while $70 \%$ thought labels were difficult to read. Men on the other hand reported difficulty in reading labels $(60 \%)$ and for labels being readable $(39 \%)$. These differences were not statistically significant. 
Sixty-seven percent of respondents between the ages of 25 - 50 reported difficulty in reading labels compared to $80 \%$ over the age of sixty. This increase with age is not unexpected since the elderly often have vision impairments. Many older Americans neglect their vision or wear improper corrections lenses. Also degenerative diseases often contribute to reduced vision. Educational levels had some effect on ease of reading the label. In those who had a trade school education, $90 \%$ reported difficulty in label reading. Generally $50 \%$ of the respondents with a high school education reported difficulty in label reading compared to $60 \%$ of those with a baccalaureate education. Among advanced degree respondents about $55 \%$ reported some difficulty in reading labels.

These data indicate that many people consider labels difficult to read. The reasons why are not specified but may include too much information in a limited space, small type, color, and label format. Clearly one would also expect that reading in general becomes more difficult as we age.

One would not expect to find a difference in readability based on gender, although national studies have shown that women read labels more then men, and as a result of being the primary care giver in the home, are more conscientious about reading the label thoroughly. Surprisingly, more education did not result in less difficulty in reading and understanding labels. It could be that only a certain level of education is necessary for a person to interpret medical terms. 
Table 12

\begin{tabular}{|c|c|c|c|}
\hline \multicolumn{4}{|c|}{ LABEL READABILITY AND UNDERSTANDABILITY } \\
\hline & Read Labels & Readable & Understand \\
\hline Category of Data & $\%$ Yes $(\mathrm{N})$ & $\%$ Yes(N) & $\%$ Yes $(\mathbf{N})$ \\
\hline $\begin{array}{l}\text { Gender } \\
\text { Males } \\
\text { Females }\end{array}$ & $\begin{array}{l}89 \%(48) \\
95 \%(105)\end{array}$ & $\begin{array}{l}31 \%(17) \\
31 \%(34)\end{array}$ & $\begin{array}{l}89 \%(48) \\
93 \%(101)\end{array}$ \\
\hline $\begin{array}{l}\text { Native Language } \\
\text { English } \\
\text { non-English }\end{array}$ & $\begin{array}{l}96 \%(138) \\
75 \%(15)\end{array}$ & $\begin{array}{c}35 \%(50) \\
5 \%(1)\end{array}$ & $\begin{array}{l}94 \%(133) \\
80 \%(16)\end{array}$ \\
\hline $\begin{array}{l}\text { Education } \\
<\text { High School } \\
=\text { High School } \\
\text { Trade School } \\
4 \text { Yr. College } \\
>4 \text { Yr. College } \\
\text { None of the above }\end{array}$ & $\begin{array}{l}75 \%(3) \\
91 \%(58) \\
92 \%(12) \\
98 \%(49) \\
92 \%(23) \\
88 \%(7)\end{array}$ & $\begin{array}{l}31 \%(19) \\
15 \%(2) \\
37 \%(18) \\
40 \%(10) \\
25 \%(2)\end{array}$ & $\begin{array}{c}100 \%(4) \\
90 \%(56) \\
92 \%(12) \\
95 \%(47) \\
79 \%(23) \\
75 \%(6)\end{array}$ \\
\hline $\begin{array}{c}\text { Income } \\
<\$ 10,000 \\
\$ 10-\$ 19,000 \\
\$ 20-\$ 29,000 \\
\$ 30-\$ 44,000 \\
\$ 45-\$ 59,000 \\
>\$ 60,000\end{array}$ & $\begin{array}{r}89 \%(26) \\
90 \%(26) \\
96 \%(43) \\
95 \%(40) \\
100 \%(17) \\
84 \%(11)\end{array}$ & $\begin{array}{l}25 \%(7) \\
28 \%(8) \\
34 \%(11) \\
31 \%(13) \\
41 \%(7) \\
33 \%(4)\end{array}$ & $\begin{array}{r}93 \%(26) \\
89 \%(26) \\
88 \%(28) \\
93 \%(39) \\
100 \%(17) \\
91 \%(12)\end{array}$ \\
\hline $\begin{array}{l}\text { Age } \\
19-24 \\
25-34 \\
35-44 \\
45-59 \\
60+\end{array}$ & $\begin{array}{l}95 \%(19) \\
94 \%(46) \\
94 \%(46) \\
92 \%(12) \\
91 \%(30)\end{array}$ & $\begin{array}{l}50 \%(10)^{*} \\
29 \%(14) \\
33 \%(16) \\
38 \%(5) \\
18 \%(6)^{*}\end{array}$ & $\begin{array}{l}95 \%(19) \\
89 \%(43) \\
94 \%(45) \\
92 \%(12) \\
91 \%(30)\end{array}$ \\
\hline $\begin{array}{l}\text { Total } \\
\text { Respondents }\end{array}$ & $92 \%(153)$ & $32 \%(51)$ & $92(151)$ \\
\hline
\end{tabular}

* denotes statistical difference 


\section{Phase II: Health Professional Survey}

In phase II of this study physicians and pharmacists were asked to provide information about the following areas: their prescribing habits, views on the $\mathrm{Rx}$ to OTC switch, patient characteristics which may effect the selection and safe use of OTC products, and finally package labeling and its effect on OTC use.

\section{Do Health Professionals approve of the trend of patient self-medication?}

With the shift in health care towards placing more responsibility on consumers for their own self-care, it is important to research whether health care professionals are ready to adjust some of their practices and attitudes regarding patient self-medication. When asked about their approval of the trend of patient self-medication 50 percent of physicians and 74 percent of pharmacists responded favorably. Thirty-five percent of physicians and 23 percent of pharmacists responded unfavorably. The results for physicians and pharmacists regarding their approval of patient self-medication are statistically different. The difference may be accounted for by the roles each professional plays with respect to medication. Pharmacists are more aware of the extent and types of information consumers obtain and may therefore have more confidence in their ability to self-medicate in a responsible manner.(Figure 3 )

\section{Do Health Professionals approve of switching prescription drugs to OTC status?}

The Rhode Island study asked both health care professional populations about their perceptions of the trend of switching prescription medicines to OTC status. Figure 3 
shows that from the physician group, 26 percent approved of the switching, 31 percent were not sure, compared to 39 percent that did not. Among pharmacists, 39 percent approved of the switch trend, 26 percent were not sure, while 34 percent did not approve . To further evaluate this issue, both groups were asked whether drugs with safe and established histories should be switched to OTC status. It was interesting to see that 35 percent of physicians and 67 percent of pharmacists felt all, or some drugs should be switched. From this data, it appears that health care professionals are concerned about allowing consumers to self-medicate, however, they are in favor of increasing the selection of products by switching more effective prescription medicines to assist them in their practice of self-medication. It is difficult to understand the reluctance of these groups to be more supportive of switching prescription products to OTC status. (Figure 3)

\section{How often do Health Professionals recommend OTC products?}

Eighty-eight percent of both physicians and pharmacists recommend OTC products to consumers with confidence. Therefore, they recognize the usefulness of these products in part of the health care of their patients. (Figure 3)

These two groups were then asked about their habits for recommending switch products. (Table 13) Eighty-nine percent of physicians and 96 percent of pharmacists routinely recommend switch products. Only 26 percent of physicians and 40 percent of pharmacists approved of switching prescription drugs for the purpose of enhancing selfmedication.. These data would seem to contradict their views on limiting the switch of prescriptions to OTC status for the purpose of enhancing self-medication. In the 
recommendation process for a switch product, both groups provide a product name and explicit directions for use. Perhaps they feel this additional guidance is needed to ensure appropriate use of switch products.

Other factors that were considered as reasons why doctors and pharmacist displayed caution about switching and patient self-medicating may be related to their current knowledge on what OTCs are available, and what source of information consumers rely on for their selection of OTC products. For these reasons, pharmacists and physicians were asked about what source they rely on to keep abreast on OTC drug products and corresponding information. It was found that most physicians( $52 \%)$ and pharmacists(67\%) depend on professional journals to update them about new products in the OTC market. Other sources include detail men/women, seminars, direct mailings, television, and package labels. The Kline study reported 41 percent of physicians relied on detail persons and only 14 percent used journal advertising as a vehicle. $(5,7)$ Additionally, they were asked to speculate about the type of advertising which their patients rely upon for OTC product selection. Since advertising of OTCs on television was expected to rank higher than other sources $(5,7)$, a question about the informational content of the advertisements was included. Both physicians and pharmacists agreed that television advertisements do not convey important information which may help consumer in OTC product selection or proper use of it. 


\section{Are Pharmacists important sources of information?}

Both physicians and pharmacists recognize the importance of a health care professional being accessible to consumers for OTC product information. Seventy-five percent of physicians and 97 percent of pharmacists responded that the information provided by pharmacists is important to assist consumers in using OTC products safely. Fifteen percent of physicians and two percent of pharmacists say this information is not at all necessary to ensure the safe use of OTC products. 
Figure 3

$\%$ Of Physicians and Pharmacists Who Approve Of

Self-medication, Trend Of Switching Rx Drugs For Improved Self-medication,

Recommend OTC Drugs, and Switching Safe Drugs

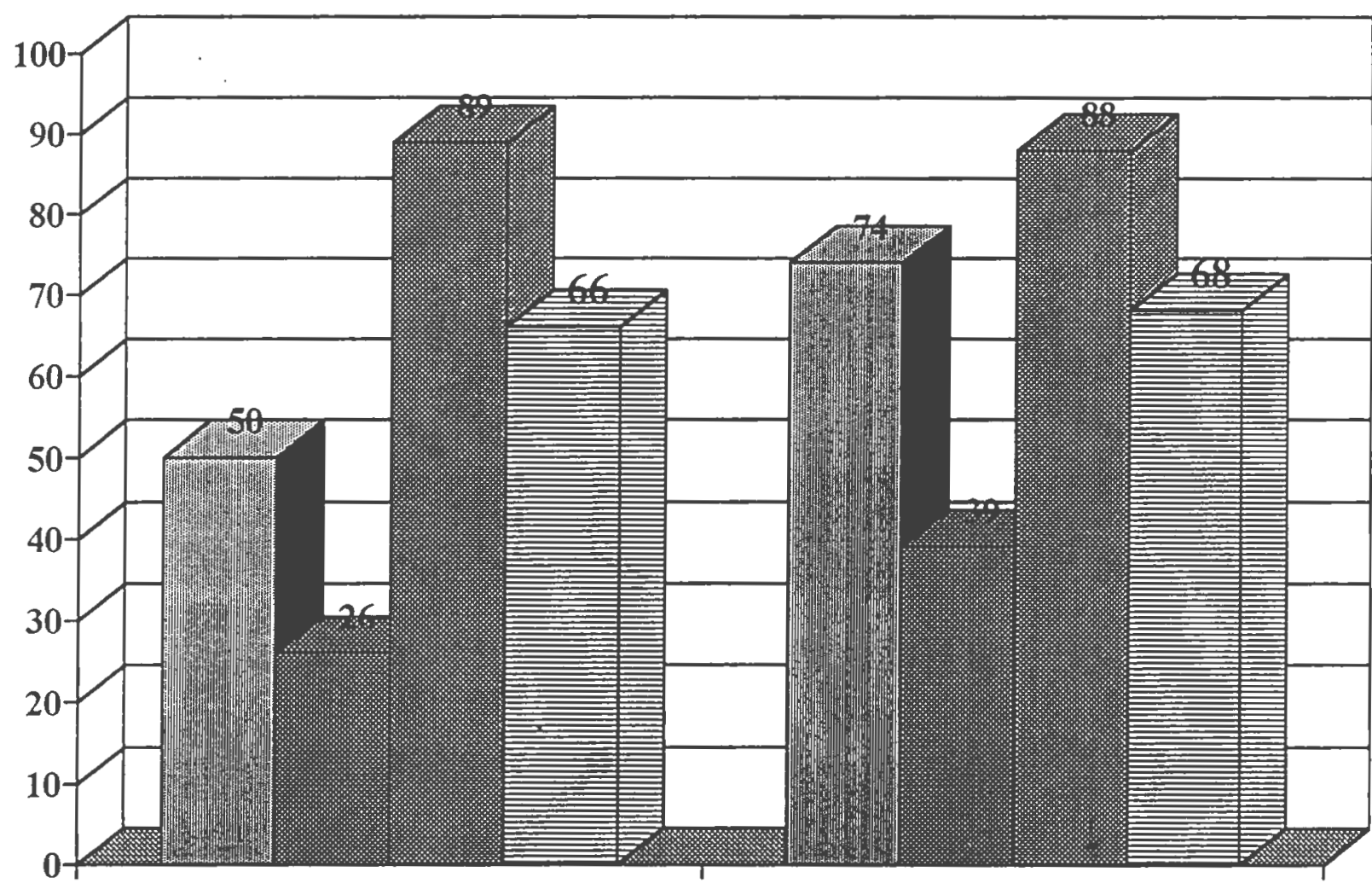

Doctors

RPhs

䧃 self-med $\mathbf{0}$ switch trend rec OTC 目 switch safe drugs 
Table 13

HEALTH PROFESSIONAL OTC RECOMMENDING PRACTICES

\begin{tabular}{lcc} 
Category of Data & \%Physicians(N) & \%Pharmacists (N) \\
\hline Recommend OTCs & $90 \%(139)$ & $88 \%(157)$ \\
Recommend switch OTCs & $89 \%(132)$ & $96 \%(165)$ \\
Prescribed/dispensed now OTCs & $87 \%(134)$ & $90 \%(161)$ \\
\hline
\end{tabular}

How often recommend switches:

Under $10 \%$

$48 \%(69)$

$37 \%(62)$

$10-24 \%$

$28 \%(40)$

$30 \%(50)$

$25-59 \%$

$8 \%(11)$

$17 \%(28)$

Method of recommending:

Name and directions

$63 \%(95)$

$77 \%(129)$

Ask MD/RPh

$6 \% \quad(9)$

$4 \%$

Name and label for info.

$24 \%(36)$

$16 \%(26)$ 


\section{What patient characteristics influence the selection of OTC products?}

The patient characteristics that physicians and pharmacists believe influence the use of OTCs are described. Figure 4 shows the results for each characteristic categorized by physician and pharmacist groups. Most professionals selected education, age, and language skills as the characteristics necessary to effect the safe and proper use of OTCs. For education, $91 \%$ of physicians and $90 \%$ of pharmacists believe this is the most important characteristic for the appropriate use of OTC medicines. A patient must be educated enough to understand the information provided. A limitation to the study was that it did not ask physicians and pharmacists how and to what extent certain characteristics affected the proper use of OTC products. Eighty-eight percent of physicians and $89 \%$ of pharmacists feel that age contributes to patient decisions in using OTC products. Twenty-six percent of physicians and $23 \%$ of pharmacists believe that language skills are an important parameter. The income and gender factors do not in their opinion have significant impact.

Other influential factors identified were package labels (10\%), friends and family (10\%). Nationally pharmacist or physician consultation were primary factors used to select particular OTC products.(5,7) In the Rhode Island study, consumers were asked to select the most important factor which influenced their selection whereas the Kline study allowed respondents to select all appropriate factors. While the results are not directly comparable, they do show that consumers rely primarily on professional information in their choice of OTC products. 
Figure 4

$\%$ Of Physicians and Pharmacists Who Believe Certain

Patient Characteristics Affect The Proper Use OfOTCS

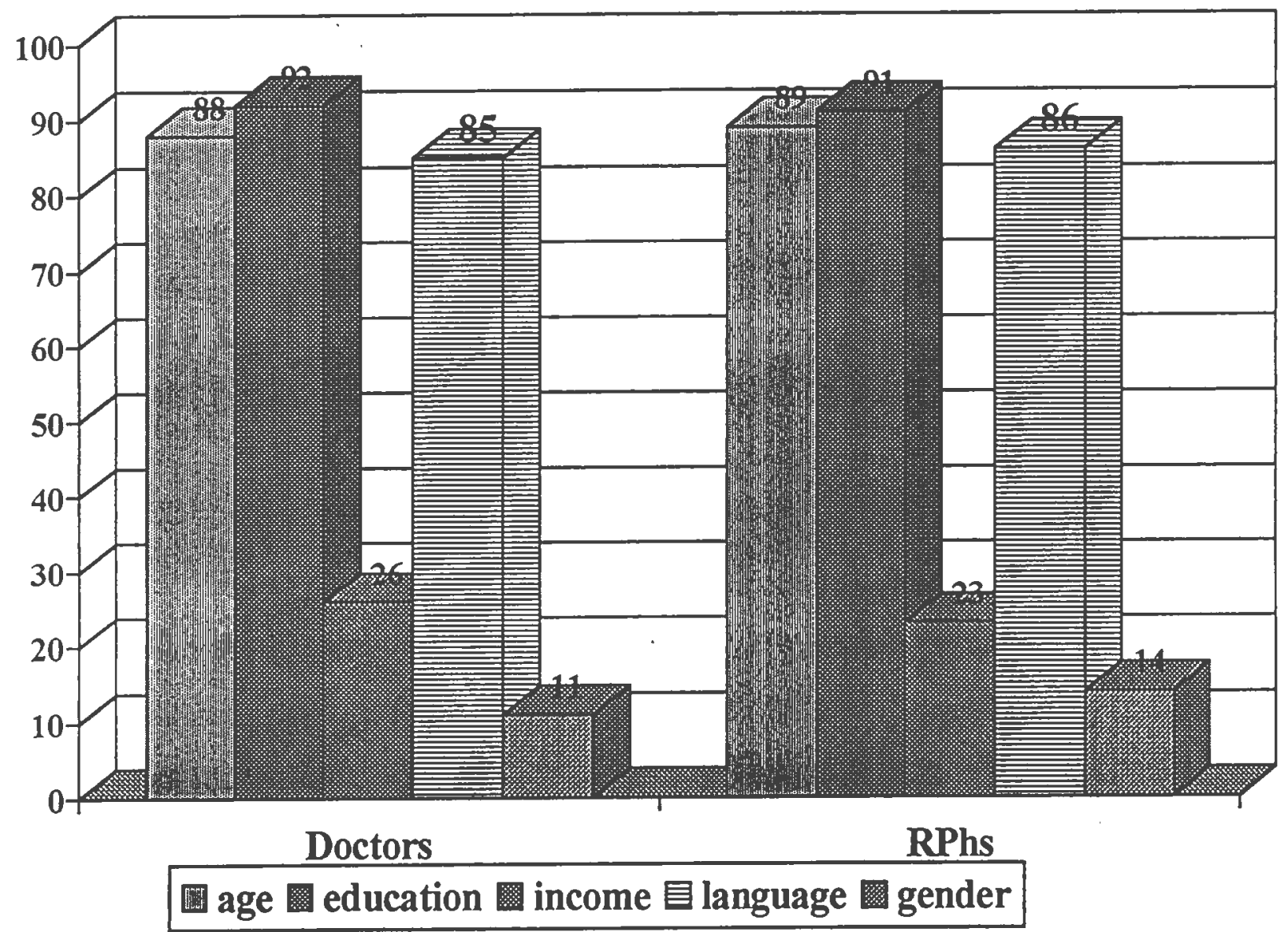




\section{Are labeling changes necessary for the success of OTC products?}

Physicians and pharmacists were asked about completeness of label information on prescription and OTC products. In the comparison of the OTC package label to a label and counseling associated with a prescription product, (counseling includes verbal or written information on the purpose of use, direction, side effects, and warnings for the drug prescribed and dispensed), 34 percent of physicians and 45 percent of pharmacists believed that an OTC label was less detailed than the information provided with a prescription product. Among the remaining respondents, 22 percent of physicians and 34 percent of pharmacists believed the OTC label was more detailed, 11 percent of physicians and 12 percent of pharmacists considered both types of information equal, 6 percent of physicians and 12 percent of pharmacists regarded neither sources of information was sufficiently detailed. Table 14 shows these results.

A rather alarming finding was that 27 percent of physicians reported that they did not know which was more detailed and 29 percent did not know which was more understandable. Since physicians are involved in recommending OTC products for patients, they should be aware of what information is presented on the labels.

It was expected that both physicians and pharmacists would recognize that more detailed labeling is required on an OTC product since a patient is expected to use it without the supervision or intervention of a health professional. Clearly physicians do not show a distinct awareness of the amount of information available with either OTC or prescription products. Pharmacists who routinely fill prescriptions are aware of the volume of information associated with dispensing a prescription product compared to an 
OTC label. Perhaps pharmacists in their responses are including OBRA regulations as part of the counseling and are therefore associating more detailed information available with prescription products rather than with OTC products.

With respect to the understandability of OTC label information compared to prescription information, a different pattern in responses is observed. Forty-five percent of physicians and 55 percent of pharmacists said OTC labels are less understandable than dispensed and counseled prescriptions, while 13 percent of physicians and 20 percent of pharmacists said OTC labels are more understandable. As far as the labels being equal in this aspect, 21 percent of physicians and 16 percent of pharmacists reported this. A small group of them believe neither types of information are understandable. Once again, an astounding 29 percent of physicians do not know. 
Table 14

MD AND RPH VIEWS ON LABEL INFORMATION

\begin{tabular}{|c|c|c|}
\hline Category of Data & \% Physicians (N) & \%Pharmacists(N) \\
\hline \multicolumn{3}{|l|}{ Label Detail } \\
\hline Dosage & $79 \%(115)$ & $86 \%(152)$ \\
\hline Directions & $86 \%(124)$ & $89 \%(158)$ \\
\hline Indications & $48 \% \quad(70)$ & $58 \%(102)$ \\
\hline Ingredients & $56 \% \quad(81)$ & $65 \%(115)$ \\
\hline Purpose of Ingredients & $10 \% \quad(14)$ & $6 \% \quad(11)$ \\
\hline Side effects & $31 \% \quad(45)$ & $33 \% \quad(58)$ \\
\hline Warnings & $49 \% \quad(71)$ & $63 \%(111)^{*}$ \\
\hline Contraindications & $37 \% \quad(54)$ & $40 \%(70)$ \\
\hline \multicolumn{3}{|l|}{ Label Understandability } \\
\hline Dosage & $76 \%(108)$ & $75 \%(131)$ \\
\hline Directions & $80 \%(113)$ & $77 \%(134)$ \\
\hline Indications & $38 \% \quad(54)$ & $41 \% \quad(72)$ \\
\hline Ingredients & $19 \% \quad(27)$ & $27 \% \quad(47)$ \\
\hline Purpose of Ingredients & $4 \% \quad(6)$ & $7 \% \quad(12)$ \\
\hline Side effects & $22 \% \quad(31)$ & $26 \% \quad(46)$ \\
\hline Warnings & $28 \% \quad(40)$ & $41 \%(71)^{*}$ \\
\hline Contraindications & $25 \% \quad(35)$ & $22 \% \quad(38)$ \\
\hline
\end{tabular}

- The percentages listed here represent favorable responses.

* Represents statistical difference based upon the Chi-square test. 


\section{Summary of Findings}

\section{Phase I- Consumers}

- Approximately 97 percent use Over-the-Counter Medicines (OTCs). Of these, 31 percent use them always, 57 percent use them sometimes, and nine percent use them rarely. Three percent of people say they never use OTCs. Study population contained drug-store patrons which may have influenced results.

- 97 percent of consumers read OTC package labels. Sixty-five percent say they read OTC labels always while 4 percent read them rarely. Only 2 percent of the respondents say they never read OTC labels.

- 65 percent of consumers feel OTC package labels are readable and 92 percent of them feel the labels are understandable. Thirty-one percent of consumers feel labels are not readable and only 5 percent feel labels are not understandable.

- 81 percent of consumers said they prefer to purchase OTC medicines in drugstores while 12 percent resort to supermarkets. (Study population contained drug-store patrons)

- 34 percent of consumers consult with pharmacists when choosing an appropriate OTC product while 29 percent contact their doctors. Ten percent of consumers refer to family or friends for help. 
- 10 responded that using the package label was the primary factor in selecting a product and an additional 10 percent are influenced by price or a discount coupon for selecting the product.

- Of the respondents, 87 percent were in favor of switching prescription medicines with safe histories for OTC use. 


\section{Phase II}

\section{Physicians and pharmacists}

- The general consensus among physicians and pharmacists for the trend towards selfmedication is favorable. Fifty percent of physicians approved of this trend while 72 percent of pharmacists approved of this trend.

- Both groups of professionals agree on certain patient characteristics which may affect the safe and proper use of OTC medicines. In rank order, these include education, age, language skills, income, and gender.

- 70 percent of physicians and 95 percent of pharmacists felt some drugs with safe and established histories should be switched to OTC medicines for the improvement of patient self-medication.

- With regard to pharmacists being helpful sources of OTC drug information, 70 percent of physicians said they were, 7 percent said not much, 2 percent were not sure and 15 percent responded as not at all. With pharmacists on the other hand, 96 percent responded that they were important for OTC information, 2 percent were not sure, and 2 percent said not at all. 
- 50 percent of doctors said they frequently recommend OTC products to their patients, forty percent said sometimes, 4 percent rarely and 3 percent do not recommend OTCs. The manner in which they recommend OTCs may influence this finding. Generally, the physician provides a product name and explicit directions for use.

- 69 percent of pharmacists frequently recommend OTCs to patients, 19 percent sometimes do, 2 percent rarely recommend and three percent do not recommend. The method of recommending for pharmacists is consistent to that of physicians.

- With regard to the "detail" of information provided on package labels, doctors responded favorably to the dosage, directions, and ingredient sections on the label. Pharmacists responded favorably to these same areas and additionally to the warning sections of the labels as being sufficiently detailed. .

- With regard to the "understandablility" of label information, both doctors and pharmacists responded favorably to the dosage and directions sections only. The remaining label information sections not considered understandable were the indications, ingredients, purpose of ingredients, side effects, warnings, and contraindications. 


\section{Summary and Future Work}

Both consumer and professional groups are supportive of self-medication trends, and they have confidence in switch products. Physicians and pharmacists however are reluctant to provide wide ranging choices of switch products to consumers without supervision. This is evident in their responses about recommending switch products. In the majority of respondents when switch and OTC products are recommended, consumers are provided with a specific tradename product along with explicit directions for use. When queried about patient characteristics necessary for appropriate use of these products, both professional groups identified age, education and language skills as prerequisite to successful use of these products. Perhaps physicians and pharmacist have low confidence in a patient's ability to make crucial interpretations of product information. On the other hand, they may also prefer to maintain their professional role in evaluating and recommending products as consumers move into the arena of self-care.

Currently, the Food and Drug Administration is conducting a study regarding label terminology and consumer comprehensibility of it. It is well established that there is a need for uniformity of package labeling but more importantly, the terminology used in the labeling must be standardized for a certain level of comprehension. More research must be carried out to determine what qualities consumers should have to assist them or enhance their ability to read and undertstand labels. Knowing these qualities will facilitate the FDA in the development of appropriate label information. 


\section{REFERENCES}

1. Conlan, M. Open wide ! Our ailing health care system, part 2: some treatments, Drug Topics 137 (13) 52-61 (1992).

2. Conlan, M. Rx to OTC switches curb health care costs, Pharmacy Times $\underline{59}(9)$ 34-36 (1993).

3. Drug Topics Research. OTCs: How much advice should you give?, Drug Topics 74 21-23 (1973).

4. Gannon, K. Health Care Reform divides pharmacists on new roles, Drug Topics Supplement (1992).

5. Greengrove Griffie, K. Physician attitudes and opinions about Rx-to-OTC switches, Rx-to-OTC Switch conference. Arlington, VA March 10-11, (1993).

6. Heller Research Group. Perceptions and Practices in Self-care, (1983, 1992).

7. Kline Company \& Associates. Physician Attitudes about Rx-to OTC switch,(1992).

8. National Women's Health Research Center. Women and nonprescription drugs, 16 (2) Washington, D.C. (1994).

9. Nonprescription Drug Manufacturers Association. Label readability guidelines, reprint Washington, D.C. (1991),

10. Princeton Survey Research Group. for Council on Family Health. Using medicines safely (1992).

11. Spalding, B. Supermarket pharmacy, a growing presence, American Druggist 37-38 (March 1990). 
12. Towne-Oller \& Associates. Tracking OTC/HBC sales, drugstores vs. foodstores, Drug Topics 137 (10) 44-64 (1993).

13. Young, F. A Doctor's advice on self-care, reprint by NDMA Washington, D.C. (1991). 


\section{APPENDIX A}

\section{Surveys}

For Ofice Use Only
STR
LNG -
NVT -
AOT $\square$
BSK

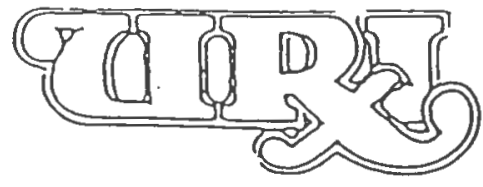

\section{Dear Consumer}

A very important issue for health care today is the switching of prescription-only medicines to over-the-counter medicines. This trend continues to be favored by regulators, manufacturers, bealth care professionals, and consumers. At the same time, a concern has been raised about whether package labeling provided by manufacturers is sufficient and understandable.

My research project focuses on this concern. Specificily, the research is assessing whether current package information is indeed sufficient to ensure safe and proper use of over-thecounter products by consumers.

I would greatly appreciate your taking five minutes of your time to answer the questions in this survey. When you have completed the survey, please fold and place it in the box on the check out counter or give it to the pharmacist on duty. Thank you.

Nancy M Hewith, RPh

Fogarty Hall

Deparment of Pharmaceutics

University of Rhode Island

. . Kingston, RI 02881

Thank you for your help.

BE ASSURED THAT ALL RESPONSES WLL BE KEPT STRICTLY CONFDENTLAL 


\section{CONSUMER QUESTIONNAIRE}

In each section, please choose one response to the following questions. Place a mark in the box next to the most appropriate choice.

अ A. Over-the-Counter Medicines: How you choose a product

1.) How often do you use over the counter medicines?

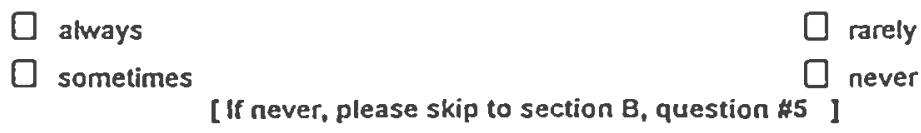

2.) Where do you purchase over-the-counter medicines most often?

$\square$ drugstore

$\square$ convenience store

$\square$ supermarket

$\square$ health maintenance organizations (HMOs)

$\square$ department store

$\square$ other (please specily)
3.) Who or what is the most infuential source in your decision to use a particular over-the-counter product?
$\square$ doctor
$\square$ television/ radio/ magazine advertisements
$\square$ phamacist
D package label
$\square$ friends/relatives
$\square$ other (please specify)

4.) How much do television advertisements for over-the-counter medicines influence you in choosing a product?

$\square$ very much

$\square$ none

$\square$ somewhat

$\square$ do not watch television

$\square$ very little 6x

5.) Do you read package labels on any over the counter medicines? (either in stores or after you purchase them)

$\square$ always

$\square$ rarely

$\square$ sometimes

never

[if never, please skip to question \#12]

6.)Please consider the overall appearance of a tyical over-the-counter package.

a.) Is the over-the-counter package label difficult to read?

$\square$ very difficult

$\square$ not difficult at all

$\square$ somewhat difficult

$\square$ not sure

b.) Is the over-the-counter package label difficult to understand?

very understandable

$\square$ somewhat understandable not understandable at all

[1 not sure 
7.) The term indication appears on all over-the-counter product labels. What does this term mean to you?

$\exists$ a cure for a condition

$\square$ a specific use or a symptom(s) the product will help minimize or reduce

$\square$ the prevention of a symptom

do nol know

3.) The term contraindication appears on all over-the-counter product labels. What does this term mean to you?

the side effects of the medicine

$\square$ conditions and/or medicines with which the product should not be used together

$\square$ the directions of how to take the medicine

$\square$ do not know

9.) In the waming section of some over-the-counter product labeis, the word hypertension is mentioned. The label says frople who have hypertension should not use the product. What does this word mean to you?

a condition of too much tension or stress

$\square$ a condition of low blood pressure

a condition of high blood pressure

$\square$ do not know

10.) The active and inactive ingredients are listed on package labels, which type of ingredient will help reduce symptoms

$\square$ active ingredients

$\square$ neither kind of ingredient

그 inactive ingredients

$\square$ do not know

$\square$ both kinds of ingredients

11.) Should manufacturers place package inserts(a piece of paper containing dng information) inside packages of over-the-counter medicines?

$\square$ yes; in English

no it is not necessary

$\square$ yes; in two languages

do not use over-the-counter medicines

$\cdot$

क. C. SWITCHING PRESCRIPTION-ONCY MEDICINES TO OVER-THE-COUNTER MEDICINES

12.) The Govemment is considering making several prescription-only medicines available as over-the-counter medicines. This means you will no longer need a doctor's order to purchse them. is the idea of switching these medicines:

a good idea (more medicines available withoul a prescription the better)

! somewhat of a good idea (only some medicines should be)

] a bad idea (keep the medicines by doctor's order only)

? I do nol use prescription medicines 
13.) Within the large selection of over-the-counter medicines, there are several medicines which used to be available by prescription-only. Considering all these products you have to choose from, how often would you choose the one which used to be available as prescription-only?

$\square$ always the product which used to be a prescription

$\square$ sometimes the product which used to be a prescription

$\square$ rarely the product which use to be a prescription

$\square$ never the product which used to be a prescription

$\square$ the product which has always been an over the counter medicine

$\square$ none of the above

14.)Oo you believe that prescription medicine works better than over-the-counter medicine?

$\square$ yes, atways

$\square$ yes, sometimes

no

$\square$ yes, rarely

I do not use medicine

mor.

15.) In each of the following categories, please mark one selection:
A. Age:
B. Last school completed
C. Individual Annual Income
under 18
$\square$ Less than High School
$\square$ under $\$ 10,000$
प 19-24
$\square$ High School or Equiv.
口 $\$ 10,000-\$ 19,000$
口 25-34
D Trade School
口 $\$ 20,000 \cdot \$ 29,000$
( $35-49$
4 Year Coillege
$\square \$ 30,000-\$ 44,000$
口 $50-59$
$\square$ More than 4 Years College
$\$ 45,000-\$ 59,000$
$\square 60+$
None of the above
$\$ 60,000+$
D. Native Language
E. Sex
$\square$ English
$\square$ Female
$\square$ Spanish
$\square$ Male
$\square$ Portugese
$\square$ other

THANK YOU FOR YOUR TIME AND EFFORT

Nancy M. Hewitt, R.Ph.

Department of Pharmaceutics

Univeristy of Rhode Island 


For Onice Usc Only
SVR
NFT -
NFO
BOT
COT

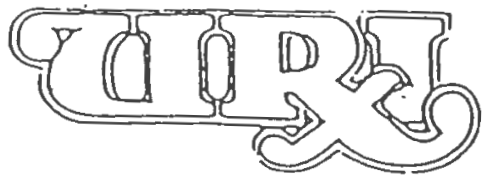

Dear Physician:

A very important issue for health care today is the switching of prescription-only medicines to over-the-counter medicines. This trend continues to be favored by regulators, manufacturers, health care professionals, and consumers. At the same time, a concern has been raised about whether package labeling provided by manufacturers is sufficiently compreheasible.

My research project focuses on this concern. Specifically, the research is assessing .. whether current package information is indeed sufficient to ensure safe and proper use of overthe-counter products by consumers.

I would greatly appreciate your taking five minutes of your tine to answer the questions in this survey. I have enclosed a pre-addressed and stamped envelope for your convenience. Please retum this form to:

Nancy M Hewitt, RPh.

Fogarty Hall

Department of Pharmaceutics

University of Rhode Island

Kingston, RI 0288 I

Please postmark no later than March 10, 1994

Thank you for your help.

BE ASSURED THAT ALL RESPONSES WUL BE KEPT STRICTLY CONFDENTIAL 


\section{PHYSICIAN QUESTIONNAIRE}

Please respond to the following questions based upon your scope of practice by placing a check mark next to the most appropriate choice.

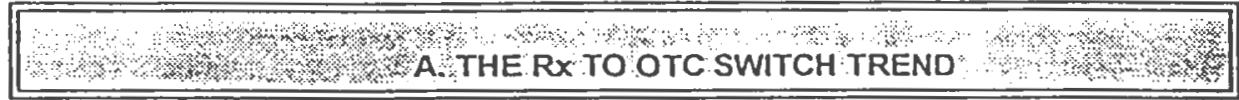

1.) As a health care professional, do you approve of the movement toward more 'patient self-medication' with over-the-counter medicines (OTC)?

$\square$ very much so

$\square$ no

$\square$ somewhat

$\square$ not familiar with issue

$\square$ not sure

2.) Over-the-counter medicines are used to treat minor ailments. Do you believe that any of the following patient characteristics affect the safe and proper use of OTC medicines? [Please check all that apply]

$\square$ age

$\square$ gender

$\square$ education

$\square$ language skilts

$\square$ level of income

other:

3.) Currently, there is a trend of switching prescription-only medicine to over-the-counter medicine status. Do you think this trend improves patient's self-medicating habits?

V very much

not at all

somewhat

not familiar with trend

$\square$ not much

4). Some prescription-only products have established histories as being safe and effective. Should such products be made accessible to patients for self-medication without a prescription?

$\square$ all such products

$\square$ some of these products

[] no such products

very few products

5.) Have you ever 'dispensed' a product which has since been switched to OTC status or is now available as nonprescription strength?

$\square$ yes

$\square$ no

$\square$ not sure

not applicable to my scope of practice

6.) In the last six months, have you recommended any OTC products to patients?

$\square$ frequently

$\square$ no

$\square$ sometimes

$\square$ not applicable to my scope of practice

C rarely

[IF NO OR NOT APPLICABLE,PLEASE SKIP TO QUESTION $\approx 10]$ 
7.) Have you 'recommended' any OrC products which were formerly available as prescription-only?

$\square$ yes

$\square$ no

not sure

8.) Of the OTC products you have recommended, what percentage would represent switched products (formerty a prescription-only product)?

$\square$ under 10 percent

$50-74$ percent

$\square \quad 10-24$ percent

75 - 99 percent

D $25-49$ percent

100 percent

$\square$ not sure

9.) In what manner do you most often recommend an OTC product to a patient:

$$
\text { [Please check only one] }
$$

$\square$ suggest a product name and provide explicit directions

$\square$ suggest asking phamacist for product and directions

$\square$ suggest a product name but allow patient to rely on package for directions

$\square$ do not recommend OTC medicines

not applicable to my scope of practice

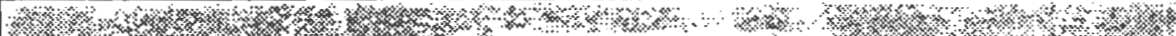

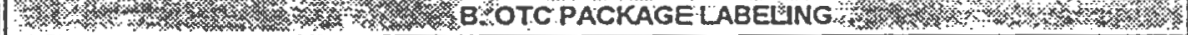

10.) Manufacturer labeling of OTC packages provides descriptive information which is designed to promote the safe and responsible use of the product.

a.) In which of the areas listed below, is the provided information sufficiently detailed for the patients? [Please check all that apply]

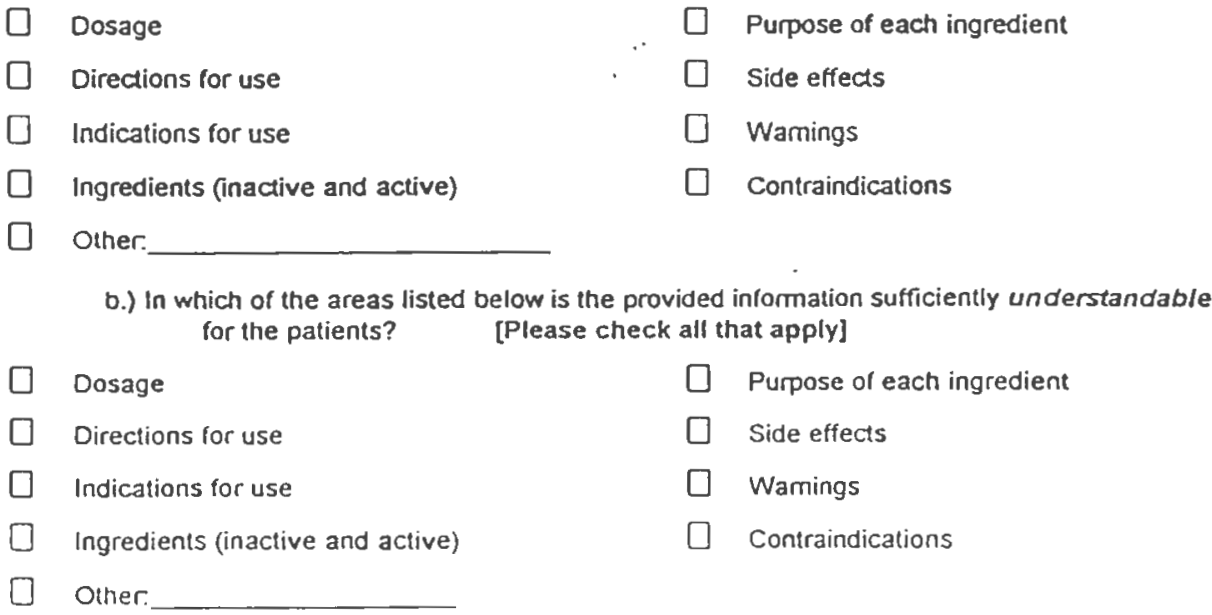


11.) Pharmacists label prescription boltles and provide verbal counseling about the prescription medication. Compared to the information the patient receives from the pharmacist and the $R \times$ battle:

a.) Is the information provided on an OTC package label:

$\square$ less detailed than a prescription product

$\square$ more detailed than a prescription product

$\square$ both forms of information are equal

$\square$ neither information is sufficient

do not know

b.)Is the information provided on an OTC package label:

$\square$ less understandable than a prescription product

$\square$ more understandable than a prescription product

$\square$ both forms of information are equal

$\square$ neither information is sufficiently comprehensible

$\square$ do not know

12.) Is the infomation provided by phamacists about OTC products important to ensure the safe and proper use of OTC products by patients?

$\square$ very much

not at alt

D somewhat

do not know

$\square$ not much

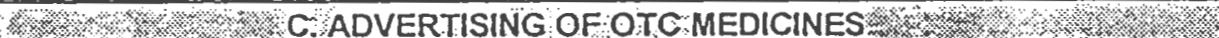

13.) Advertisements for over-the-counter medicines appear in most forms of media. On which source do you rely most heavily to keep you updated or informed about new products available in the OTC market?[please check only one source]

$\square$ newspaper

direct mailings (brochures) from manufacturers

$\square$ professional joumals

Dackage labels

nonprofessional joumals

- professional seminars

Television

other

14.) Which form of advertising for OTC products do you believe has the most influence on patients in choosing an OrC product?

$\square$ newspaper

$\square$ instore displays

$\square$ television

$\square$ friends/relatives

$\square$ joumals (all nonprofessional)

$\square$ other.

$\square$ package tabeis

15.) Do you believe that television advertisements for orc products provide sufficient information in any of the lollowing areas?[Please check all that apply]

$\square$ indications for use

$\square$ wamings

$\square$ directions for use

contraindications

_ side effects

other: 


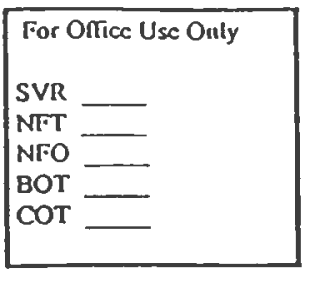

Dear Phamacist:

A very important issue for health care today is the switching of prescription-only medicines to over-the-counter medicines. This trend continues to be favored by regulators, manufacturers, health care professionals, and consumers. At the sanie time, a concern has been raised about whether package labeling provided by manufacturers is sufficiently comprehensible.

My research project focuses on this concern. Specifically, the research is assessing whether current package information is indeed sufficient to ensure safe and proper use of overthe-counter products by consumers.

I would greatly appreciate your taking five minutes of your time to answer the questions in this survey. I have enclosed a pre-addressed and stamped envelope for your convenience. Please return this form to:

Nancy M. Hewitt, R.Ph.

Fogarty Hall

Department of Pharmaceutics

University of Rhode Island

Kingston, RI 02881

Please postmark no later than March 10, 1994

Thank you for your help.

BE ASSURED THAT ALL RESPONSES WILL BE KEPT STRICTLY CONFIDEINTLAL 


\section{Appendix B \\ CONCLUSIONS AND FUTURE WORK}

This dissertation has presented important policies and issues stemming from the switching of prescription-only medicines to Over-the Counter (OTC) status.

1. The FDA and drug manufacturers have expended considerable effort in the development of regulations, reveiw processes, and labeling to provide consumers with non-prescription products which are safe and effective when used according to directions.

2. Switching products from prescription to OTC status has provided consumers and health professionals with products in which they have confidence.

3. Consumers rely primarily on physician and pharmacist recommendations in their choice of OTC products, while only about $10 \%$ report that television has a significant impact on their selection. Physicians and pharmacists believe however that consumers are significantly influenced by television advertising in product selection.

4. Many consumers routinely read OTC product labels at the time of purchase and first use. Although labels are designed to provide information in easy to read formats and understandable terminology, it is clear from this study that consumers have difficulty reading and interpreting them. Physicians and pharmacists agree that some 
portions of the label are difficult for consumers to understand. Given these results, it is crucial that regulatory agencies and drug manufacturers develop ways to address these problems to insure safe and effective use. The appearance of more potent prescription products in the OTC market compounds the problem and increases the risk of adverse effects and misuse.

5. While physicians and pharmacist are supportive of the self-care trend, they are not wholly convinced that consumers are capable of making all decisions related to self medication. Evidence is given to show that when they recommend an OTC or newly switched product, they provide the consumer with a specific product name and give particular instructions for use.

6. Future Work: Although this study brought to light some important issues related to the continued success of OTC products, it did not provide sufficient information about the following:

a. The degree to which physicians and pharmacists feel particular patient characteristics affect their ability to use OTC products successfully. A study should be designed to identify specific age, education and language levels which are thought to be required to insure appropriate use of these products. The extent to which these perceptions agree with consumer views should be studied to identify issues which may hinder use of OTC products. 
b. Labeling: This study identified that labels are a particular problem for both consumers and heath professionals in terms of readability and comprehension. A study needs to be initiated to find more appropriate ways to improve the ease of reading labels and understanding of label contents.

c. The extent to which health care providers need to be involved in successful use of OTC products. It is evident from this study that consumers are enthusiastic about the use of OTC switch products, but physicians and pharmacists are unwilling to give their whole hearted support to this practice. A study could be designed to investigate why health professionals feel this way, and to see if health care professionals can use their professional knowledge in more innovatives ways. Also other primary health care providers need to be assessed for their impact and perceptions on OTC drug use.

d. The extent to which economics impact the use of OTC products, and the effect this has on future use of those products. Clearly OTC drugs are becoming a significant part of patient care. The trade off between economic benefit to appropriateness of use should be studied. 


\section{BIBLIOGRAPHY}

Alexander, A, and Anderson, C. Counter Prescribing for Patients at Risk, part 5 Cardiac Patients, The Pharmaceutical Journal 223-224 (Feb. 15, 1992).

Barton-Hutt, P. Drugs for self-medication: their source and the social, political, and regulatory climate, Drug Information Journal 19195-199, 1985.

Barton-Hutt, P. A legal framework for future decisions on transferring drugs from prescription to nonprescription status. Propritary Association Symposium, Washington, D.C. (1982).

Beed, T., \& Stinson, R. Survey Interviewing; Theory and Techniques, North Sydney: George Allen and Univ. Pub. Ltd. (1972).

Bezold, C. What happens when most drugs are OTC? Drug Information Journal 19 179-183 (1985).

Bloom, M. FDA's Kessler: A Prescription for change, American Pharmacy $\underline{12}$ 34-37,874 Dec.(1991).

Botstein, P. Criteria for switching new molecular entities from prescrition to over-the-counter. Drug Information Journal, 24:29-31, 1990.

Bowen, B., Weisberg, H. An Introduction to Survey Research and Data Analysis, San Francisco: Freeman and Co( 1977).

Boyle, H. Obtaining and using patient information, American Pharmacy 31517 $523(1992)$. 
Busch,G. OTC drugs sailing on steady course. Chemical Marketing Reporter, March 20: $23522(1989)$.

Chaplin, S. Clinical trials in community pharmacies, British Medical Journal Jan. 11 $\underline{304}$ 63-64 (1992).

Conlan, M. FDA may move to allow sale of drugs as both $\mathrm{Rx}$ and OTC, Drug Topics 133 (51) Nov. 20 (1989).

Conlan, M. Open wide! our ailing health care system part 2:some treatments, Drug Topics 136 (13) 52-61 (1992).

Conlan, M. Health Care Reform divides pharmacists on new roles, Drug Topics Supplement 105-115(1992).

Conlan, M. The R.Ph. and his image, Drug Topics Supplement 21s (October 1991).

Denysyk, O.S. Five year prediction made for OTC products, Drug Topics 131(64) Aug. 17(1987).

Digges, I.W. The Modern Law of Advertising and Marketing, Funk \& Wagnalls Co. NY (1964).

Driver, J, and Foxall, G. Advertising Policy and Practice, St. Martin's Press New York, NY (1984).

Drug Topics. Pharmacists role study, Drug Topics 21-22 (July 2,1973).

Eckian, A. G. The impact of switch on the public, Drug Information Journal 19 153154(1985).

Eckian, A. G. The frontiers of Rx-to-OTC switch. NDMA reprint from R \& D conference, NY,Washinton, D.C Dec. 12 (1986). 
Farley, D. Benefil vs. risk: how FDA approves new drugs, FDA Consumer 10 (6) (Dec/Jan 21 1987).

Fisher, G.M. et al. Legal aspects of Rx/OTC switches. Regulatory Affairs Professionals Society Annual Meeting. NY (1991).

Friedman, M. OTC drug interactions soar in cold, flu season, Grocery Marketing $\underline{56}$ $(2): 42$.

Gannon, K. The Rx-to-OTC switch race: drugstores setting the pace, Drug Topics 30-31 (Nov. 22, 1993).

Gannon, K. Patients content with OTC information from R.Ph.s, Drug Topics 134 26-28 March 19, 1990)

Gannon, K. Pharmacists step up level of counseling on OTCs, Drug Topics 42-43 Dec.(1993).

Gannon. K. Switched drugs fuel OTC while dampening Rx allergy market, DrugTopics $\underline{135} 9$ Jan. 21 (1991).

Gannon, K. hot, hot, hot: new switces to brighten OTC market, Drug Topics 13532 Aug. 5 (1991)

Gannon, K. Switched drugs lend vitality to surging OTC market: prescrition to OTC switches, Drug Topics 135 32(.May 20 (1991).

Gannon, K. OTC's; what's making them tick, Drug Topics $44-48$ (Feb. 17, 1992).

Gannon, K. Gyne-Lotrimin taps into OTC revenues; Monistat 7 to follow, Drug Topics 135 (1) 30 Jan. 7 (1991).

Gardner, S. Remarks, Food Drug Cosmetic Law Journal 29 300-307 June (1974). 
Garrity, M. Coming to grips with the RX to OTC switch, Drug Topics 133 (11) 58.

Gibbons, J.D. Nonarametric Methods for Quantitative Analysi,s Holt, Rinehart and Winston. NY(1976).

Gilbertson, W. The OTC Drug Review-switch without regulation or application, Drug Information Journal 19 101-109 (1985).

Greengrove Griffe, K. Physician attitudes and opinions about Rx-to-OTC switches, how health care providers influence OTC drug use, Rx-to-OTC Switch conference Arlington, VA (March 10-11 1993).

Guerard, C. The impact of advertising and its regulation, a Federal Trade Commission perspective, Drug Information Journal 19 163-172 (1985).

Guiteras, P.G. OTC drugs: are they safe? Executive Health's Good Health Repor, 292 (Oct. 1992).

Halperin, J. A. What comes after Rx-to-OTC switch? Drug Information Journal 19 $177-178(1985)$.

Halperin, J. A. Strategic issues in the Rx-to-OTC switch, Drug Information Journal $\underline{24}$ $13-18$ ( 1990).

Harns, L. \& Associates. Patients turn to pharmacists for help on OTC labels, (patient counseling section) American Pharmacy 32 (11) (9 Nov. 1992).

Hatoum, H. The Pharmacy Patients Bill of Rights, U.S. Pharmacist 60-67 May (1992).

Haverkost, L. F. How industry assesses and picks suitable candidates for switch, Drug Information Journal_19 133-138 (1985). 
Heller Research Corp. Health care practices and perceptions: A consumer survey of self-Medication, The Proprietary Association (1984), (1992).

Heslin, M. M. A consumer perspective, Drug Information Journal 19 159-161(1985).

IBC USA Conference Inc. Rx to OTC Switch notes (March 10-11, 1993).

Arlington, VA.

Johnstone, James M. Direct to consumer prescription drug advertising: current legal and regulatory developments, Pharmacy Law Anual 3-13 (1989).

Jolly, C. N. To switch or not to switch? GRAS/GRAE is still the question, Drug Information Journal 19 111-117(1985).

Juergens, J .R.. The FDA and Community Pharmacy: Today and Tomorrow, Drug Topics 88-94 (Aug. 1992).

Kaplan, A. OTC and prescription drugs: the legal distinction under federal law, The Proprietary Association symposium. Washington, D.C. (1982).

Katzenstein, L. Rx to OTC; who pays and who profits when prescription drugs go over-thecounter, American Health:Fitness of Body and Mind 10 April (1991).

Kiley, D. The OTC industry embraces the newly converted, Adweek's Marketing Week $\underline{31}$ 166-170_Sept. 17 (1990).

Kanig, J. Advisory Committees: An expanding concept in the field of drug regulation. The perspective of a liason representative, Food Drug Cosmetic Journal 29 (7) 353 359 (1974).

Kolosta, D. Total Pharmaceutical Care and Patient Outcomes, U.S. Pharmacist 58-68 Nov. (1991). 
Konnor, C. FDA Enforcement of the PDMA, U. S. Pharmacist 37-42 Nov (1991).

Krucoff, C. OTC drugs can fool you, Saturday Evening Post 26466 Nov-Dec (1992).

Lebhar-Friedman Inc. FDA wants imprinted id codes on OTC and RX products, Drug Store News $\underline{13}$ (11) 23 June 10 (1991).

LeBlang, T. When you sell a "defective OTC," American Druggist 79-80 (March 1990).

Link, M. OTC drugs: read the label before taking, Current Health $2 \underline{19}$ (6)13-16 (Feb. 1993).

Maclean Hunter Media Inc. Will suppliers get their share of the Rx-OTC business? Progressive Grocer 72297 June (1993).

Mahinka, S.P. Direct- to- OTC Marketing. NDMA R. \& D. conference. Washington, D.C Nov. 12 (1992).

Martin, S. Exploring the benefits of a third class, American Pharmacy $\underline{869}$ (12) 29- 32(1991).

McCaffrey, D.,. Banahan, B., Smith, M. Pharmacy support staff and OTC recommendation, Pharmacy Times 40-50 Sept. (1992).

McCarthy, R. Impact of OTC H2 antagonists on retail pharmacy, Pharmacy Times (May 1993).

Meade, V. Patients need advice as array of cold products grow, American

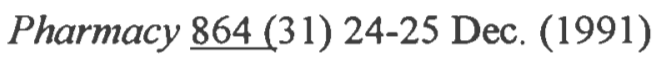

Medical Consumers Inc. FDA review of OTC drug safety and effectiveess: an update, HealthFacts $1640 \mathrm{Jan} .(1991)$

Medical Economics Co. OTC drugs can be a low-cost alternative., Business \& Health Annual $101(2)(1992)$

Mintz, M. By prescription Only, Houghton Mifflin Company, Boston, MA (1967). 
National Council of Negro Women pamphlet. Healthy living and safe self-medication tips for african american women and their families, Washington,DC Fall (1993).

National Women's Health Resource Center. National women's health report, women and nonprescription drugs, Washington, D.C. (Spring 1994).

NCC Bulletin. National Consumer League $\underline{53}$ Washington DC (July/Aug 1991).

NDMA Execuive Newsletter. 41-93 Nov. 12 (1993).

NDMA reprint from Pharmacy Business Rx-to-OTC switch: the right trend for the '90s,. Washington DC (April 1993)

NDMA Compilation of nine national consumer studies:American consmers support selfmedication and practice it responsibly, Washington, D.C. (1992)

NDMA Executive Newsletter. Study shows switched drugs are big sellers, Washington, D.C. Dec. 10(1993)

NDMA. Facts and figures, Washington, D.C. (1991).

NDMA. Label readability guidelines, Washington, D.C. (1992).

NDMA. Issues and perspectives, Washington D.C. (1992).

NDMA. Nonprescrition drugs; modern medicines for mature Americans, Washington, D.C. (1993).

NDMA. Research and Scientific Development Conference, Washington, D.C. (Nov. 12-13 1992).

NDMA. Proceedings to Rx to OTC Switch, the next generation: empowering the consumer, Washington, D.C. (Sept. 15 1992).

NDMA. Voluntary codes and guidelines of the OTC medicines industry, Washington, D.C. 
(1991).

NDMA. Focus in 1992-1993 Cost Benefits and Consumer Power, Staff Panel Report from Washington Enclosure to XNL 8-93 (March 8 1993).

Nielson, J.R. Handbook of Federal Drug Law. Lea \& Febiger, Philadelphia, PA (1986).

Novitch. Direct to consumer advertising of prescription drugs, Food Drug Cosmetic Law Journal $\underline{39}$ 306-311 (1984).

O'keefe, Daniel Jr. The Over-the-Counter drug review-helping the client make decisions, Food Drug Cosmetic Law Journal May (1974).

Pinco, R. G. A legal Perspective on regulatory approaches to switch, Drug Information Journal, 24 5-11 (1990).

Popovich, N. Not All Over-the-Counter Drugs are safe, American Journal of Pharmacy Education 55 166-172 summer of (1992).

Posner, R. Regulation of advertising by the FTC, american enterprise institute for public policy research Washington, D.C. (1973).

Princeton Survey Research Associates Using medicines safely, A prevention magazine Council on family health report (1993).

Proprietary Associations (NDMA) Rx-OTC new research in self-medication A symposium condensation of papers and discussions Washington D.C. Nov 1 (1992).

Public Laws ch.675. 1040-1053 June 24, 25 (1938).

Public Law 215 [65 statute] 648-649 Oct. 25 (1951).

Public Law 87-781. [76 statute] 780-796 Oct. 10 (1962). 
Public Record 215-51 16 CFR part 450. Federal Trade Commission, advertising for over-the counter drugs, (October 1978).

Public Record 215-51 16 CFR part 450. Federal Trade Commission staff report and recommendations: advertising for over-the-counter medicines, (May 22, 1979)

Raschanow,G. The switch of drugs from prescription to over the counter status, Food Drug and Cosmetic Law Journal 39 201-10 (1984).

Rheinstein, P. Criteria used by the FDA to determine what classes of drugs are appropriate switch candidates, Drug Information Journal 19 139-142 (1985).

Rheinstein, P. The regulation of prescription drug advertising, Legal Med. Ann. 40 (1978).

Richardson,E. Rx to OTC Switches: A double-edged word? Drug Store News (2) (Sept. 1990).

Rippere, J.L. FDA Regulation of OTC oral health care drug products. J. Public Health Dent, $\underline{42}$ (6) 329-332 (1992).

Robertson, T. et al. Televised Medicine Advertising and Children, Praeger Publishers NY (1979).

Rosendahl, I. Topical hydrocortisones Get 1\% Lift From FDA, Drug Topics 68 (Feb. 19, 1992).

Rosendahl, I. Expense of physician care spurs OTC, self-care market, Drug Topics $\underline{32}$ (Aug. 1, 1988).

Rubin, I. Does Soviet pharmacy differ sharply from U.S. practice? Pharmacy Times 48- 60 (Sept. 1990).

Salmo, R. Rx to OTC switches curb health care costs, Pharmacy Times 59 (9) 34-36 (1993). 
Scarlett, J. The selection of switch candidates- industry, FDA, and scientific perspectives, Drug Information Journal 19 (131) (1985). .

Schnell Publishing Co. Drug ingredients swept from OTC market by FDA, Chemical Marketing Reporter 238 (20) 3-4. (Nov. 12 1990)

Schondelmeyer, S. W. Pharmacists, pharmaceuticals and drug information in the 21 st century, Drug Information Journal 19 185-193 (1985).

Segal, M. Rx to OTC; the switch is on. FDA consumer, 25 (2) (March 1991).

Srnka, Q. Implementing a self-care-consulting practice, American Pharmacy $\underline{33}$ (1) 61-70 (Jan. 1993).

Siegelman, S. The coming wave of Rx-to-OTC switches, American Druggist 37-42 (Aug 1990).

Silverman, M. and Lee, P. Pills Profits \& Politics, Univeristy of California Press Los Angeles, CA (1974).

Smith, M. Principles of Pharmaceutical Marketing, Lea \& Febiger. Philadelphia (1983).

Spalding, B.J. Supermarket Pharmacy A Growing Presence, American Druggist 37-38 (March 1990).

Strauss, S., Rumore. M. Pharmacoepidemiology: A Primer for Pharmacists, Pharmacy Times 67-72 (Sep 1990).

Stone, A. Economic Regulation and the Public Interest, the Federal Trade Commission in theory and practice, Comell University, NY (1977).

Sudman, S. Applied Sampling, Academic Press NY (1976). . 
Temin,P. Costs and benefits in switching drugs from Rx to OTC, Journal of Health Economics 2 187-205(1983).

Temin, P. The origin of compulsory drug prescriptions, Journal of Law and Economics 22 91(1979).

Temin, P. Taking Your Medicine, Drug Regulation in the United States, Harvard University Press Cambridge MA(1980).

Thomas, P. OTC Drugs: concerns mount as choices shift.Medical World News 31-32 (Dec 1990).

Tilson, $\mathrm{H}$. Use of adverse reaction data bases and makinng risk assessments of proposed switch candidates, Drug Information Journal 19 143-149 (1985).

Troy, M. Rx-to-OTC Switches; is the power on? Drug Store for the Pharmacist 17-18 (Feb. 15 1993).

Towne-Oller \& Associates. Tracking OTC/HBC sales, drugstores vs. foodstores, Drug Topics $\underline{137}$ (10) 44-64 (1993).

Ukens, C. New congressional battles loom, politicos tell OTC makers, Drug Topics 44 (April 22 1992).

21 USCS 353, Food Drug, and Cosmetic Act 321-325 (1962).

21 USCS 355, Food Drug, and Cosmetic Act 326-327 (1962).

21 USCS 321, n6 Food Drug, and Cosmetic Act 146-151 (1962).

Vickery, D.M. A medical perspective, Drug Information Journal 19 155-158 (1985).

Vogenburg, R, Pisano, D.,. Drug utilization review: Quality Assurance in Pharmacy, Pharmacy Times 114-122 Sep.(1992). 
Walters, P.G. Use of FDA Advisory Committees: present and future, Food Drug Cosmetic Low Journal $\underline{29}$ 348-359 (1974).

Washington PR Newswire. FDA actions on OTC warning labels, Aug. 26 (1993).

Wion, A. Rx-to-OTC switch-the process and procedures, Drug Information Journal 19 119- $126(1985)$.

Zoeller, J. Emphasis on OTC switches prescribed, Supermarket News 43 (24) 1 (June 14 1993).

Zoeller, J. Numerous switches to OTC expected as patents end. Some Rx drugs will become OTC, Supermarket News $\underline{42(42)} 9$ Oct. 19 (1992). 